Journal of the Scientific Agricultural Society of Finland

Vol. 52: 85-184, 1980

Maataloustieteellinen Aikakauskirja

\title{
UDDER DISEASES IN DAIRY COWS - FIELD OBSERVATIONS ON INCIDENCE, SOMATIC AND ENVIRONMENTAL FACTORS, AND CONTROL
}

Selostus: Lehmän utaresairaudet - kenttähavaintoja esiintymisestä, lehmästä ja ympäristöstä johtuvista tekijöistä sekä torjunnasta

H A N N U S A L O N I E M I

Department of Animal Hygiene, College of

Veterinary Medicine SF-00550 Helsinki 55, Finland

To BE PRESENTED, WITH THE PERMISSION OF the College of Veterinary Medicine, for pUblic Criticism in AUditorium Maximum, Hämeentie 57, Helsinki, on March 21th, 1980, AT 12 o'CLOCK NOON.

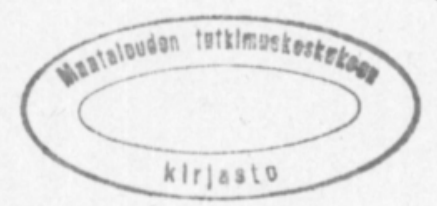





\section{Preface}

The present study was carried out at the Department of Animal Hygiene, College of Veterinary Medicine, Helsinki. I wish to express my deep gratitude to my teacher, Professor KaArlo Kallela, D.V.M., Agr., Rector of the College of Veterinary Medicine, for his encouraging supervision throughout the work. My thanks go also to the acting Head of the Department, Docent Laurj Vasenius, Ph. D., D.V.M., for his help and stimulating discussions during this work.

I am grateful to Professor Kauko Roine, D.V.M., Head of the Department of Obstetrics and Gynecology, my coworker in Kantele-studies, for valuable help during collection of material and for his constructive criticism of the manuscript. I am also grateful to Professor Esko Nurm, D.V.M., Director of the State Veterinary Medical Institute for his valuable criticism of the manuscript.

I express my hearty gratitude to Docent Leo Kolranen, D.V.M., State Veterinary Medical Institute, for his help in milk sample examinations and for stimulating discussions during this work.

I am grateful to Mr. Jouko SyväJärvi, M. Agr. Sc., for the computer programming and for help with the statistical problems.

My best thanks are also due to Ms. Ritva Pertril $\ddot{A}$ and Ms. Saim Heikkinen-Hannpä for milking machine testing. The staff of the Department of Animal Hygiene and the staff and students of the Department of Obstetrics and Gynecology, Hautjärvi, have given their valuable technical help throughout this study.

My thanks are extended to Mr. Seppo Talvitie, and Ms. Margaret MuUrman for translating and revision the manuscript and Ms. KertTU Räty and Ms. Seija Kavander for typing the manuscript.

This study has been partly supported by grants from the Finnish Veterinary Science Foundation, the Ministry of Agriculture and Forestry, the August Johannes and Arno TrurA Agricultural Research Foundation and the Laäke Oy Science and Research Foundation. I am grateful to the Scientific Agricultural Society of Finland for including this study in their series of publications.

Finally, I would express heartfelt gratitude to my family, ElinA, Trmo and Trins, for their understanding and support during this study.

Helsinki, January 1980 



\section{CONTENTS}

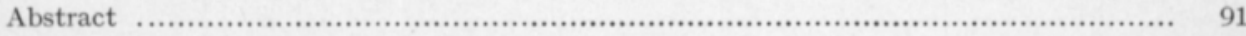

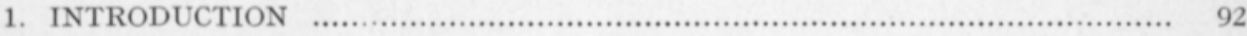

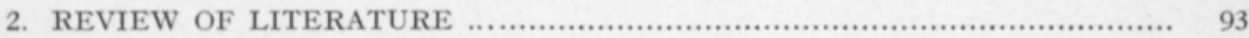

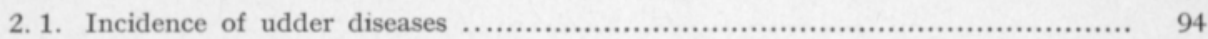

2. 1. 1. Subclinical mastitis ................................................................ 94

2. 1. 2. Clinical mastitis ................................................................ 95

2. 1. 3. Teat injuries ............................................................... 96

2. 2. Influence of physiological and anatomical characteristics of cow and that of certain other somatic factors on udder health .................................... 97

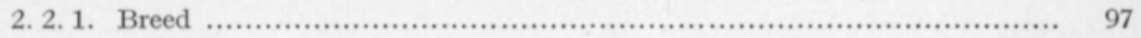

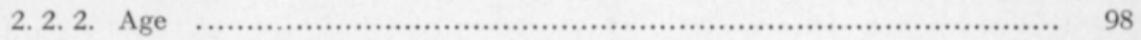

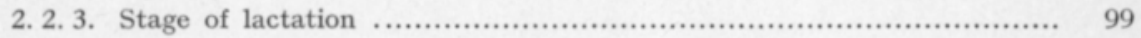

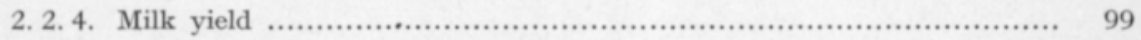

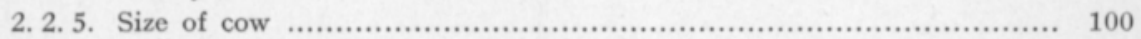

2. 2. 6. Conformation of udder and teats ......................................... 100

2. 2. 7. Milkability ......................................................................... 101

2. 2. 8. Condition of hooves and feet ............................................. 102

2. 3. Effect of environmental factors on udder health .................................. 102

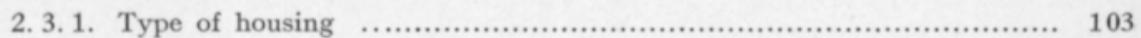

2. 3. 2. Ventilation ......................................................................... 103

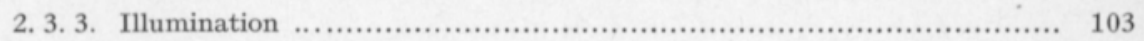

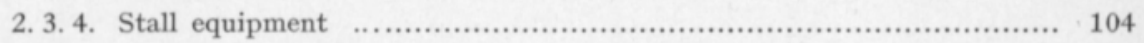

2. 3. 5. Bedding materials …............................................................. 104

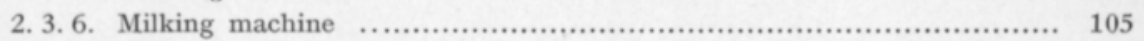

2. 3. 7. Technique of milking …....................................................... 106

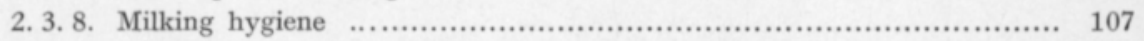

2. 3. 9. Mistakes made in feeding and composition of fodder .................. 107

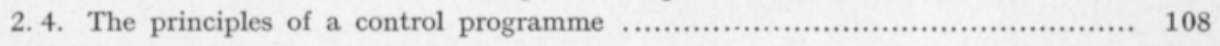

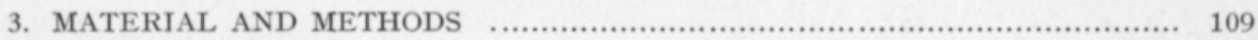

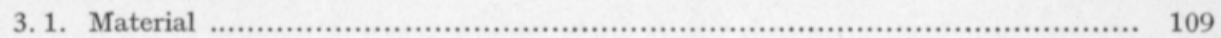

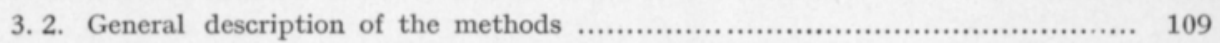

4. UDDER HEALTH IN COWS AND HERDS ............................................. 110

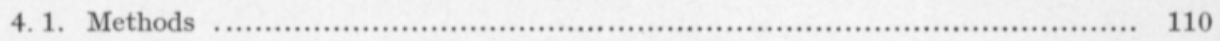

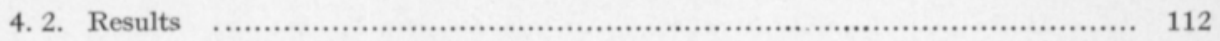

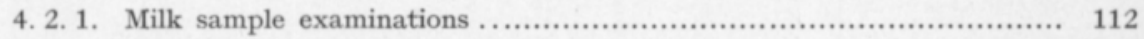

4. 2. 2. Incidence of clinical udder diseases ....................................... 117

4. 2. 3. External injuries to the udder ........................................... 118

4. 2. 4. Relation between the measures describing udder health ................. 120

4. 3. Discussion ................................................................................... 124

5. EFFECT OF COW'S CHARACTERISTICS ON UDDER HEALTH ................. 127

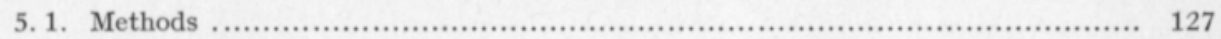

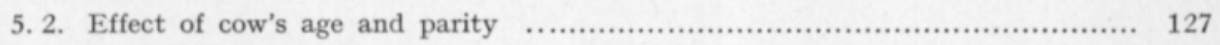

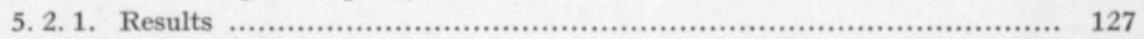

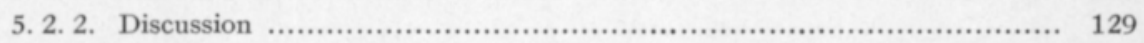

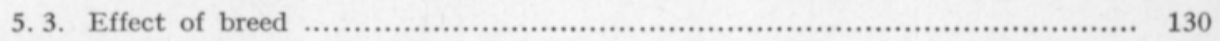

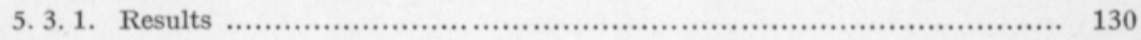

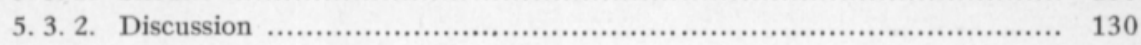




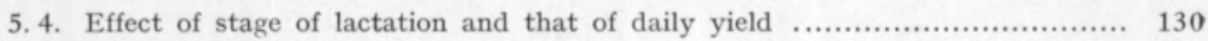

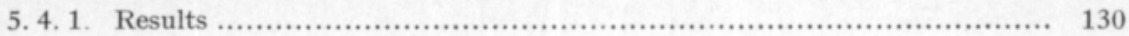

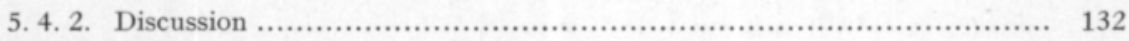

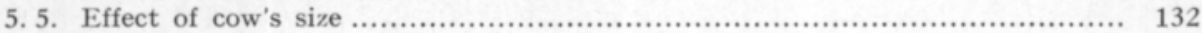

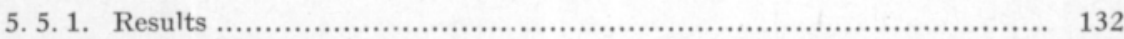

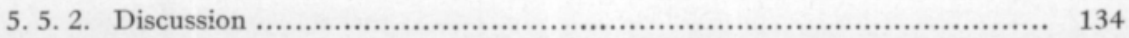

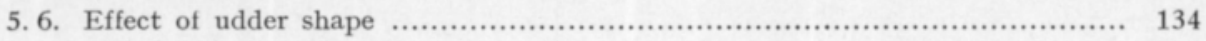

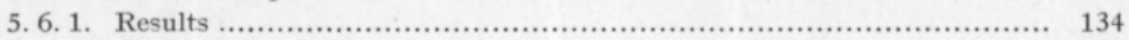

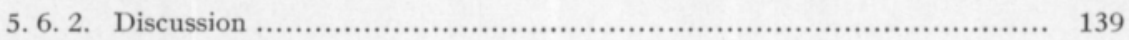

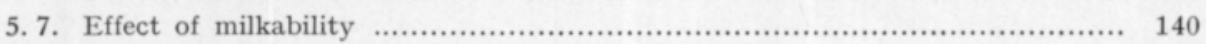

5. 7. 1. Results ........................................................................... 140

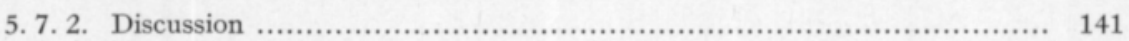

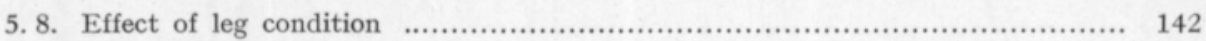

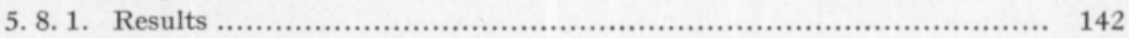

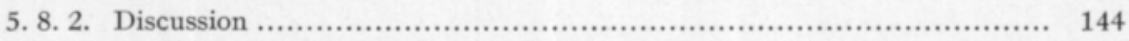

5. 9. Simultaneous effects on udder health of the characteristics of cow and herd 145

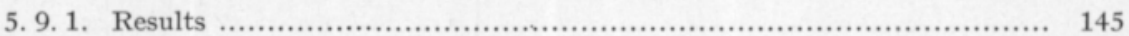

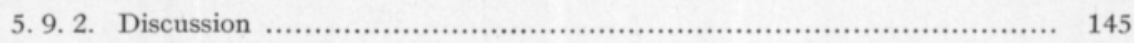

6. EFFECT OF ENVIRONMENTAL FACTORS ON UDDER HEALTH ............. 146

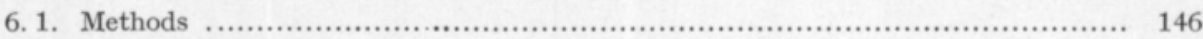

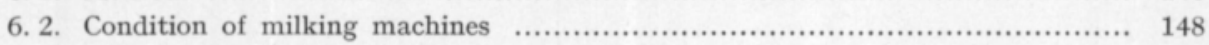

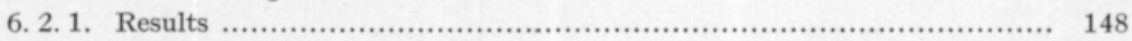

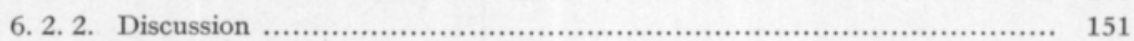

6. 3. Effect of condition of milking machine .......................................... 151

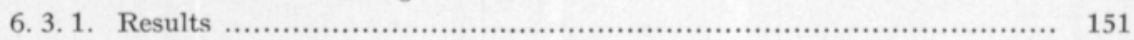

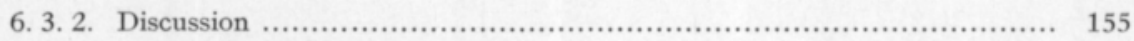

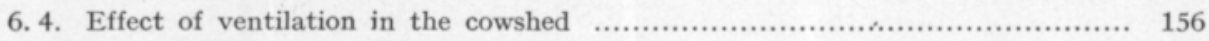

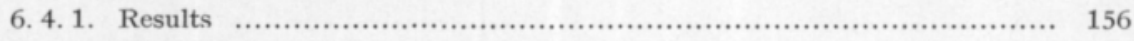

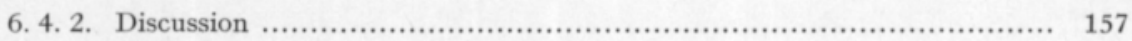

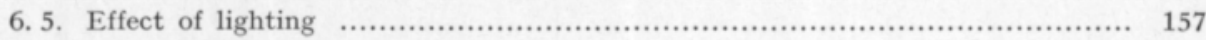

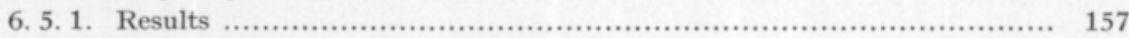

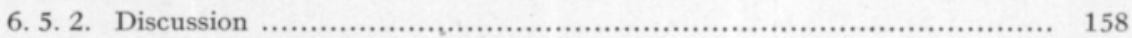

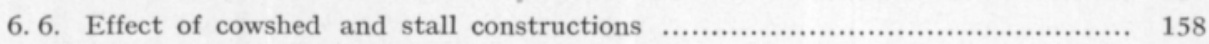

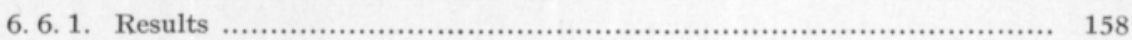

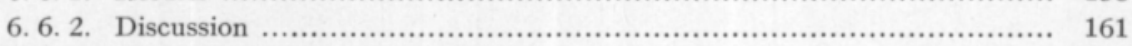

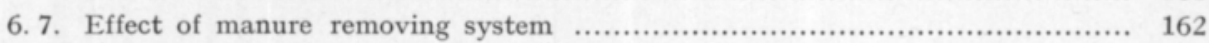

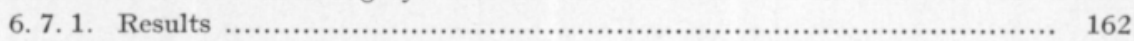

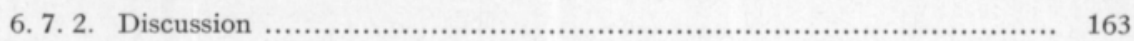

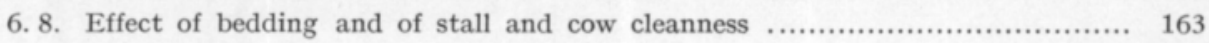

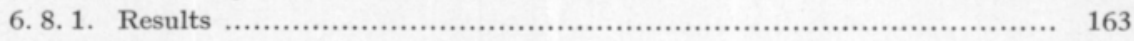

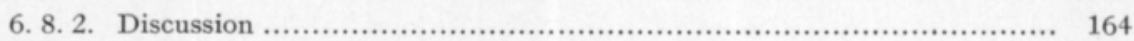

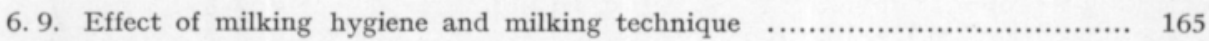

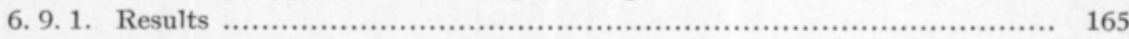

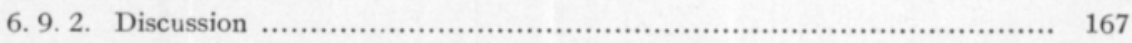

6. 10. Effect of size of herd, participation in milk recording, level of milk yield and

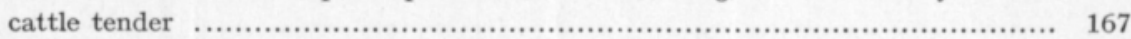

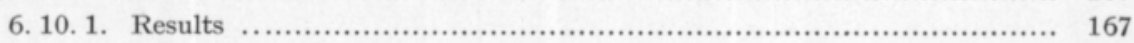

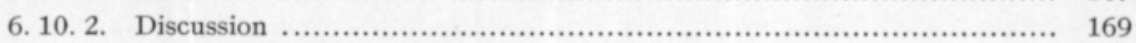

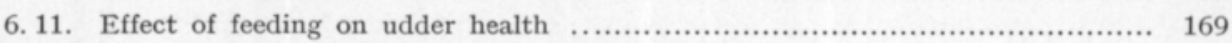

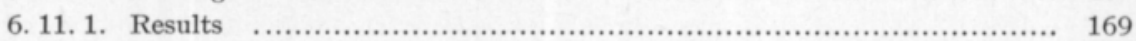

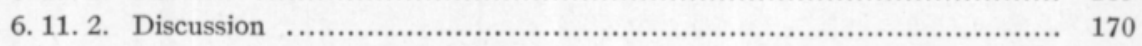

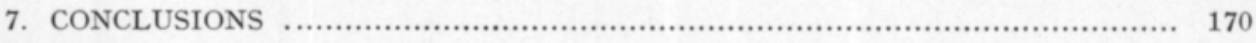

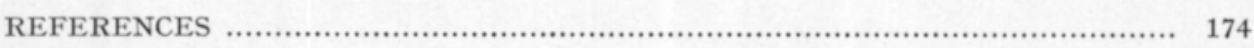

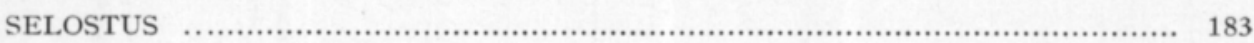




\title{
Saloniemi, H. 1980. Udder diseases in dairy cows - field observations on incidence, somatic and environmental factors, and \\ control. J. Scient. Agric. Soc. Finl. 52: 85-184.
}

\begin{abstract}
The incidence of udder diseases and the predisposing factors were examined in 32 herds, in a total of 500 cows During a 3-year-period 0.32 cases of clinical mastitis occurred per cow per annum. Subclinical mastitis was detected in $61.2 \%$ of the cows during one year. The average incidence based on a single sampling was $36.5 \%$. In order to obtain reliable information on the udder health of a herd the occurrence of both clinical and subclinical mastitis must be followed. Clinical cases, both those treated by a veterinarian on a farm visit and those treated by the owner according to phone prescription must be filed statistically. In this study the incidence of mastitis as reported by owner was only half of that actually detected. The incidence of teat injuries requiring veterinary treatment was 0.03 cases per cow per annum.

The diagnosis spresence of bacterias obtained from a milk sample examination using Nordic methods means according to this study in most cases the probable occurrence of infection and mastitis.

Scoring of observations made from udder health, and indexes based on these scores prove to be good tools when studying relationships between udder diseases and predisposing factors.

Of the somatic factors the age of the cow, stage of lactation, the distance of the rear teats from the stall floor and the position of the teats influence the incidence of mastitis. Therefore, these factors must be taken into consideration in preventive work, especially in the culling of cows. Neither teat shape nor milkability had any connection with the incidence of udder diseases.

With regard to the factors in the production environment the incidence of clinical mastitis was influenced especially by the function of the milking machine. Diurnal changes in temperature, when exceeding 5 degrees centigrade, increased the occurrence of mastitis. The use of a thermohygrograph is proposed in preventive work.

Because of the small number of the herds only in few cases reliable proof could be obtained as to whether the constructional details of the cowshed or stall or the milking hygiene had any effect on udder health. The observations made, however, were not in disagreement with those findings published in other Nordic countries.

The significance of the cattle tender as an environmental factor is great. When a mastitis control programme is worked out, therefore, the mastitis situation in a herd, and the predisposing factors detected on the farm must be reliably demonstrated to the owner and the measures required for improvement must be clearly proposed.
\end{abstract}




\section{Introduction}

Of all diseases affecting dairy cattle in Finland mastitis is the disease which causes the greatest economical loss to the cattle owner and the disease most often involving veterinary treatment. It has been estimated that in 1977 economical losses suffered by the cattle owners amounted to approximately 300 million marks, and that the total output of milk for the country was decreased by some $5 \%$ due to mastitis (SALOniemi 1978 a). The number of farm visits made because of mastitis (62 455 visits) was $14.3 \%$ of the total number of visits made by veterinarians in 1978, and furthermore, the prescriptions given by phone for treatment of mastitis was 2.8 -fold the amount of actual farm visits (ANON. 1979 a). However, despite the obviously great significance of mastitis it is only now that organized measures to control the disease at the herd level are being taken (KoIRANEN 1979a), although control programs adapted to Finnish conditions have been publised earlier (Nurmi and KoIrANEN 1971 a). Experience both in Sweden (Anon. 1979 c) and Denmark (KLASTRUP 1978 a) over several years has shown that organized measures of control do lead to economically profitable results.

Knowledge of the nature and characteristics of a disease is the basis for its prevention. Mastitis is an inflammation of the udder caused by infections, tissue injury or secretory malfunction, and nearly all those cases of mastitis which are of economic significance may be associated with an infection by the streptococcus, staphylococcus or coliform bacteria. The mere wealth in variety of causative microorganisms in mastitis with the resulting great variation in the symptoms and pathogenesis ensures a disease difficult to control. Neither the extensive work in microbiological research nor the ample use of antibiotics have resulted in a decrease in the incidence of the disease. Besides the infective factors the somatic characteristics of the cow and the production environment are essentially contributive to the incidence of mastitis.

The great difference in the individual cow as to its susceptibility to the disease is due to many factors - anatomical, physiological or immunological. The correlation between udder conformation and udder disease has been studied to a considerable extent. It is possible to utilize these findings and to breed a dairy cow which is able to withstand mastitis better than before (Schalm et al. 1971). The prevention of mastitis by means of breeding is, as yet ineffective because of insufficient knowledge as to the effects of physiological and especially immunological factors (AnON. 1979 d).

Extensive research has been done in the wide environmental field during the past twenty years, but the magnitude of the environmental factors and their correlation hinder this work, and not unrarely result in contradiction. However, the three-part etiology of the mastitis complex is generally recognized, and for this reason the leading researchers of the disease emphasize the importance of observing environmental factors on an extensive scale in its control (Funke 1963, Klastrup 1971, Dodd 1975, Tolle 1975). The positive and negative influence of the environmental factors on udder health may unexpectedly cancel each other in the single herd or in the individual cow. The cattle-tender, especially, has a strong influence as one factor in the pro- 
duction environment, but an influence not easily measured. In the control of udder disease the problem of mastitis shall be viewed on an all-inclusive basis, as far as each separate herd is concerned (WILson 1968, Nurmi and Kolranen 1971 a).

There have been few studies of mastitis published in Finland whose results could be used in the control of the disease. When this study was commenced very little was known even about the incidence of clinical udder diseases and such knowledge there was, was partly unreliable. Most work done throughout the world concerned with mastitis has been done mostly in the area of microbiology, and the adaption of the results obtained to suit Finnish circumstances probably presents the least difficulty. Far more difficulty arises in the utilization of the results obtained from the research work in the characteristics of the cow. This is due to differences between breeds. The most common breed of dairy cattle in the country, that of Ayrshire, is seldom discussed in the studies of other countries, and furthermore, the Ayrshire breed in Finland probably differs to some extent from those in other countries because the population has been almost closed since 1923 until the 1960's (VASENIUS 1965). This racial difference diminishes the utility value of the results obtained in other Nordic countries as to the influence of environmental factors. The production conditions outside the Nordic countries differ so much that it is difficult to adapt results from more distant countries. On the basis of what has been stated above, research work in mastitis is greatly needed in Finland.

The aim of this study is

1. to increase the knowledge of the incidence of mastitis and other udder diseases of dairy cattle in Finland,

2. to estimate the reliability of the information obtained from cattle owners as to the incidence of disease,

3 . to examine by simple methods of observation the influence of environmental factors and the somatic factors of the individual cow on the incidence of udder diseases in Finnish conditions,

4. to estimate how to adapt the method of measuring the predisposing factors mentioned to the control of mastitis.

\section{Review of literature}

The literature dealing with mastitis began towards the end of the 1700's (WILlbuRg 1775) and by the middle of the 1930's consisted of thousands of publications (Munch-Petersen 1938). In the bibliography published by the Commonwealth Agricultural Bureau, "Mastitis Literature Survey", some 500 new publications on mastitis were listed annually in the 1970's. A considerable part of the publications on mastitis deals with the microbiology and therapy. The literature dealing with the incidence of udder disease and the etiological factors is also extensive. Efforts are made in this literature survey 
to review firstly the Nordic literature relating to the subject of this study, and to complement this with British (NIRD, The National Institute for Research in Dairying) and German (Kieler Milchforschung Anstalt) publications.

\section{1. Incidence of udder diseases}

The availability of reports on the incidence of mastitis which are reliable and allow comparison is rather small due to the fact that the research methods and the definition of mastitis vary. The incidence of mastitis is mostly described on the basis of bacteriological or/and cytological study of milk samples or on the basis of the number of clinical cases treated.

The norms for the bacteriological-cytological research work in milk samples were fixed by the International Dairy Federation (IDF) as late as in 1966, and even these norms need to be developed further (HeEschen 1978). A method of research corresponding to the IDF norms is applied in the Nordic countries except that the critical limit of the cell content in a quarter sample of milk is $300000 \mathrm{pcs} / \mathrm{ml}$ instead of $500000 \mathrm{pcs}$ as fixed by the IDF (KLASTRUP and Madsen 1974).

\subsubsection{Subclinical mastitis}

By employing the Nordic method of studying milk samples KoIranen (1976) established that, in the material of 588 herds and 4349 cows, gathered from different parts of the country, the incidence of mastitis was $34.8 \%$ of the cows examined. By adapting the same method of study to a small amount of material higher percentage figures than the one stated above have been established in Finland: fairly large herds with a high yield in tying stalls $70.2 \%$ (NIEMINEN et al. 1975), herds in tying stalls 7 months after the primary renovation - $52 \%$ (SAloniemi $1977 \mathrm{c}$ ), and the same material 25 months after the primary renovation - $46 \%$ (SAloniemi $1978 \mathrm{c}$ ) as well as loose housing herds $-37.6 \%$ (KARHUNEN et al. 1979). By employing a similar method in four different areas of Denmark the infection percentage in 399 herds was found to be $23-32 \%$ in 1972 (MADSEN et al. 1975), and in another Danish material of about 4000 cows $39.9 \%$ in 1971 (KLASTRUP et al. 1974 a). In Norway, again employing the Nordic method, the incidence of mastitis was found to be $33 \%$ in 29 herds (about 750 cows) in 1966 (NYGAARD and ENGANSKEI 1974), and in the laboratory examinations carried out in 1977 (39000 cows) the incidence of subclinical mastitis as defined by the IDF was $34.7 \%$ (BAKKEN 1978).

In mass examination, the bacteriological study of milk samples has been replaced by cell count (Tolle and Whittlestone 1976, Tolle et al. 1977). The correlation between the cell content of a cow milk sample (geometric mean) and the percentage of mastitis as defined by the IDF was about 0.7 according to ToLLE's research group (1977). The cell count method with joint samples of cow milk has been in progress in Finland since the beginning of 1978, as far as herds subjected to milk recording are concerned. The high percentage of cell content in milk from a diseased quarter is decreased in a 
joint milk sample, therefore a greater degree of interpretation is necessary when judging the samples. According to the preliminary reports the geometric mean of six samples taken was over 250000 cells $/ \mathrm{ml}$ in $30.6 \%$ of the cows examined (SYväJÄRVI 1979).

\subsubsection{Clinical mastitis}

In Finland the information on the incidence of clinical mastitis is based on treatment reports made by veterinarians. According to the instructions for collecting official statistics each clinical case of mastitis was to be reported when treated for the first time. The incidence of mastitis in Finland, based on the number of mastitis officially reported for the statistics in the 1970's, is shown in Table 1 .

Table 1. The incidence of clinical mastitis in 1971-1978 according to statistics of Veterinary Department, Ministry of Agriculture and Forestry (Anon. 1977, 1978 a, 1979 a, b).

\begin{tabular}{lrrrrrrrr}
\hline Year & 1971 & 1972 & 1973 & 1974 & 1975 & 1976 & 1977 & 1978 \\
\hline & & & & & & & & \\
Number of cases & 114753 & 127335 & 131764 & 136043 & 138296 & 197836 & 188945 & 235290 \\
Number of cows & 849000 & 837000 & 824000 & 819000 & 773000 & 763000 & 752000 & 742000 \\
Incidence & 0.135 & 0.152 & 0.160 & 0.166 & 0.179 & 0.259 & 0.251 & 0.317 \\
\hline
\end{tabular}

The figures describing the incidence of mastitis show a steady increase until 1975, then a marked increase in 1976 in connection with the introduction of a new annual reporting system, and again a marked increase in 1978 when a monthly method of reporting was introduced. In 1978 the cases of mastitis treated by farm visit and by prescription were reported separately, their relationship being $1: 2.77$.

Reports have been published, based on small materials, with regard to the incidence of clinical mastitis in Finland: 0.26 and 0.15 cases per cow per annum in tying stalls (SALONIEMI $1977 \mathrm{c}, 1978 \mathrm{c}$ ) as well as 0.20 cases per cow per annum in the loose housing conditions (KARHUNEN et al. 1979). According to the material gathered from the area served by the ambulatory clinic of the College of Veterinary Medicine (109 herds, about 1100 cows) the number of mastitis cases treated by the veterinarians on farms during a period of 8 years was 0.09 cases per cow per annum (SAloniemi and RoIne 1976). The forementioned materials show very clearly a strong variation in the incidence of mastitis between the separate herds. According to the milk recording statistics in 1977 the incidence of udder disease was only 0.03 cases per cow per annum on the farms where milk recording was carried out. The information for these statistics was obtained from the cattle owners (ANon. 1978 b). According to a questionnaire examination covering 426 herds and 4062 cows the frequency of the clinical mastitis cases observed by the owners was $\mathbf{1 5 . 4}$ cases per 100 cows per annum (SYVÄJÄRVI and LindSTRöm 1978). 
According to the information available from the so-called health cards $13.8-16.3 \%$ of the cows subjected to milk recording were treated for mastitis in Norway during the years 1975-1978 (Solbu 1977, 1979), but according to the official veterinary statistics for the area of Hedmark the number of cows treated for mastitis was double that reported on the health cards (SIMENSEN 1976 b). According to BAKKEN (1978) the incidence of clinical mastitis was about 0.30 in Norway in 1976. In central Sweden the percentage of mastitis cases treated by veterinary farm visits was $14.4-16.2 \%$ during the years $1971-1973$ (ВёскSTRöм et al. 1975). Only a part of the mastitis cases treated by prescription was included in the health card information from Norway and in the material from central Sweden. In Denmark in the material of 416 herds and 6583 cows (ELLEBY et al. 1969) the incidence of mastitis was found to be 0.26 . Even between the different Nordic countries an exact comparison of the incidence of mastitis is hindered by the different methods in filing statistical information, furthermore, the incidence is influenced by differences between breeds (EKesbo 1966, Elleby et al. 1969, Erb and Martin 1978) and even by regional variations (Simensen 1976 b, Solbu 1977).

In order to provide a basis for the prevention of mastitis, especially subclinical mastitis, it is necessary to obtain a knowledge of the frequency of new infections (KINGWILl et al. 1977). However, no follow-up examinations of long duration have as yet been carried out in Finland. In Denmark in the material of 4000 cows $27 \%$ of earlier healthy cows were infected during a year (KLASTRUP et al. $1974 \mathrm{a})$.

\subsubsection{Teat injuries}

The usual conclusion made from the field examinations and reports is that teat injuries increase the incidence of mastitis (Oliver 1955, Funke 1963, Jackson 1970, Ekesbo 1966, Grommers 1967, Carrol 1977, Nieminen et al. 1975, Saloniemi $1977 \mathrm{c}$ ), although the number of teat injuries in the herds troubled by mastitis does not always exceed the average (PEARson et al. 1972, Nieminen et al. 1975). Teat injuries provide a medium for the growth of the pathogenic bacteria which affect the udder so that in the case of injury the risk of an infection increases (TAYLOR 1949, PHILPOT 1975, Kingwill et al. 1977). According to the statistical information from central Sweden $54 \%$ of the trampled teats which had demanded a veterinary visit and treatment were at the same time mastitis cases, $90 \%$ of which were diagnosed as acute (BÄскSTRöm et al. 1975). A significant positive correlation has also been established between very slight skin injuries in the teat and the occurrence of subclinical mastitis (SALONIEMI $1977 \mathrm{c}$ ).

Information on the incidence of traumatic diseases of the udder and teats has been published in different countries, but diagnosis incoherence and differing methods of gathering information make it difficult to draw comparisons. In the Finnish official statistics based on veterinary reports the diagnosis has been reported as nteat defects" since 1976. The number and incidence of teat defects are shown in Table 2 . 
Table 2. The incidence of teat defects in 1976-1978 according to statistics of Veterinary Department, Ministry of Agriculture and Forestry (ANon. 1978 a, 1979 a, b).

\begin{tabular}{lrrr}
\hline Year & 1976 & \multicolumn{1}{c}{1977} & \multicolumn{1}{c}{1978} \\
\hline & & & \\
Number of teat defects & 27070 & 26096 & 30651 \\
Incidence & 0.035 & 0.035 & 0.041 \\
\hline
\end{tabular}

In the material of 109 herds (about 1100 cows) gathered from the area of the College of Veterinary Medicine's ambulatoric clinic the incidence of teat injuries treated by veterinarians was 0.038 cases per cow per annum during the years 1968-1975, the average of incidence in herds varying between $0.00-$ 0.25 (SAloniemi and RoINe 1976). In the previous report concerned with the primary renovation of the tying stalls the incidence of teat injuries was 0.13 7 months after and 0.0624 months after the primary renovation (SALONIEMI $1977 \mathrm{c}, 1978 \mathrm{c}$ ). In the material of some $\mathbf{5 5 0}$ cows living in the loose housing conditions the number of the teat injuries treated was 0.023 cases per cow per annum (KARHUNEN et al. 1979).

In central Sweden the frequency of the teat diseases treated by veterinarians was $4.9 \%$ in 1973 (ВёскsтRöm et al. 1975). In the Danish material the incidence of teat diseases was 0.067 (Elleby et al. 1969).

In the clinical examinations covering all the animals of a herd the injuries to the teat and udder have seldom been the object of scrutiny. NygaARD and ENGAN-SKEI (1974) in the material of about 750 cows detected mechanical injuries and wounds in $2.1 \%$ of the teats, most of them on the tip. The orifice of the teat canal was everted in $15.4 \%$ of the cases. Papillomas were found in $0.7 \%$ of the teats.

\section{2. Influence of physiological and anatomical characteristics of cow and that of certain other somatic factors on udder health}

The breed, age, stage of lactation, production level and constructional factors of a dairy cow: the size of the animal, the construction of the udder and teats as well as the milking characteristics are the most common of those qualities of a cow which are believed to have effect on the health of an udder. All together they contribute to "a cow's capacity to resist udder diseases». The knowledge of the different components of this "capacity to resist" is still insufficient, and for instance, the immunology of mastitis is the object of extensive study (AnON. 1979 d). Vaccination is used extensively already now in mastitis control in Finland (KoIRANEN 1978).

\subsubsection{Breed}

The breed of a dairy cow greatly influences her liability to contract mastitis. According to two Finnish studies based on enquire the Friesian breed suffers considerably more often and also more seriously from mastitis than the Ayrshire and Finncattle breeds (Lindholm 1978, Lindström and SyväJärvi 1978). 
According to the milk recording statistics Friesian cows are culled from a herd more often than cows of other breeds because of udder defect (ANON. 1978 b). One reason to the greater mastitis incidence in Friesian cows might be the bigger size of this breed and the short stalls used earlier for Finncattle. In Sweden EKesbo (1966) detected more cases of mastitis in cows belonging to the Swedish Black and White breed than in those belonging to the Swedish Red and White breed. The difference was greater in tying stalls than in loose housing conditions. In the Norwegian Red breed the Sidet Colored Tronder has been proved to be more sensitive to Streptococcus agalactiae than the Red Tronder (EIEland 1963). As far as mastitis and teat defects are concerned, the Jersey breed is clearly healthier than the Danish Red breed or the Danish Black and White breed (RASBECH et al. 1967). In a Canadian clinic material (ERB and MARTIN 1978) the Guernsey breed was clearly healthier than the Jersey or Holstein-Friesian breeds, and the Ayrshire breed was found to be more sensitive to mastitis than even these. The share the Ayrshire cows had in that material, however, was small.

\section{2.2. Age}

With increasing age and lactation numbers, a still greater section of the dairy cows contract mastitis. The culling of cows makes it difficult to examine objectively the age influence, the older population of cows already being selected. The likelihood of an infection increases naturally with time. Once an udder has been diseased, it is more likely than a healthy udder to sicken again, and the infection of one udder quarter adds to the risk of the others getting infected (Miller et al. 1976). During the period of one year $65 \%$ of the new infections were detected in the cows which had had at least one quarter infected. The examination covered 14 herds and 478 cows (DoDD et al. 1977). Cases of subclinical mastitis have more often been detected in older cows (Walser et al. 1972, NygaArd and Engan-Skei 1974, Madsen et al. 1974, Kingwill et al. 1977, SAloniemi 1977 c, Bakken 1978). The examinations based on cell count showed the same age distribution (ZEIDLER et al. 1969, SYVÄJÄRVI 1979). There is no certain proof to be found in the literature, however, as to whether an old cow which has not previously contracted mastitis is more liable to this disease than a young one. Fodstad (1966) found out that the onset of new infections caused by the B-streptococcus is not dependent on age. The same observation was presented by OLIVER et al. (1956) as applying to all infections. However, opposite opinions about the age distribution have been presented as well (Rendel and Sundberg 1962, Schalm et al. 1971, Natzke et al. 1978). According to studies of Erb and Martin (1978) the incidence of acute mastitis has proved to be independent of age. In other cases, as far as young cows at the stage of high production are concerned, the occurrence of acute mastitis may be relatively more common (WALSER et al. 1972). According to Scandinavian investigations the incidence of clinical mastitis increases with age and with lactation times (ВӓскотRöм et al. 1975, Solbu 1979). When the problem of mastitis in a single herd is being solved, the mean age of the cows must be taken into consideration (PEARson et al. 1972). 


\subsubsection{Stage of lactation}

At the stage of early lactation the incidence of clinical mastitis is greatest (Bratlie and Fodstad 1955, Oliver et al. 1956, Walser et al. 1972, Roine and Munsterhjelm 1974), most of the teat trampling also take place at this time (Grommers 1967, Roine 1975, Kubicek and Meinecke 1978). Oliver et al. (1956) proved that the incidence of first new infections is more numerous during the first month of lactation, the total number of infections being below the average during the 1-2 months of the milking period. The Norwegian material of 36700 cows shows a steady occurrence of subclinical mastitis in the different phases of the lactation period (BAKKEN 1978). In the examination of milk samples the incidence of mastitis was actually found to be slightly more numerous in the beginning of lactation (MADSEN et al. 1974, SAloniemi 1977 c) or even less numerous than average (NYGAARD and ENGAN-SKEI 1974) due to the great number and long persistence of subclinical mastitis. According to NIRD's researchers the onset of new infections is even most numerous at the beginning of the dry period (Thомаs et al. 1972, Kingwill et al. 1977). They concluded that the risk of infection increases due to the fact that the bacteria which have entered the teat and udder are not removed with foremilk at the beginning of milking.

\section{2. 4. Milk yield}

There are reports that when the annual milk yield of the cow is increasing, there is a remarkable increase in the incidence of mastitis (WALSER et al. 1972, Rutzmoser 1975, Solbu 1978). It is stated as an explanation that the udder when dilated by the high rate of yield runs a greater risk of injury and that the power of resistance is weakened by the stress caused by the milk yield (EKESBO 1973). On the basis of a questionnaire examination carried out in Finland (progeny of 365 Ayrshire bulls) the correlation between milk yield and mastitis incidence was $0.14-0.19$, or in other words, the bulls from which the best capacity of yielding milk can be inherited produce female offspring whose liability to mastitis is slightly above the average (LINDSTRöM and SYVÄJÄRVI 1978). However, the udders of the cows with the best annual yield are often healthier than average, it not being possible for a sick cow to attain the high rate of milk yield (SYVÄJÄrvi and LindSTRöm 1978, KoIranen et al. to be published). Five years' observations made by RENDEL and SundBerg (1962) on about 47 herds give support to this concept, the milk fat yield having no connection with the incidence of mastitis. In a German examination of $\mathbf{5 8 8}$ herds there was on average a remarkable lowering of the mean milk yield in herds with a high percentage of mastitis (HINRICHSEN et al. 1978).

The daily milk yield of a cow is highest during the first two months of lactation. Most cases of acute mastitis occur in the cows with a rich daily yield. The daily milk yield of the cows suffering from acute mastitis did not, however, very often exceed 20 kilos (WALSER et al. 1972), cows with the highest daily yield do not get mastitis more often than other cows. When measuring the health of an udder by means of cell count it must be borne in mind that there is physiological increase in the cell number, typical of even a healthy udder, 
in the beginning and at the end of the lactation period (Tolle 1975, Syrstad and Røn 1978, Grootenhuis et al. 1979).

\subsubsection{Size of cow}

As far as the conformation of a cow is concerned, the health of an udder is influenced by the cow's size in such a case when the dimensions of the cowshed, especially those of the stall, and the size of the cow are in disproportion (EKEsBo 1966, Grommers et al. 1972). There is a marked growth in a Finnish Ayrshire cow until the third year of age (KENTTÄmIEs et al. 1974) and thereafter a small growth until the sixth year of age (SALONIEmi $1977 \mathrm{c}$ ). In the case of a single herd there is a marked variation in the relationship between the size of the animal and the dimensions of stalls because of the growth of dairy cows.

\section{2.6. Conformation of udder and teats}

Several exact accounts have been made of the conformation of udder and teats (Johansson 1957, Johansson and Malven 1960, Andreae 1963, Witt et al. 1967, Heidrich and Renk 1963, Schalm et al. 1971). Paizs (1973) has presented a fairly large survey of the literature dealing with the correlation between the conformation of the udder, milkability and the health of the udder. ANDREAE (1971) submits the following characteristics to be aimed at when breeding: 1. long, flattened udder (= dish-shaped udder), 2. the same size and milk yield of the front and hind udder quarters, 3. as small an udder as possible in relation to the milk yield ( $=$ "a richly glanded udder $n$ ), 4 . the teats being symmetrical in position and size. The size and shape of the udder change with the age of the cow, this shows itself especially in regard to the decrease in the distance between the udder and the stall floor, teat-floor distance (Johansson 1957, Burnside et al. 1963, Andreae 1963, Aehnelt et al. 1969, NygaARd 1973, Saloniemi 1978 b). The high rate of milk yield decreases the teat-floor distance as well (BURNSIDE et al. 1963). When the teat-floor distance becomes shorter, the risk of mastitis and teat injuries grow (Young et al. 1960, Paizs 1973, Grommers et al. 1971, Karlsson and Gustafsson 1977, Kubicek and Meinecke 1978). Paizs (1973) found out that the dish-shaped and round udders are emptied more completely in the process of normal milking. According to PaIzS the larger amount of residual milk in the pendulous udder leads to the more frequent occurrence of mastitis.

The production environment can have an effect on the conformation of the udder. In his examination of twins Grommers (1967) found out that the twin half kept in the stall had a teat-floor distance some $2 \mathrm{cms}$ shorter than the twin kept in the loose housing conditions.

Hickman (1964) and Rathore (1976) detected that the milk from the cylindrical shaped teats had a remarkably higher cell content than that from the funnel shaped teats. As an explanation Rathore (1977) states that in the case of the cylindrical shaped teats the milking machine teat liners ascend more freely. Based on a study of milk samples the udder health of the cows with cylindrical shaped teats was found to be slightly better - statistically not significantly - in a Finnish material of 140 cows, $75 \%$ of which were cows with 
cylindrical teats and $25 \%$ with funnel teats (SAloniemi $1977 \mathrm{c}$ ). Ryniewicz and Bassalik-Chabielska (1978) have presented results to the same effect.

Scattered teats are exposed to external injury, and succumb more easily to infection. A lot of residual milk is left in the udders of the cows with scattered teats during machine milking, which contributes to the increased occurrence of mastitis together with the leakage of air caused by the position of the teats (Paizs 1973). According to PaIzs the incidence of mastitis is 2.5-fold the average, as far as cows with scattered teats are concerned.

Hyperthelia where the supernumerary teat is so close to the proper ones that milking is hampered by it, or hyperthelia where hypermastia is involved may advance the onset of an udder infection (Sснацm et al. 1971). According to Finnish milk recording statistics first calvers (24 000 cows) had supernumerary teats as follows: Ayrshire breed $22.1 \%$, Friesian $18.0 \%$ and Finncattle $23.4 \%$. One percent of first calvers had supernumerary teats that hindered milking (LindHOLM 1978). Johansson (1957) detected supernumerary teats in $56 \%$ of the Swedish Red and White cows and in $18 \%$ of the Swedish Black ja White cows. In other reports distinct racial differences have appeared as well (Heidrich and RENK 1963, Schalm et al. 1971). Most of the supernumerary teats are small, caudally placed, and active secretory tissue is associated only with the largest of them (Johansson 1957).

\section{2.7. Milkability}

The time needed for milking a herd is greatly influenced by the milkability or rate of milking of the cows at different stages of milking. Parameters showing the speed of milk flow are used to measure milkability: peak flow of milk $(\mathrm{kg} / \mathrm{min})$, mean flow rate of milk $(\mathrm{kg} / \mathrm{min})$, and a quantity of milk produced during the first three minutes expressed in percentage of the total quantity of the milk produced. The correlation coefficients between the different methods of measuring are high (Nielsen 1970). When the mean flow values are corrected to agree with the quantity of the milk produced by a cow, a fairly reliable and easily observable standard of milkability is produced (NiELsen 1970).

The milkability is influenced by the width of the teat canal (JoHANsson and Malven 1960, Grøndahl 1975) and the sphincter tone at the teat end (Nito et al. 1965). The technique of milking has also a quite marked effect on the measures denoting milkability (NÄsI et al. 1977, Lindholm 1978). The heritability $\left(\mathrm{h}^{2}\right)$ of milkability parameters ranges between 0.2 and 0.8 in various studies (LUNDBERG 1974). In the Finnish material of 24000 first-calved cows the heritability was 0.20 on the basis of mean flow results (LindHolm 1978).

DODD and NEAve (1951) observed that clinical and subclinical mastitis strongly increases with the growth of the peak flow. The research workers' opinion was that this was due to the wider teat canal of the cows being easily milked; Appleman (1973) endorsed this. Overmilking, more probably occuring in the cows being milked quickly, may also be an explanation for this.

Certain other research workers are also of the opinion that the high peak flow or mean flow value contributes to the increase in the incidence of mastitis 
(Johansson and Malven 1960, Schluep 1966, Terplan and Hounens 1967). The cows with a high peak flow or mean flow value from whose teats milk leaks before the milking are indisputably more liable to mastitis (PoLITIEK 1968, Lindholm 1978). When the cows with leaky teats are not included, the good milkability does not, however, add to the risk of mastitis according to a number of research workers (Leffler 1965, Politiek 1968, Nielsen et al. 1970, Lundberg 1974, Ryniewicz and Bassalik-Chabielska 1978, Lindström and Syväjärvi 1978, Lindholm 1978, Miller et al. 1978, GrooTENHUIS et al. 1979).

On the other hand, it has been proved that suffering from mastitis leads to a weakening in milkability (NIELSEN et al. 1970). The occurrence of injuries to teat ends weakens milkability as well (SALONiemi $1977 \mathrm{c}$ ). When the milk flow, slowed down by the injuries to teat ends, is increased by the surgical extention of the teat canal, there is an increase in the occurrence of clinical mastitis, obviously as a result of the resistance mechanism of the teat canal being injured (BAUMGARTNER and TSCHAPPAT 1974).

\section{2.8. Condition of hooves and feet}

In several publications hooves which are in bad condition are considered a factor increasing teat trampling and mastitis (HEIDRICH et al. 1968, AEHNELT et al. 1969, Knezevic 1971, Kubicek and Meinecke 1978, Simensen 1979). Foot injuries and teat trampling are also considered to be interdependent because of the same predisposing environmental factors (de Groot 1966, Ekesbo 1966, Heidrich et al. 1968, Knezevic 1971, Kaltenböck 1972).

The connection between the condition of the hooves and feet and the incidence of subclinical mastitis remains as yet unproved in the Finnish material (SALONIEMI $1977 \mathrm{c}$ ). A corresponding result on teat trampling has been obtained from a Swedish examination of accurately controlled material (KARLSSON and Gustafsson 1977).

According to the veterinary reports $1.7 \%$ of the cows treated in Finland in 1978 were treated for foot injury (ANon. 1979 a). In the area served by the College of Veterinary Medicine's ambulatory clinic the corresponding figure was $1.4 \%$ in the years 1968-71 (Saloniemi 1979). More detailed account of the occurrence of foot and hoof injuries and of their connection with the environmental factors have been published in a couple of limited materials in Finland (Nieminen et al. 1975, Saloniemi 1977 c, 1978 c). Information on the occurrence of the foot and hoof diseases treated is to be found in the Nordic health statististics (Elleby et al. 1969, Bäckström et al. 1975, Anon. 1978 c), but only a small amount of more accurate information on the incidence of this disease group has been published (GreENough et al. 1972).

\section{3. Effect of environmental factors on udder health}

The effects of the environmental factors on the incidence of disease in dairy cattle have been dealt with quite much, especially after the extensive studies 
carried out by Ekesbo (1966) and Grommers (1967). A survey of the literature on this subject has been published in Finland (SAloniemi 1977 a).

\subsubsection{Type of housing}

In his extensive material EKEsBo (1966) compared loose houses with tying stalls and came to the following conclusion: "Loose housed SLB and SRB cows with soft bedding in the resting area had a lower incidence of mastitis than both loose house cows with hard bedding and cows in traditional cowsheds». In the case on trampling the differences were greater than in the case of mastitis. As far as trampling is concerned, Grommers (1967) found the difference to be nearly tenfold in favor of loose housing. Several other comparative studies have led to the recommendation of loose houses with a view to udder health (Jørgensen 1970, Rasbech 1970, Maton and de Moor 1975, Groth and Eichler-Steinhauff 1977, Hinrichsen et al. 1978, Klastrup 1978 b), including the report made in Finland (KARHUnen et al. 1979). Kingwill et al. (1977), however, warned against condemning a certain type of cowshed in reference to mastitis; according to their opinion nthe effects on mastitis of the different management methods found within each of the main housing systems will be much greater than the differences between the systems themselves».

\subsubsection{Ventilation}

It is stated fairly often in studies of mastitis from subjective observation that high temperature and humidity, poor heat insulation and draught add to clinical mastitis (Bratlie 1966, Pedersen 1975).

In the latest Nordic examinations the humidity of the cowshed (MADsEN 1978) and the draught affecting the udders (SIEmensen 1976 a) have been proved to be factors which increase the incidence of mastitis. Draughts are found to appear more often in cowsheds where teat injuries occur in large number (KARLSSON and GUSTAFSSON 1977). In a damp cowshed large numbers of coliform bacteria can be found (CARROL 1977). The ventilation in the cowsheds in Finland often works rather inefficiently (NIEMINEN et al. 1975, KARHUNEN et al. 1979), although there is a good deal of technical information available as to how to install ventilation in cowsheds (SÄLlviK 1973).

\subsubsection{Illumination}

If the udders are poorly lighted during milking, it is difficult to observe the hygiene standards required during the milking, which contributes to the onset of mastitis (GUDDING and BAKKEN 1975). In a study of the tying stalls made in Finland (NIEMINEN et al. 1975) it was shown that not a single cowshed had lighting in the milking areas which met with the Swedish recommendation of 300 lux, but that lighting varied between $3-72$ lux.

The lack of night lighting increases the occurrence of teat trampling (KARLSSON and GUSTAFSSON 1977). If frightened in the dark, the cow quickly scrambles to her feet injuring her udder at the same time. 
A Swedish survey has been published with recommendations as to how to arrange the lighting of a cowshed (SUNDAHL 1977), and these may be adapted for the cowsheds in Finland.

\section{3. 4. Stall equipment}

Of the constructional stall details, shortness (Livoni 1955, Garpman 1958, Ekesbo 1966, Keller 1977, Saloniemi 1977 c, Bakken 1978, Madsen 1978) and narrowness (Bratlie 1966, Ekesbo 1966, Madsen 1978) as well as the lack of stall partitions (Bratlie 1966, Nieminen et al. 1975, Bakken 1978, MADSEN 1978) have at least been proved to be factors leading to the increase in udder disease. An electrical cow trainer which prevents the cow defecating onto the stall floor adds to the incidence of teat injury and clinical mastitis (BAKKen 1978). The slipperiness of the stall (Nieminen et al. 1975, Madsen 1978) and a low feeding table in relation to the level of standing (EкEsBo 1969, KALTENBöcK 1972) are also among those factors increasing the incidence of udder diseases. The types of tying which strongly restrict the movements of the cow, especially when she is getting up, increase the risk of injury (EKEsBo 1969, Jørgensen 1970, Klastrup 1971, Mortensen 1971, Nieminen et al. 1975). In practice it is difficult to show that a certain factor in the stall construction has caused teat trampling or mastitis (Grommers et al. 1972).

A dung grid connected to the liquid manure system is a cause of traumatic injury (de Groot 1966, Ekesbo 1966, Heidrich et al. 1968, Maton and Moor 1975, Nieminen et al. 1975, Karlsson and Gustafsson 1977) and clinical mastitis as well (BAKKEN 1978, HINRICHSEN et al. 1978), but the great number of the traumatic injuries detected in the short stalls equipped with a liquid manure system is partly due to the scarcity of bedding material (EKEsBo 1966, 1969).

\subsubsection{Bedding materials}

According to ЕкEsBo (1966) the use of straw in tying stalls and in loose houses clearly improves udder health.

From an extensive Danish study on loose houses it has also been proved that straw bedding, when amply used, is a factor which decreases clinical udder disease (Keller 1977). Straw, when used sufficiently, has also a preventive effect on the incidence of teat injuries (KARLSSON and GuSTAFsson 1977). On the other hand, it has not shown in the latest Nordic field material

any effect of the use of bedding material in tying stalls on the incidence of mastitis (BAKKEN 1978, MADSEN 1978). The amount of the bedding material used in tying stalls is usually so small that it does not give the udders the kind of protection as the soft bedding that EKEsBo (1966) meant.

A small amount of sawdust, usually used in liquid manure stalls as bedding material, may cause a great deal of small skin injuries because of its sharpness (KoIranen $1979 \mathrm{~b}$ ). Sawdust provides a good medium for the growth of coliform bacteria, which often contains, already when being brought into the stall, a great deal of Klebsiella bacteria (Bramley and Neave 1975, Korranen 
$1979 \mathrm{~b})$. The causative microorganisms of mycotic mastitis may also originate from sawdust (DAnko and HengL 1975).

\section{3.6. Milking machine}

Several thorough surveys of the literature have been published concerned with the effects of the milking machine and the machine milking on udder health (Oliver 1955, Fell 1964, Walser 1966, Schalm et al. 1971, Schneider 1971, Thiel 1975, Tolle and Whittlestone 1976, Thompson 1977, Kingwill et al. 1977). Although quite a great deal of research work has been done, the knowledge of the effect the milking machine has on the incidence of mastitis is still considered to be insufficient (THIEL 1975).

A milking machine may risk the health of the udder by acting as a vector, by causing mechanical injury or by advancing the passage of an infection through the teat canal.

The significance of a milking machine as a mechanical conveyer of an infection, a vector, is shown in the report made by BuddLE and CoOpER (1979), according to which $50 \%$ of the first-calved cows contracted a staphylococcal infection when being milked together with old cows, but less than $10 \%$ of the first-calved cows contracted an infection when milked first.

A high vacuum injures the teat end. The vacuum of $50 \mathrm{kPa}$ can already cause damage to the skin of the teat if the teat liner does not close entirely (WALSER 1966). The risk of infection increases if the vacuum level exceeds $50 \mathrm{kPa}$ (Sørensen 1963, Nicolai et al. 1977), the risk becoming greater when the vacuum level exceeds $55 \mathrm{kPa}$ (Bratlie 1958, Kingwill et al. 1977). The vacuum level in the loaded machine must be $50 \pm 0.7 \mathrm{kPa}(38 \pm 0.5 \mathrm{cmHg})$ or in certain older types of machine $44 \pm 0.7 \mathrm{kPa}(33 \pm 0.5 \mathrm{cmHg})$ according to the recommendations applied in Finland.

The vacuum level inside the liner can vary between $30-60 \mathrm{kPa}$ because of pulsation. The cyclic fluctuation of the vacuum as such is not considered to endanger health, but the irregular fluctuation of the vacuum caused by a lack of reserve capacity or defective function of the vacuum regulator can lead to the increase of infection because of milk reflux (NyHan 1968, ThIEL et al. 1969, Bramley and Neave 1975, Brandsma and Maatje 1978, Thompson et al. 1978). The artificial fluctuation of the vacuum has also been proved to increase the number of new infections and to cause keratinization of the teat ends (Klastrup et al. $1974 \mathrm{~b}$ ), as well as to increase cell content (Stanley et al. 1962), but contrary results have also been reported (THIEL et al. 1973). The large number of pipeline leaks correlates with the incidence of clinical mastitis in the Norwegian material of about 300 herds, where a corresponding correlation with subclinical mastitis cannot be proved (BAKKEN 1978). The answer as to how successfully the vacuum level of $50 \mathrm{kPa}$ can be obtained and constantly maintained at this level can be deduced from milking machine tests by measuring the vacuum level evacuation time, pump capacity, reserve capacity, the air flowrate of vacuum taps and the performance of vacuum regulator (ANON. 1975). 
The time period of vacuum application to the teat end and the mechanical stress caused by milking are influenced by the pulsation rate and suction ratio. A quick pulsation rate (over 60 cycle/min, BRATLIE et al. 1959) and/or a high suction ratio (over 0.75, JAckson 1970) lead to injuries, because the liner has no time to close, and the vacuum is applied continously to the teat end. Bratlie et al. (1959) discovered, when comparing with a pulsation rate of $40 \mathrm{c} / \mathrm{min}$, that the pulsation rate of 60 and $75 \mathrm{c} / \mathrm{min}$ caused injuries to the teat end, the cell content of the milk being increased. According to Norwegian tests a suction ratio of 0.75 does not have any effect on udder health at the vacuum level of $47 \mathrm{kPa}$ (BRATLIE et al. 1963). WALSER (1966) has discovered that also a low rate of pulsation (under $40 \mathrm{c} / \mathrm{min}$ ) causes injury to the teat ends. A complete stoppage of pulsation has led to serious problems with mastitis (KINGwill et al. 1977). A faltering of pulsation, one udder half being milked more strongly than the other leads to partial overmilking and adds to the risk of mastitis (PAIzs 1971).

When the teat liner opens after the period of massage, a bigger vacuum is created inside the liner than the one in the short milk tube, in the claw and in the long milk tube. As a result of this, the milk and aerosol flow rapidly and surge back into the liner and against the teat end (NyHAN 1968). The narrowness of the tubes and the claw and the ineffectiveness of the vacuum pump advance the reflux. The reflux makes it possible for an infection to be transmitted to another quarter. WorstorfF (1970) has examined the phenomena associated with the reflux and has proved the existence of infection risk. The significance of the reflux as a factor increasing the risk of infection has been generally approved (WorstorfF et al. 1972, Thompson and Miller 1974, O'Shea et al. 1975, Thiel and Mein 1977, Brandsma and Maatje 1978). In a pipeline milking machine with the high pipeline installation the milk may - in certain circumstances - move even from one cluster to another during the milking operation (Whittlestone and FelL 1969, Whittlestone 1972).

\subsubsection{Technique of milking}

If the preliminary preparations are insufficient, more time is then needed for milking, and the udder is thereby subjected to an increased mechanical stress caused by the milking machine, and as far as at least first-calved cows are concerned, there is an increase in the milk cell content (WALSER 1966). The high percentage of mastitis in cattle with recurrent mastitis is proved to have a connection with a lack of preliminary preparation (HOARE and ROBERTS 1972). The removal of milk from the teat cistern before the udder is washed seems to decrease the onset of new infections (PHILlips et al. 1969).

To milk the udder empty by means of careful stripping has been considered a part of the correct milking technique. Stripping however seems to strain the udder and to increase the infection risk to a healthy udder (GARPMAN 1958, Bratlie 1966, Smith et al. 1978) because of the leakage of air into the teat liner, for instance (BRAndsma and MaAtje 1978). The stripping of infected teat quarters is still considered to be necessary (KINGwILL et al. 1977). 
Various results have been published with regard to the effect of overmilking on udder health. 10-20 minutes' overmilking resulted in the increase of the cell content and oedema in the teat wall but did not cause more marked clinical symptoms (WALSER 1966). Although mucous membrane injuries can be detected in the teat canal as a result of overmilking (PETERson 1964), and though the use of an automatic cluster remover can lead to a lower CMTreading and to less erosion of the teat ends, compared with ordinary milking (PhILPOT 1972), no definite proof has been found in the controlled studies that overmilking increases the number of infections (SEelemann and Obiger 1959, Kingwill et al. 1977, Brandsma and MaAtje 1978, Natzke et al. 1978). The lower percentage of infections in the front quarters, though they are subjected most to overmilking, is considered to be practical proof of the little effect overmilking exercises (KINGwILL et al. 1977). Since the milk when the cluster is being unfastened - may surge back into the teat (THIEL and MEIN 1977), a short period of overmilking is recommended in order to secure the entire removal of milk from the cluster. Because of the practical results which may be achieved BRAndsma and MAatje (1978) recommend the use of automatic cluster removers.

\subsubsection{Milking hygiene}

Defective milking hygiene is an important factor, endangering the health of the udder (Hoare and Roberts 1972, Philpot 1975, Tolle et al. 1977, Kingwill et al. 1977). In order to prevent the spread of infection the use of individual udder cloths for each cow is recommended, also recommended is the disinfection of the clusters between the milking of each cow and the dipping of teats into disinfecting liquid after milking. The significance of hygiene in milking and teat dipping with a view to control mastitis has been established in the Finnish studies as well (Nurmi and KoIranen 1971 b, Koiranen and NURMi 1973). StRANDBERG and FUnKE (1978) have presented a detailed survey of teat dipping and its effect on the improvement of udder health.

\subsubsection{Mistakes made in feeding and composition of fodder}

The information available from literature on the connection between feeding and mastitis is almost entirely based on the observations made in the field and not on experimental work. Mistakes made in quantitative and qualitative feeding are also considered to cause a decrease in the resistance capacity of the udder. Pedersen (1975) has presented a list of those mistakes in feeding which have had an connection with an increase of mastitis (Table 3). Olsen (1968) and CARROL (1977) are of the opinion that a marked change in feeding is a sufficient stress factor to trigger the onset of mastitis.

Several studies concerned with the possibility that plant oestrogens may have an effect in increasing mastitis have been published (Pounden et al. 1958, Frank et al. 1967, Brookbanks et al. 1969). The oestrogenic activity in Finnish pasture and fodder plants (KALlela 1964) makes this point of view interesting. The parenteral application of oestrogens seems also to add to 
the incidence of mastitis ( $\AA$ ström 1972). The effect of oestrogens, however, is still considered to be uncertain (GUIDRY et al.1975).

Table 3. Mastitis caused by feeding. (Pedersen 1975).

Quantitative errors consist of poorly composed diet or overfeeding:

- change of feed of freshly cut roughage with excessive quantities of concentrates

- feed consisting of legumes possibly with high contents of oestrogens

- feeding excessive amounts of protein to heifers in calf

- feeding excessive amounts of protein to milking cows

Qualitative errors caused by poor hygienic conditions of fodder and water:

- contaminated drinking water containing large amounts of Gram-negative rods

- frozen fodder, soiled silage of beet leaves

- silage with a high $\mathrm{pH}$ or with a high content of butyric acid, mouldy feed, concentrates of poor quality

\section{4. The principles of a control programme}

The extent of the economical loss caused by mastitis (Livoni 1955, King 1968, Wilson 1968, Pearson et al. 1972, Morris 1973, 1975, Dobbins 1977, Koiranen 1977, Hinrichsen et al. 1978, Saloniemi 1978 a, Klastrup 1978 a) and the decrease of disease achieved by means of a control programme (HoARE et al. 1977, Mylrea et al. 1977, Hoff and Skoglund 1977) as well as an economically profitable result (AsBy et al. 1974, Benson and Detrman 1977, Dijkhuizen and Renkema 1978, Klastrup 1978 a, Anon. 1979 c) are the starting points for a control programme.

Regular farm visits, the effective care of subclinical diseases, the registration of information, educational services for the cattle owner and the employment of experts can be considered as the basic principles of health control (CoTE 1976). The importance of several control methods being used in conjunction with each other is emphasized also in the control of mastitis (MorRIs 1975). Concentrated efforts must be made with problem herds, at least in beginning, although the best results can be expected where measures involve all herds (Morris 1975). The best success in the motivation for control work will surely be achieved when problem herds may be used as an example, as the situation in an extreme group is likely to improve even without measures within a certain time period (DAvis 1976).

A control programme for mastitis can be expected to have results when it includes all or some of the following measures: 1. advisory visits to farms and the plans how to improve the environmental factors (EKEsBo and Vilson 1978, Saloniemi 1978 c, Saloniemi and Auvinen 1979), 2. the emphasizing of hygiene in milking (Tolle et al. 1977), 3. the regular use of teat dipping (Nurmi and Kolranen 1971 b, Strandberg and Funke 1978), 4. the testing of milking machines and technical instruction associated with them (HoFF and SKogLund 1977), 5. the ascertaining of the mastitis situation in each cow, 
the removal of infection carriers and effective therapy either during the lactation period or when the dry period is starting (Nurmi and KoIranen 1971 a, Tolle 1975, Anon. 1979 c).

\section{Material and methods}

\section{1. Material}

This study involved 32 dairy herds in the village of Kantele, which is part of the Pukkila commune in north-east Uusimaa. It is an area served by the ambulatory clinic managed by the College of Veterinary Medicine. The owners of the herds in the village, altogether 42 in number, were consulted as to their willingness to participate in the study. In May 1977 these 32 herds consisted of 500 cows, on average $15.6 \pm 7.4$ cows per herd, ranging from 4 to 38 cows. In 1968 the average number of cows per herd was $12.3 \pm 4.9$ and after a steady increase in number this figure was $16.1 \pm 7.2$ by the end of the year 1977. Of the total number of herds, 11 were participating in the milk recording system, the average yield of these being in $19765470 \mathrm{~kg}$ of $4 \%$ milk.

\section{2. General description of the methods}

Four different methods were employed in measuring the udder health of the herds participating in the study.

1. During the year of 1977 three separate samples of milk were taken from the cows for bacteriological examination at the State Veterinary Institute. Nordic methodology was used (Klastrup and Madsen 1974).

2. The incidence of clinical udder diseases in the different herds, during the years 1968-1977, was ascertained on the basis of the herd cards kept by the clinic (RoINe 1969) and, as far as the years 1975-1977 were concerned, on the basis of the phone prescriptions registered as well.

3. Injuries of the udders and teats as well as the occurrence of warts were ascertained by inspection in May 1977.

4. Histories of previous udder diseases were obtained from the cow owners during the farm visits made in May 1977, when the physical appearance of the udders was judged, the legs and the hooves were inspected, and the age, breed, stage of lactation etc. of the cows were ascertained.

The rate of mean milk flow was measured to discover the milkability.

The factors in the production environment were mapped out by means of a questionnaire form containing $\mathbf{5 4}$ points. The milking machines were tested at the beginning of 1977 and thermohygrograms were taken in February-April 1977 to test the ventilation.

The results from the measuring and observations were punched on cards, and the information analysed using ordinary statistical methods at the Agricultural Data Processing Centre in Tikkurila. The effect on udder health of certain characteristics of the cow was also examined by means of least square analysis of variance (HARVEY 1966). In the presentation of the results the 
number of observations (n), the mean value $(\overline{\mathrm{x}})$ and the standard deviation (S.D.) are stated; in the statistical tests the degree of significance is stated as follows:

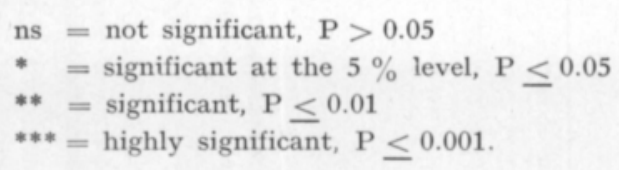

\section{Udder health in cows and herds}

\section{1. Methods}

The examination of the individual cow: Three samples of milk were taken from the study herds during 1977. The samples were taken during the early hours of the afternoon between milking times. The first samples were taken in January-February and 432 cows were examined. The second samples were taken in March (after an interval of 5-8 weeks) and 393 cows were examined. The third samples were taken in August-October (after an interval of 2035 weeks) and 362 cows were examined. Samples were mainly taken during lactation period, however, altogether $\mathbf{5 8}$ cows were sampled during early dry period or just before calving $(33,15$ and 10 cows during each sampling). A CMT-test, which established the cell content of the milk, was made on each udder quarter at the farm by the person taking the samples. If the CMTreading was less than 3 , a joint sample was taken from the cow, otherwise quarter samples. The bacteriological and cytological examinations of the samples were carried out at the State Veterinary Institute which adhered to the recommendations of the Nordic team (Klastrup and Madsen 1974). The total number of samples examined bacteriologically was 1571 . The cell content was estimated by means of a CMT-test, and the findings are presented as numbers from 1 to $\mathbf{5}$. To show the state of udder health and the incidence of subclinical mastitis an index for one sampling (A-index) and a united index for all the samplings (B-index) have been calculated on the basis of the findings obtained from the milk sample examinations (Table 4). Of the 500 cows examined on the farm visits in May 1977 a B-index could be calculated for 495 cows.

The skin of the udder and every teat as well as the teat end were examined on the farm visits made in May 1977. The observations were judged according to the scale in Table 4, and on the basis of these an index for each cow was calculated as a sum of the observation score of each udder quarter.

A history was obtained from the cattle owner or tender as to the previous incidence of mastitis and teat injury. If, then, the number of cases was divided by the number of the cow's production years (age minus 2 years), the ownerreported incidence of mastitis and teat injuries» could be obtained (Table 4).

The examination of the individual herd: On the basis of B-indexes, skin indexes and teat end indexes obtained for individual cows in a herd, corresponding indexes for a herd were calculated as a mean value (Table 5). 
Table 4. The nieasures of udder health used in this study.

$A$-index - findings from the single milk sample examination of the individual cow.

$1=$ all quarters healthy

$2=$ presence of bacteria in one or more quarters, CMT $<3$

$3=$ mastitis according to cell content, CMT $\geq 3$

$4=$ infectious mastitis, CMT $\geq 3$ and isolation; of pathogenic microorganisms $(3+4=$ subclinical mastitis)

B-index - combined findings trom all the milk sample examinations of the individual cow. The index is formed by adding the A-indexes for the individual cow and by dividing the sum with the number of sampling times.

Skin index - index for lesion in the udder and teat skin. The skin of the udder and the skin of the four teats were judged separately according to the scale below; the index is the sum of the five observations made.

$1=$ healthy skin

$2=$ cicatrices from healed skin lesions

$3=$ superficial, slight skin lesion

$4=$ inflammed or deep lesion

Teat end index - index for injury to the teat end. Each teat was judged separately according to the scale below, the index is the sum of the four observations made.

$1=$ smooth, healthy

$2=$ hard, no signs of acute inflammation

$3=$ eversion of the mucous membrane in the teat canal

$4=$ acute trauma or inflammation

The incidence of mastitis as reported by the owner - the number of mastitis cases during the lifetime of the cow reported by the owner, divided by the number of production years (the age of cow minus two years)

The incidence of teat injuries as reported by the owner - the number of injuries during the lifetime of the cow divided by the number of production years (the age of cow minus two years)

Table 5. The measures of udder health for the individual herd.

Mastitis percentage - the percentage of cows affected by subclinical mastitis based on milk sample examinations.

Herd B-index - the mean value of the B-indexes for the individual cows in a herd.

Herd skin index - the mean value of the corresponding indexes for the individual cow in a herd. Herd teat end index - the mean value of the corresponding indexes for the individual cow in a herd.

The incidence of clinical mastitis - the annual number of mastitis cases treated by veterinary farm visit or phone prescription divided by the annual number of cows in a herd in the year in question.

The incidence of teat diseases - the annual number of thelitis cases and teat wounds treated by veterinary farm visit divided by the annual number of cows in a herd in the year in question.

Since 1968 udder diseases treated by veterinarian have been stated on the herd card for each herd (RoINE 1969). The udder diseases have been defined as follows: 
- mastitis: cases of clinical mastitis, diagnosed from clinical symptoms,

- thelitis: cases of teat canal stricture treated by veterinarian, cases of trampling leading to teat canal injury as well as all trampled teats with slight skin lesions,

- teat wound: external trauma to the teat skin caused, for example, by barbed wire or trampling.

The number of clinical mastitis cases in the study herds treated by phone prescription has been filed statistically since 1975 .

The annual incidence of clinical udder disease in each herd was calculated so that the annual number of diseases was divided by the number of cows in the herd during the year in question.

\section{2. Results}

\subsection{Milk sample examinations}

The diagnoses made on the basis of the milk sample examinations are shown in Table 6. Subclinical mastitis was detected in $25.5 \%$ of the cows in the first sampling, $45.6 \%$ in the second cows and $39.8 \%$ in the third sampling. The average for the whole material was therefore $36.5 \%$. From the whole material during the study period $31.7 \%$ of cows were negative. When the presence of bacteria was included it was seen that $38.8 \%$ of the cows were healthy and $61.2 \%$ were affected by subclinical mastitis.

Table 6. Udder health according to milk sample examinations.

\begin{tabular}{|c|c|c|c|c|c|c|c|c|}
\hline \multirow{3}{*}{ Diagnosis } & \multicolumn{6}{|c|}{ Sampling time } & & \\
\hline & \multicolumn{2}{|c|}{ I } & \multicolumn{2}{|c|}{ II } & \multicolumn{2}{|c|}{ III } & \multicolumn{2}{|c|}{ Total } \\
\hline & $\mathrm{n}$ & $\%$ & $\mathbf{n}$ & $\%$ & $\mathbf{n}$ & $\%$ & $\mathrm{n}$ & $\%$ \\
\hline No mastitis ................ & 276 & 63.9 & 184 & 46.8 & 197 & 54.5 & 657 & 55.3 \\
\hline Presence of bacteria ... & 46 & 10.6 & 30 & 7.6 & 21 & 5.8 & 97 & 8.2 \\
\hline $\mathrm{CMTT} \geq 3 \ldots \ldots \ldots \ldots \ldots$ & 54 & 12.5 & 99 & 25.2 & 71 & 19.6 & 224 & 18.9 \\
\hline \multirow[t]{2}{*}{ Infectious mastitis ..... } & 56 & 13.0 & 80 & 20.4 & 73 & 20.2 & 209 & 17.6 \\
\hline & 432 & & 393 & & 362 & & 1187 & \\
\hline
\end{tabular}

The A-index of the first sampling was highly significantly lower than that of the second and third samplings, as can be seen from Table 7. As regards the second and third samplings, there is no statistically significant difference between the means of the A-indexes. Table 7 also shows the mean value of the B-indexes for the cows participating in each sampling. The differences are small. The mean value of the B-indexes for the cows in the material was $1.99 \pm 0.90$ (Fig. 1). The herd B-indexes varies between 1.23 and 2.78, the mean value being $1.96 \pm 0.37$ (Fig. 2). 
Table 7. The A-indexes for the different sampling times (mean and standard deviation) and the B-indexes for the cows included at each sampling time.

\begin{tabular}{cccccc}
\hline $\begin{array}{c}\text { Sampling } \\
\text { time }\end{array}$ & $\mathrm{n}$ & $\begin{array}{c}\text { A-index } \\
\overline{\mathrm{x}}\end{array}$ & S.D. & $\overline{\mathrm{x}}$ & S.D. \\
\hline I & 432 & $1.75^{\mathrm{a}}$ & 110 & $1.99^{\mathrm{a}}$ & 0.88 \\
II & 393 & $2.19^{\mathrm{b}}$ & 1.22 & $2.02^{\mathrm{a}}$ & 0.88 \\
III & 362 & $2.06^{\mathrm{b}}$ & 1.24 & $1.95^{\mathrm{a}}$ & 0.87 \\
\hline
\end{tabular}

Means with different letters are significantly different. $\mathrm{a} / \mathrm{b}(\mathrm{P}<0.001)$

Fig. 1. Frequency distribution of the B-index. 495 cows, $\overline{\mathrm{x}}=1.99$.

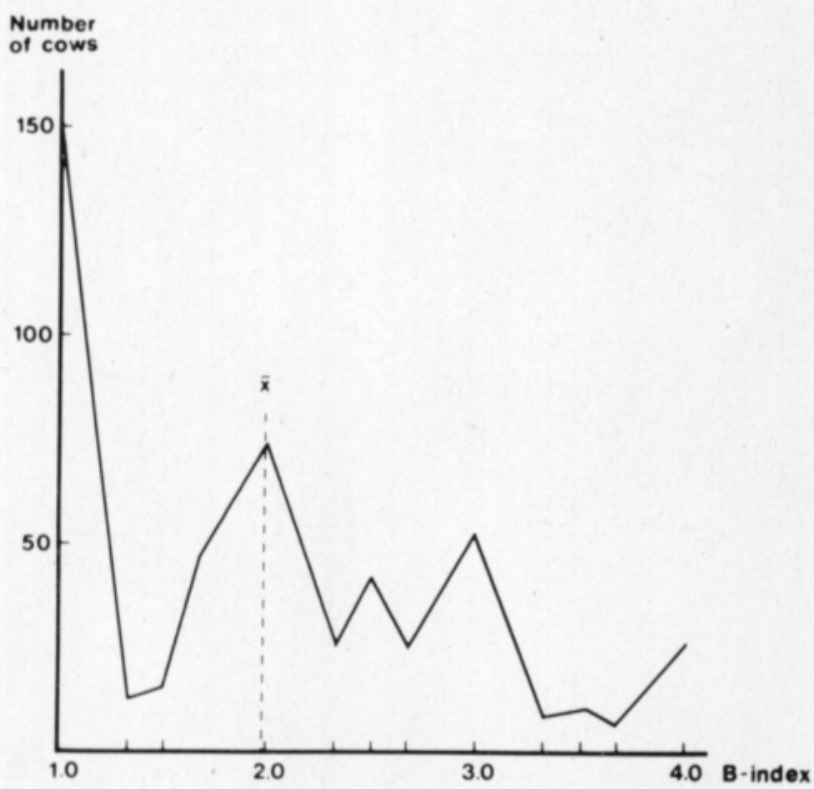

In the cases where the udder was found to be healthy on the basis of one of the samplings $(\mathrm{A}$-index $=1)$, the $\mathrm{B}$-index for the cows was on average 1.5. In the same way, the average B-index was 2.2 or 2.4 for the cows whose sample classified them as belonging once to the "bacteria present" group (A-index $=2$ ) or to the "CMT $\geq 3$ " group $(\mathrm{A}$-index $=3$ ), and the $\mathrm{B}$-index was about 3.1 for the cows which were found to have infectious mastitis $(A$-index $=4)$ on one of the samplings (Fig. 3). The differences are small compared with theoretical, random indexes $(2.00,2.33,2.67$ and 3.00$)$. Only healthy cows, apparently, have a chance to keep their index shealthier" than a random index. There was a great variation therefore in the state of udder health at the three different times of sampling (Figs. 4-7). For the cows in which no mastitis was detected at the first sampling, only in $54.6 \%$ of them had the situation remained unchanged at the second sampling, similarly only in $\mathbf{5 8 . 8} \%$ of the cows at the third sampling. Of the healthy cows at the second sampling $\mathbf{7 5 . 3} \%$ were healthy at the first sampling. Only $11.1 \%$ of the cows in the bacteria present group at the second sampling had the same diagnosis at the first 


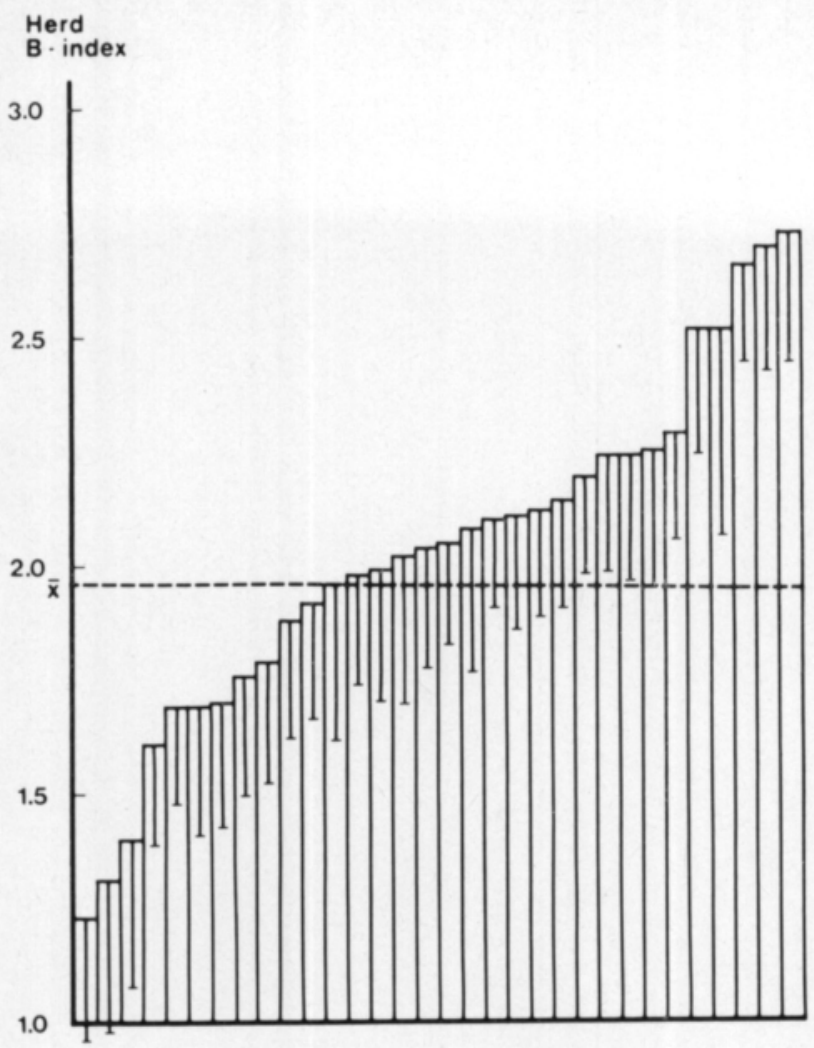

Herds

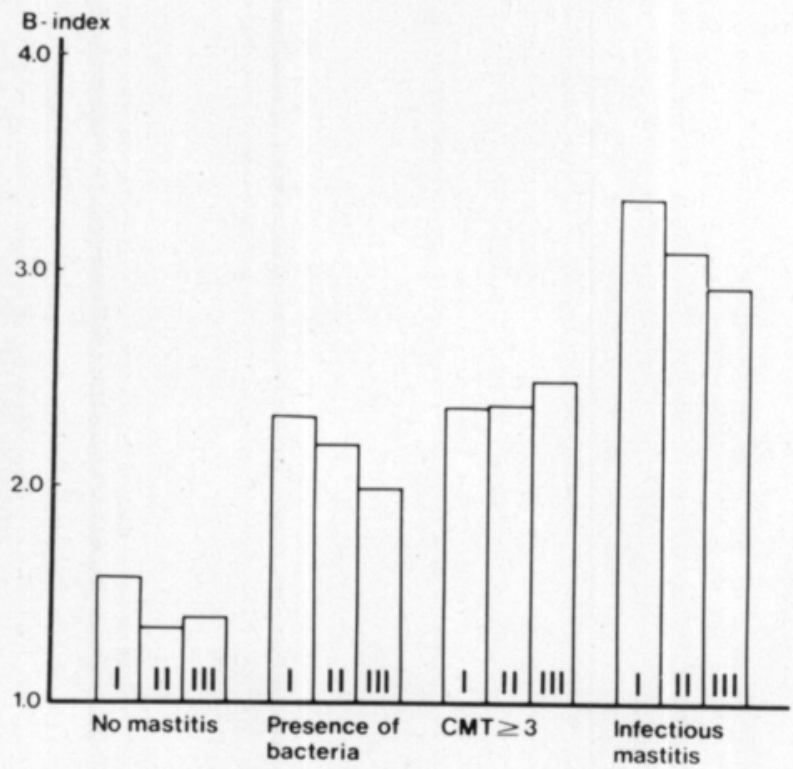

Fig. 2. Distribution of the herd B-indexes. 32 herds, $\bar{x}=1.96$.

Fig. 3. Mean B-indexes of cows grouped according to diagnosis obtained at first, second and third milk sampling. 


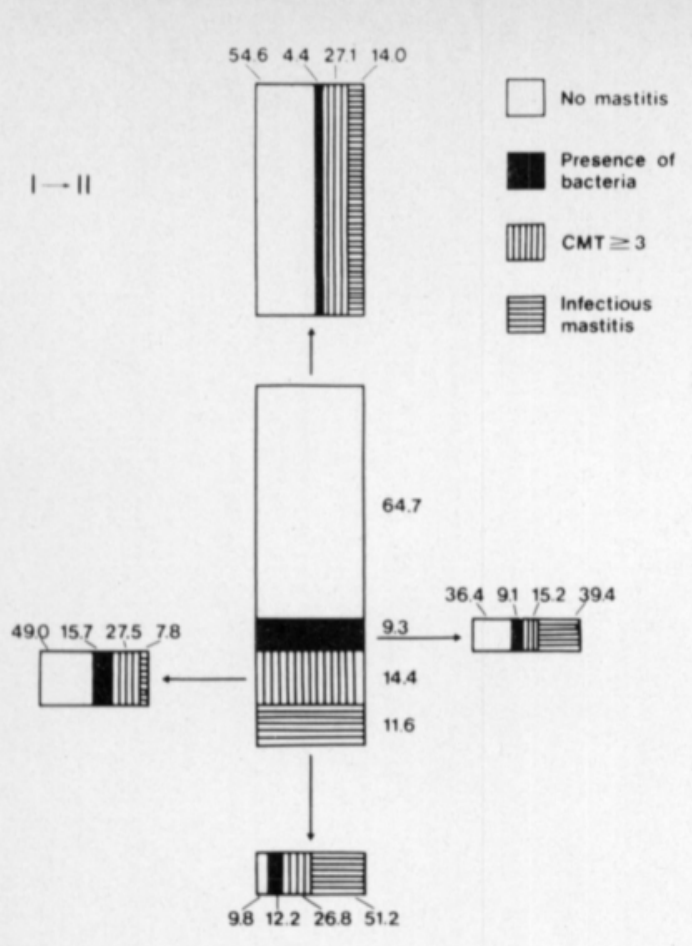

Fig. 4. Changed distribution of primary diagnosis (central figure) at repeated (second) sampling (peripheral figures). Numerical values in figures $4-7$ show percentual proportion of each diagnosis. 354 cows.

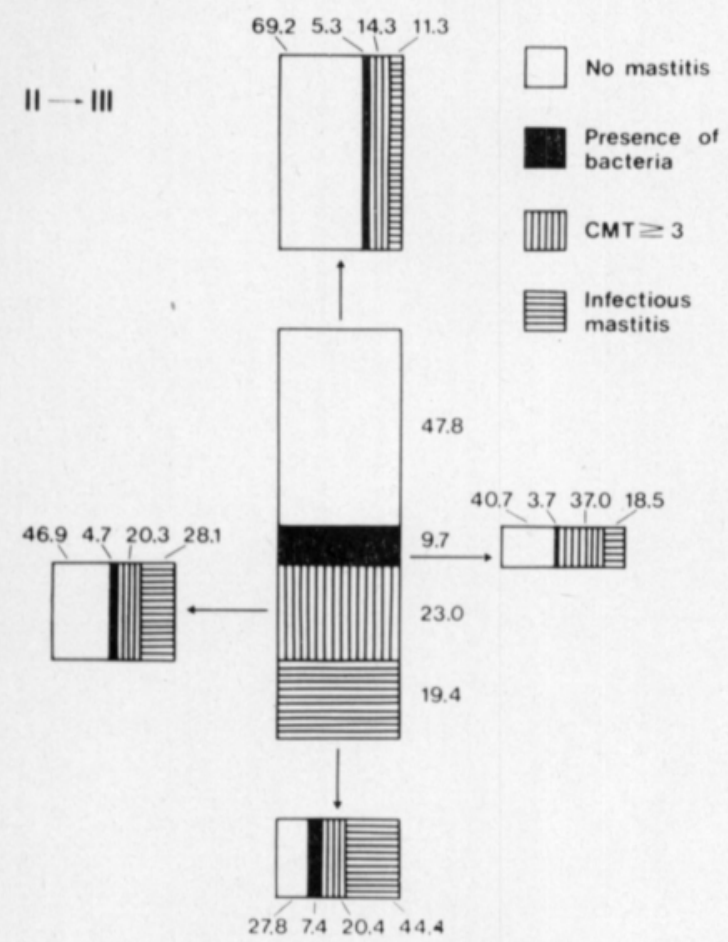

Fig. 6. Changed distribution of second sample diagnosis (central figure) at repeated (third) sampling (peripheral figures). 278 cows.
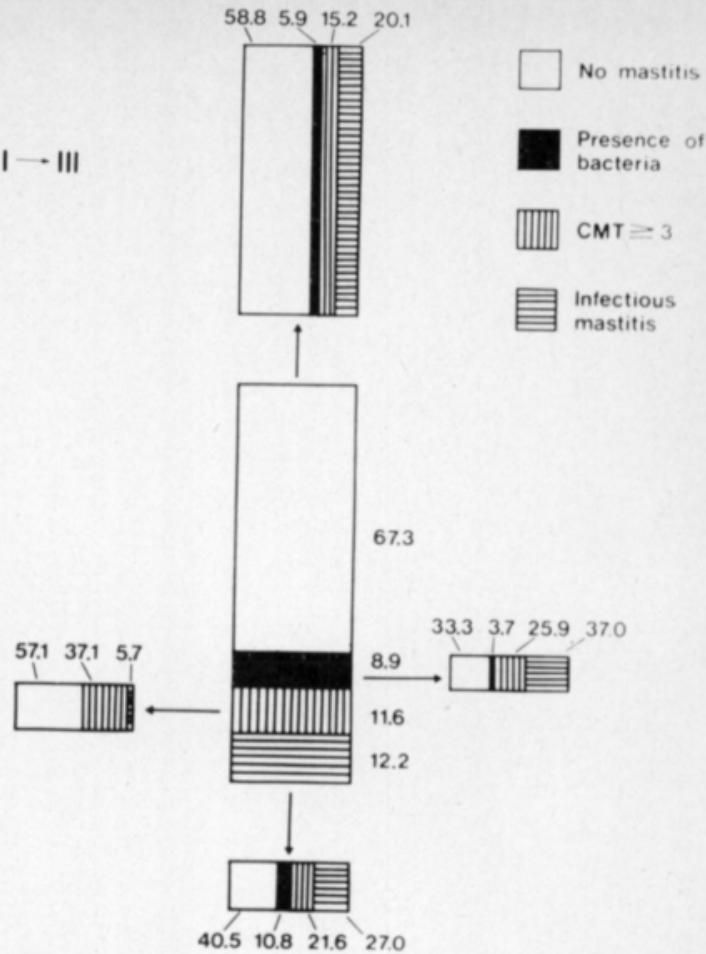

Fig. 5. Changed distribution of primary diagnosis (central figure) at repeated (third) sampling (peripheral figures). 303 cows.

I

II

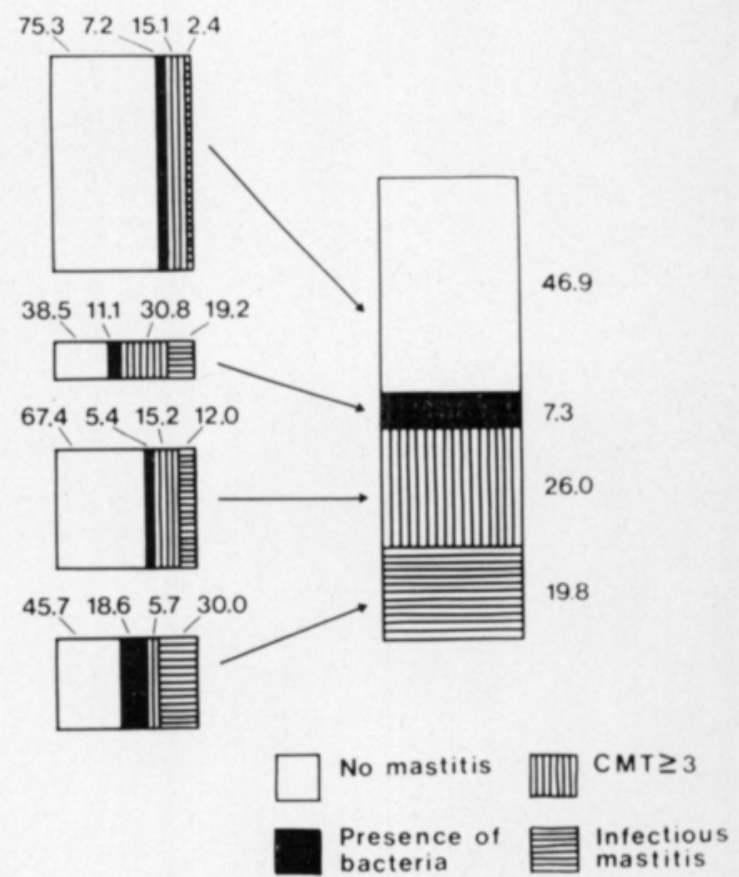

Fig. 7. Milk sample diagnoses on the first sampling (left figures) grouped according to the milk sample diagnoses on the second sampling (right figure). 354 cows. 
sampling. For the cows of CMT $\geq 3$ group the situation was the same in $15.2 \%$ of them at the first sampling, and $30.0 \%$ of the cows of the infectious mastitis group were suffering from mastitis also at the first sampling. The correlation coefficients between the A-indexes for the three sampling times, as shown in Table $\mathbf{8}$, are small, which also denotes a great variation in the state of udder health. The correlation coefficient between the first and third sampling times does not show any statistically significant deviation from zero.

Table 8. The correlation coefficients (r) between the A-indexes for the different sampling times ( $\mathrm{n}=$ number of observations).

\begin{tabular}{lllllll}
\hline & & I & & & II & \\
& & & & & & \\
II & $024^{* * *}$ & 354 & & \\
III & $0.09^{\text {ns }}$ & 303 & $0.34^{* * *}$ & 278 \\
\hline
\end{tabular}

As far as the herds are concerned, the mean values of the A-indexes vary quite much with the three sampling times. Between the first and second sampling there was an increase in the mean value of the A-indexes in 23 herds and a corresponding decrease in 9 herds. Between the second and third sampling the mean value of the A-indexes was increased in 13 herds and decreased in 19 herds.

Table 9. The distribution of bacteriological findings at different sampling times $(n=$ number of samples).

\begin{tabular}{|c|c|c|c|c|c|c|c|c|}
\hline \multirow{3}{*}{$\begin{array}{l}\text { Bacteriological } \\
\text { finding }\end{array}$} & \multicolumn{6}{|c|}{ Sampling time } & & \\
\hline & \multicolumn{2}{|c|}{ I } & \multicolumn{2}{|c|}{ II } & \multicolumn{2}{|c|}{ III } & \multicolumn{2}{|c|}{ Total } \\
\hline & $\mathrm{n}$ & $\%$ & $\mathrm{n}$ & $\%$ & $\mathrm{n}$ & $\%$ & $\mathrm{n}$ & $\%$ \\
\hline Str. agalactiae .......... & 7 & 6.0 & 5 & 3.5 & 1 & 0.9 & 13 & 3.5 \\
\hline Str. dysgalactiae ...... & 9 & 7.7 & 5 & 3.5 & 13 & 11.7 & 27 & 7.3 \\
\hline Str. uberis ................. & 23 & 19.7 & 18 & 12.8 & 14 & 12.6 & 55 & 14.9 \\
\hline Other streptococci & 5 & 4.3 & 13 & 92 & 12 & 10.8 & 30 & 8.1 \\
\hline S. aureus $\ldots \ldots \ldots \ldots \ldots$ & 60 & 51.3 & 71 & 50.4 & 57 & 51.4 & 188 & 51.0 \\
\hline S. epidermidis $\quad . . . . . .$. & 7 & 6.0 & 15 & 10.6 & 4 & 3.6 & 26 & 7.0 \\
\hline Other micrococci $\quad \ldots .$. & 4 & 3.4 & 12 & 8.5 & 2 & 1.8 & 18 & 4.9 \\
\hline Coliforms . ................. & 2 & 1.7 & 2 & 1.4 & 6 & 5.4 & 10 & 2.7 \\
\hline \multirow{2}{*}{$\frac{\text { Pseudomonas sp. ....... }}{\text { Total }}$} & 0 & 0.0 & 0 & 0.0 & 2 & 1.8 & 2 & 0.5 \\
\hline & 117 & 100.0 & 141 & 100.0 & 111 & 100.0 & 369 & 100.0 \\
\hline No growth $\ldots \ldots \ldots \ldots \ldots$ & 421 & 78.3 & 432 & 75.4 & 349 & 75.9 & 1202 & 76.5 \\
\hline Total examined ........ & 538 & & 573 & & 460 & & 1571 & 100.0 \\
\hline
\end{tabular}


The bacteriological results are shown in Table 9. Staphylococcus aureus occurred in about $\mathbf{5 0} \%$ of the bacteriologically positive samples. Of the results $63 \%$ showed staphylococci and micrococci, $34 \%$ streptococci and $3 \%$ Gram-negatives.

\subsection{Incidence of clinical udder diseases}

The incidence of clinical udder diseases in the study herds during the years 1975-77 is shown in Table 10. The average incidence of clinical mastitis during the 3-year-period $1975-77$ was altogether $0.315 \pm 0.217$. The increase of the incidence of clinical mastitis from 1975 to 1977 was statistically significant at the $5 \%$ level $\left(\mathrm{t}=2.23^{*}, 62 \mathrm{df}\right)$. The incidence of all udder diseases also increased almost significantly $\left(\mathrm{t}=2.14^{*}, 62 \mathrm{df}\right)$. When during the 3 -year-period the annual number of clinical mastitis cases treated was 124, 155 and 193, and the annual number of the cows on the farms was 483,490 and 515 , the average incidence of clinical mastitis was $0.257,0.316$ and 0.375 per cow per annum. During the 3-year-period 1975-77 40 cases of thelitis and 5 cases of teat wound were treated, the average incidence of teat diseases being 0.030 cases per cow per annum.

Table 10. The incidence of clinical udder diseases in the herds of this study during the years 1975-77 (means and standard deviations).

\begin{tabular}{|c|c|c|c|c|c|}
\hline & & 1975 & 1976 & 1977 & Mean \\
\hline \multirow[t]{2}{*}{ Mastitis treated by farm visit .................... } & $\overline{\mathbf{x}}$ & 0.097 & 0.093 & 0.135 & 0.109 \\
\hline & S.D. & 0.101 & 0.199 & 0.151 & 0.096 \\
\hline \multirow[t]{2}{*}{ Mastitis treated by phone prescription } & $\overline{\mathbf{x}}$ & 0.150 & 0.212 & 0.257 & 0.206 \\
\hline & S.D. & 0.138 & 0.169 & 0.211 & 0.150 \\
\hline \multirow[t]{2}{*}{ Clinical mastitis, total } & $\overline{\mathbf{x}}$ & 0.247 & 0.305 & 0.392 & 0.315 \\
\hline & S.D. & 0.208 & 0.238 & 0.303 & 0.217 \\
\hline \multirow[t]{2}{*}{ Thelitis and teat wounds ......................... } & $\overline{\mathbf{x}}$ & 0.025 & 0.026 & 0.028 & 0.027 \\
\hline & S.D. & 0.045 & 0.039 & 0.049 & 0.030 \\
\hline \multirow[t]{2}{*}{ Udder diseases, total } & $\overline{\mathbf{x}}$ & 0.272 & 0.331 & 0.421 & 0.341 \\
\hline & S.D. & 0.233 & 0.245 & 0.318 & 0.227 \\
\hline \multicolumn{2}{|l|}{ 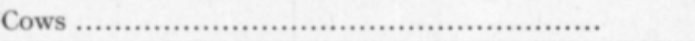 } & 483 & 490 & 515 & 496 \\
\hline
\end{tabular}

During the 10-year-period 1968-1977 the mean values of the incidence of disease treated by farm visits were in the individual herd: mastitis $0.082 \pm$ 0.056 , thelitis $0.025 \pm 0.023$ and teat wounds $0.005 \pm 0.009$. There was a great variation between the different years, but there was a strong increase in the incidence of mastitis cases treated by farm visits during the 10-yearperiod (Fig. 8). During this period cases of mastitis treated by farm visits occurred in each herd, in 7 herds no cases on thelitis occurred and in 20 herds no cases of teat wound.

The incidence of mastitis and the proportion of the prescriptions given by phone vary very much between the different farms (Fig. 9). For one case of mastitis treated by a farm visit, an average of 1.7 cases are treated by phone prescription. For the average number of mastitis cases occurring in individual 


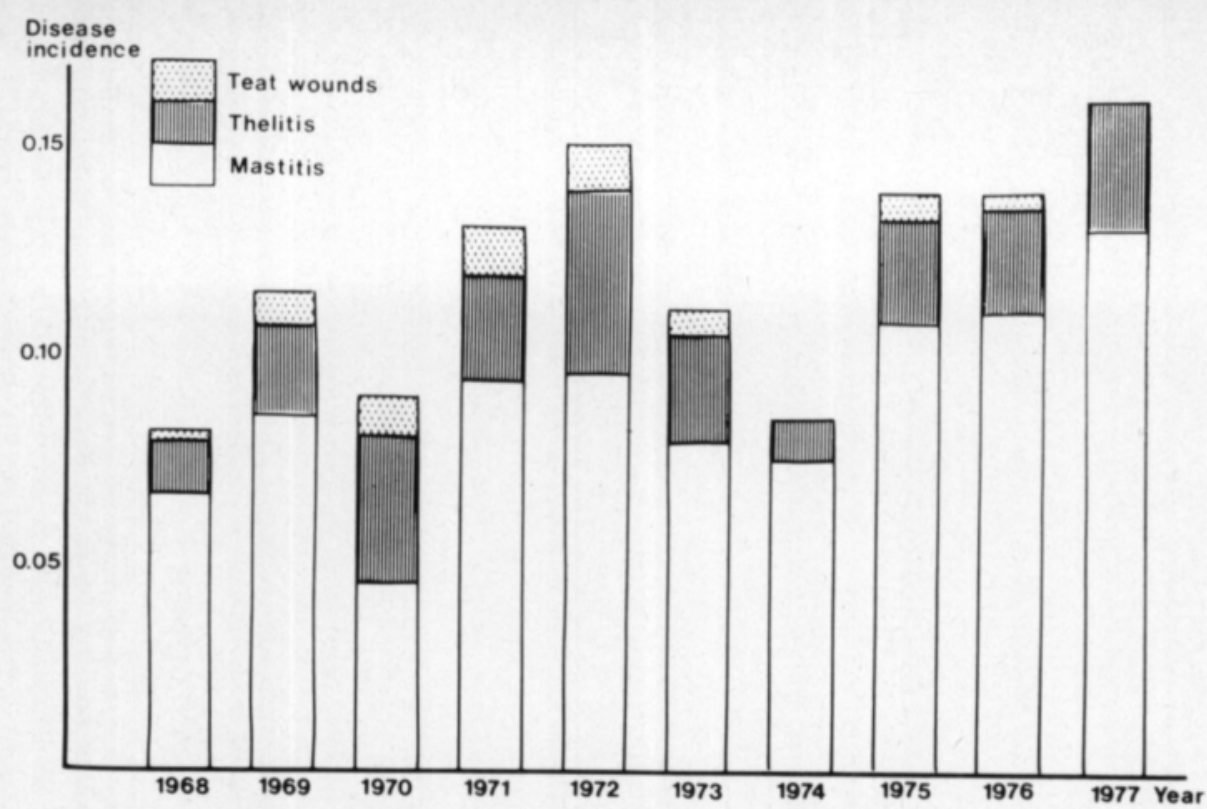

Fig. 8. Incidence of udder diseases treated by veterinarian during farm visits in $1968-77$.

herds during one year a regression equation of the cases treated by phone prescriptions $(y)$ on those treated by farm visits $(x)$ took the form of $y=5.33+$ $0.74 \mathrm{x}, \mathrm{r}=0.60 * * *$.

According to owner information in May 1977, 168 of the 500 cows on the farms or $33.6 \%$ were affacted by mastitis. One case of mastitis was detected in 109 cows, two cases in 39 cows, three cases in 10 cows, $4-7$ cases in the total of 10 cows. When the total number of diseases was divided by the number of production years of the cow, the mean incidence for all the cows was 0.181 $( \pm 0.364)$.

According to owner information different kinds of teat injuries occurred in 43 cows $(8.6 \%)$, the total number of cases being 59 . The average number of teat trampling divided by the number of production years of the cow was $0.036( \pm 0.156)$.

\section{2. 3. External injuries to the udder}

As can be seen from Table 11, very few cases of udder and teat skin injury were detected, no injuries being detected in $96 \%$ of the cows. The mean value of the index describing the total skin injuries was $5.07 \pm 0.39$ in the whole material. No significant differences were found between the udder quarters. The herd skin index was $5.07 \pm 0.10$. No injuries were detected in the cows from 19 herds. The teat end injuries were more common than the skin injuries (Table 12). In $55.8 \%$ of the cows all the teat ends were smooth and healthy. The mean value of the teat end index for the whole cow material was $5.46 \pm 2.21$. There is no significant difference between the mean values of the different udder quarters. The mean of the herd teat end index was $5.26 \pm$ 0.98 (Fig. 10). Table 13 shows the occurrence of warts with different shape. Occasional flat warts, which do not hinder milking, were detected on the udder of every fourth cow. 


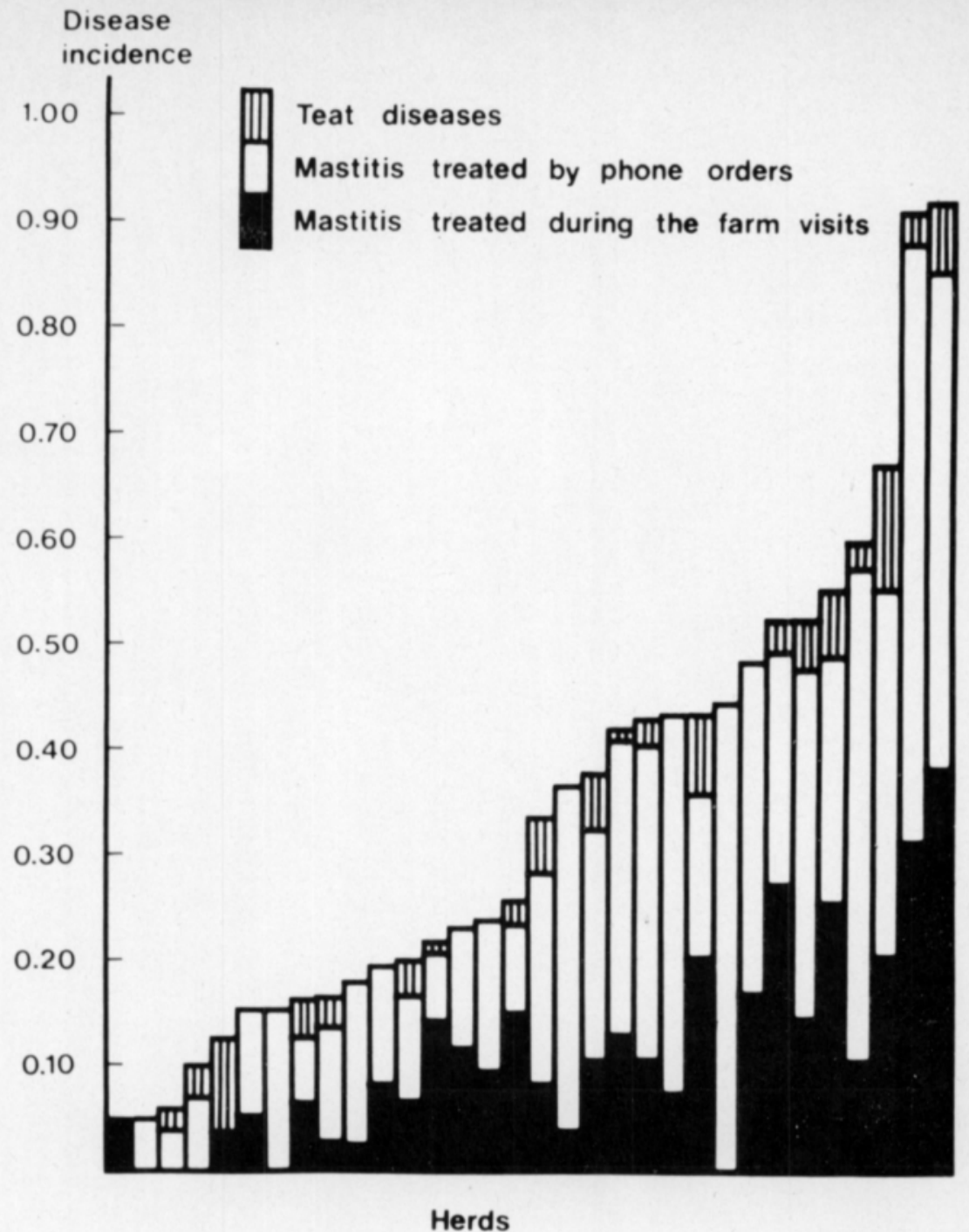

Fig. 9. Incidence of clinical udder diseases in 32 herds in $1975-77$.

Table 11. Injury to the udder and teat skin $(\mathrm{LF}=$ left front, $\mathrm{RF}=$ right front, $\mathrm{LH}=$ left hind, $\mathrm{RH}=$ right hind, $\mathrm{n}=$ number of cows).

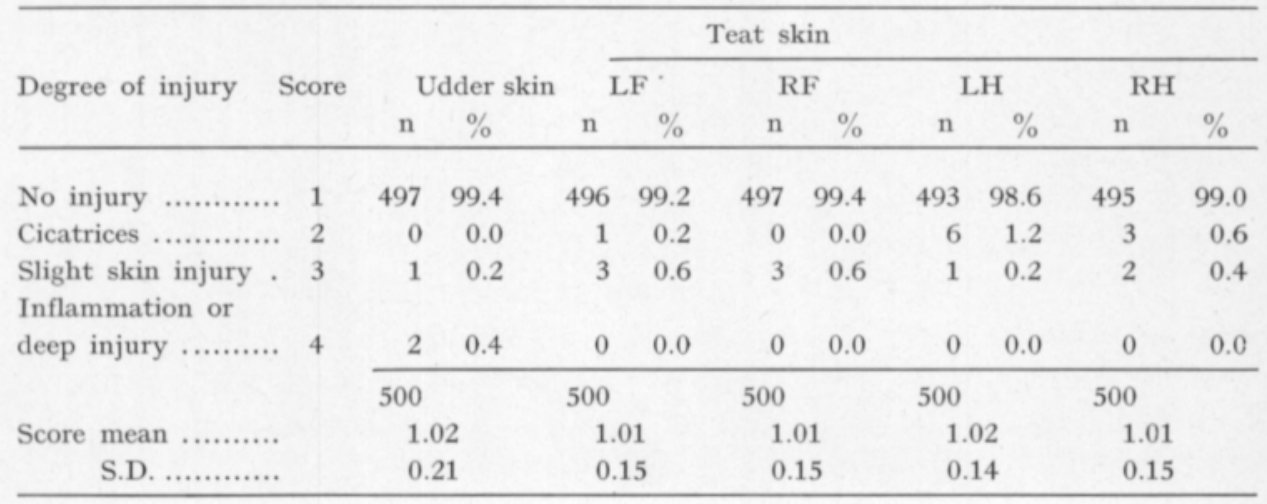


Table 12. The observations made on teat ends ( $\mathrm{n}=$ number of cows).

\begin{tabular}{|c|c|c|c|c|c|c|c|c|c|}
\hline \multirow{2}{*}{ Degree of injury } & \multirow[b]{2}{*}{ Score } & \multicolumn{2}{|r|}{ LF } & \multicolumn{2}{|r|}{ RF } & \multicolumn{2}{|r|}{ LH } & \multicolumn{2}{|c|}{ RH } \\
\hline & & $\mathrm{n}$ & $\%$ & $\mathrm{n}$ & $\%$ & $\mathrm{n}$ & $\%$ & $\mathbf{n}$ & $\%$ \\
\hline Smooth, no injury $\ldots \ldots \ldots \ldots \ldots . . . . .$. & . 1 & 358 & 71.7 & 361 & 72.2 & 370 & 74.0 & 377 & 75.4 \\
\hline Hard, fibrotic $. . . \ldots \ldots \ldots \ldots \ldots \ldots \ldots . . . . . . .$. & - 2 & 89 & 17.7 & 91 & 18.2 & 86 & 17.2 & 86 & 17.2 \\
\hline Eversion of mucous membrane . & 3 & 49 & 9.8 & 46 & 9.2 & 41 & 8.2 & 36 & 7.2 \\
\hline Acute trauma or inflammation & 4 & 4 & 0.8 & 2 & 0.4 & 3 & 0.6 & 1 & 0.2 \\
\hline $\begin{aligned} \text { Score } \operatorname{mean} & \\
& \text { S.D. }\end{aligned}$ & & $\begin{array}{r}500 \\
1 . \\
0 .\end{array}$ & $\begin{array}{l}40 \\
70\end{array}$ & $\begin{array}{r}500 \\
1 . \\
0 .\end{array}$ & $\begin{array}{l}37 \\
67\end{array}$ & $\begin{array}{r}500 \\
1.3 \\
0.6\end{array}$ & & $\begin{array}{r}500 \\
1.32 \\
0.61\end{array}$ & \\
\hline
\end{tabular}

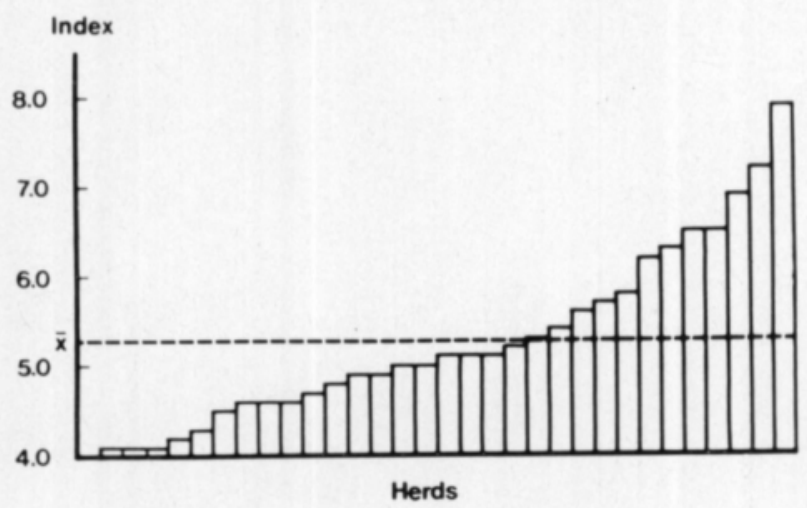

Fig. 10. Distribution of the herd teat end indexes. 32 herds, $\overline{\mathrm{x}}=5.26$.

Table 13. The occurrence of flat warts and nodular warts or papillomas in the udder $(n=$ number of cows).

\begin{tabular}{|c|c|c|c|c|}
\hline \multirow{2}{*}{ Observation } & \multicolumn{2}{|c|}{ Flat warts } & \multicolumn{2}{|c|}{ Nodular warts } \\
\hline & $\mathrm{n}$ & $\%$ & $\mathrm{n}$ & $\%$ \\
\hline None & 373 & 74.6 & 495 & 99.2 \\
\hline On udder skin & 2 & 0.4 & 2 & 0.4 \\
\hline Occasionally on teat skin ............... & 121 & 24.2 & 2 & 0.4 \\
\hline \multirow{2}{*}{ Hindering the milking $\ldots \ldots \ldots \ldots \ldots \ldots$} & 4 & 0.8 & 0 & 0.0 \\
\hline & $\overline{500}$ & & $\overline{500}$ & \\
\hline
\end{tabular}

\section{2. 4. Relations between the measures describing udder health}

In this material the $10 \%$ increase in the percentage of subclinical mastitis (=A-index 3 or 4 ) corresponds to an average increase of 0.25 units in the A-index, and a change of 0.1 units in the A-index corresponds to a change of 4 percent in the percentage of mastitis. If only infectious mastitis is considered, the corresponding coefficients are 0.33 and 3 percent. Should the findings obtained from the milk sample examinations have been spread at random, the coefficient values in each case would be 0.2 and 5 percent. The A-index describes the change in the udder health better than the mastitis percentage. In this material a change of 0.1 units in the B-index corresponds to a change of about 8 percent in the percentage of mastitis obtained from a single milk sample examination. 
Table 14. The B-index for cows grouped according to the number of mastitis cases as reported by the owners.

\begin{tabular}{|c|c|c|c|c|c|c|c|c|}
\hline Cases per cow & 0 & 1 & 2 & 3 & 4 & 5 & 6 & 7 \\
\hline B-index .................. & 1.74 & 2.42 & 2.50 & 2.59 & 3.09 & 2.75 & 4.00 & 3.56 \\
\hline Number of cows ....... & 330 & 107 & 39 & 9 & 4 & 2 & 1 & 3 \\
\hline
\end{tabular}

Table 15. The B-index for cows grouped according to the incidence of mastitis as reported by the owners.

\begin{tabular}{lccccc}
\hline Incidence & 0 & $0.001-0.250$ & $0.251-0.500$ & $0.501-1.000$ & $1.001-$ \\
\hline B-index $\ldots \ldots \ldots \ldots \ldots \ldots \ldots \ldots$. & 1.74 & 2.42 & 2.50 & 2.55 & 2.82 \\
Number of cows $\ldots \ldots \ldots \ldots \ldots$ & 330 & 55 & 62 & 39 & 9 \\
\hline
\end{tabular}

$\mathrm{F}=20.78^{* * *}, 4$ and $489 \mathrm{df}$

The relationship between the B-index of the cow and the number of mastitis as reported by the owners can be seen from Table 14. The numerical value of the correlation coefficient was $r=0.38 * * *$. The value of the regression coefficient was 0.34 , or the B-index was on average 0.34 units greater for a cow who, according to the owner, had been affected by mastitis one more time than another. The incidence of mastitis as reported by the owner and the B-index also correlated highly significantly, $\mathrm{r}=0.27 * * *$. The values of the B-indexes as stated in Table 15 differ in the different categories of incidence, the difference, however, being statistically significant only between the 0 -category and the others. In a least squares analysis where the effects of the age of the cows and the udder shape, as well as the effects of different farms were included in the model, the LS-mean value of the B-index was $1.71 \pm 0.07$ for the cows reported to be healthy by the owners, and $2.36 \pm$ 0.08 for the cows who suffered from mastitis.

As far as an individual herd is concerned, the incidence of mastitis as reported by the owners and the herd B-index did not correlate significantly, $r=0.28^{\mathrm{ns}}$ $(\mathrm{n}=32)$.

A highly significant correlation, $\mathrm{r}=0.56^{* * *}$, was established between the herd B-index (y) and the incidence of clinical mastitis $(\mathrm{x})$ calculated for the years $1975-77$. The regression equation was $\mathrm{y}=1.66+0.95 \mathrm{x}$ (Fig. 11). The correlation between the herd B-index and the incidence of mastitis treated by phone prescription in the years $1975-77$ was found to be nearly as definite, $\mathrm{r}=0.55^{* * *}$. The correlation between the herd B-index and the incidence of mastitis treated by veterinary farm visits during the corresponding period was found to be less definite than the previous ones, $r=$ $0.42^{\mathrm{ns}}$, and the correlation between the herd B-index and the incidence of mastitis treated by farm visits during the years $1968-77$ proved to be even less definite $\left(r=0.28^{n s}\right)$. The regression equation of the herd B-index $(y)$ on the incidence of clinical mastitis in 1977 (x) is much the same compared with the observations from the 3 -year -period, $y=1.69+0.69 x, r=0.57 * * *$. 


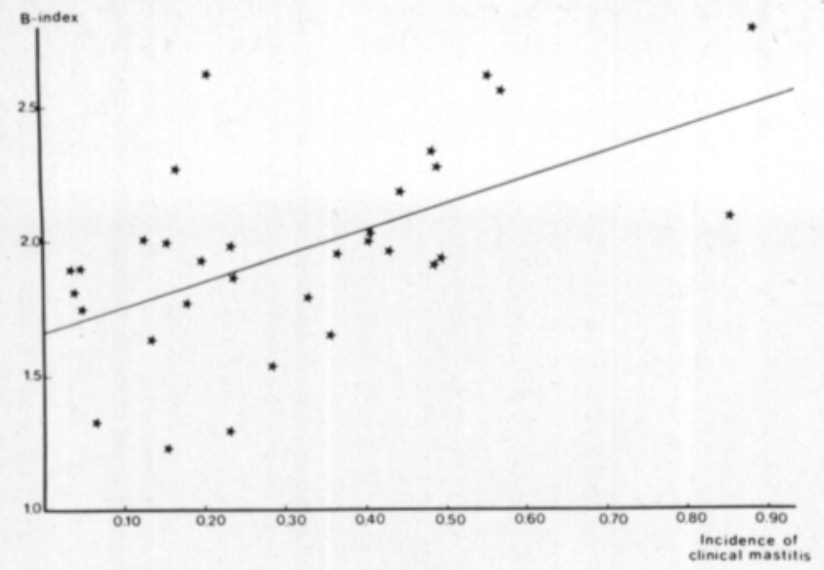

Fig. 11. Relationship between herd B-index and the incidence of clinical mastitis. The regression equation is $\mathrm{y}=1.66+$ $0.95 \mathrm{x}, \mathrm{r}=0.56^{* * *}$.

The incidence of clinical mastitis in the years $1975-77$ (y) was statistically highly significantly related to the incidence of the disease calculated on the basis of the mastitis cases reported by the owners $(\mathrm{x}), \mathrm{y}=0.15+0.89 \mathrm{x}, \mathrm{r}=$ $0.58 * * *$ (Table 16). The regression equation shows, that the incidence reported by owners is much smaller than the actual incidence of clinical mastitis, especially in relatively healthy herds.

The B-index was on average greater (2.34) for those 18 cows who were found to have skin injuries of the udder and teat than for the cows who were healthy in this respect (1.98). The difference between the mean values is not statistically significant. The relation between these observations can also be seen from Table 17.

Table 16. The incidence of clinical mastitis in herds in 1975-77. The herds grouped according to the incidence of the disease as reported by the owners.

\begin{tabular}{llllllll}
\hline $\begin{array}{l}\text { Incidence reported by } \\
\text { owners }\end{array}$ & 0 & $\begin{array}{l}0.001- \\
0.050\end{array}$ & $0.051-$ & $0.101-$ & $0.151-$ & $0.201-$ & $0.301-$ \\
\hline & & & & & & & \\
Incidence of clinical & & & & & & & \\
mastitis & 0.055 & 0.137 & 0.313 & 0.254 & 0.266 & 0.497 & 0.467 \\
Number of herds & 2 & 6 & 5 & 3 & 4 & 5 & 7 \\
\hline
\end{tabular}

Table 17. The relationship between the incidence of injury to the udder and teat skin (skin index) and the B-index.

\begin{tabular}{|c|c|c|c|c|}
\hline & \multicolumn{2}{|c|}{ B-index $=1$} & \multicolumn{2}{|c|}{ B-index $>1$} \\
\hline & $\mathrm{n}$ & $\%$ & $\mathrm{n}$ & $\%$ \\
\hline Skin index $=5$ & 154 & 98.1 & 323 & 95.6 \\
\hline Skin index $>5$ & 3 & 1.9 & 15 & 4.4 \\
\hline Number of cows & $\overline{157}$ & & $\overline{338}$ & \\
\hline
\end{tabular}

$\chi^{2}=1.29,1 \mathrm{df}, 0.3>\mathrm{P}>0.2, \mathrm{n}=495$ 
Table 18. The relationship between the different values for the teat end index and the B-index.

\begin{tabular}{ccc}
\hline Teat end index & Number of cows & B-index \\
\hline 4 & 276 & 1.90 \\
5 & 54 & 1.90 \\
6 & 59 & 2.16 \\
7 & 17 & 2.21 \\
8 & 38 & 2.26 \\
$9-12$ & 51 & 2.12 \\
\hline
\end{tabular}

The B-index for the cows whose teat ends were healthy was 1.90 (Table 18). When there was an increase in the number of injuries to the teat end, there was a slight increase in the B-index, the correlation coefficient remaining however small, $\mathrm{r}=0.11 *$. There is statistically no significant difference between the B-indexes in the different categories shown in Table 18 on the basis of the analysis of variance.

On the basis of a Chi-square test the occurrence of injury to the teat end, however, involves the risk of an increase in the incidence of subclinical mastitis, because $\chi^{2}$ obtained the value of $7.41 * *(1 \mathrm{df})$ in Table 19.

The herd B-index was smallest for the herds with the least cases of teat end injury, Table 20. A statistically not significant correlation $\left(r=0.32^{n s}\right)$ was established between the herd B-index and the incidence of thelitis treated by farm visit during the years 1968-77. The corresponding incidence of teat wounds $\left(\mathrm{r}=0.49^{* *}\right)$ and teat diseases (= cases of thelitis + teat wounds, $\mathrm{r}=0.41^{*}$ ) correlated significantly with the herd B-index. No significant correlation has been established between the B-index and the incidence of teat trampling as reported by the owners, $\mathrm{r}=0.08^{\mathrm{ns}}$.

The B-index for those cows on whose udders and teats flat warts could be found was 2.11, and for the others 1.95. On the basis of a Chi-square test the

Table 19. The relationship between the occurrence of injury to the teat end (teat end index) and the incidence of subclinical mastitis (B-index).

\begin{tabular}{|c|c|c|c|c|}
\hline & \multicolumn{2}{|c|}{ B-index $=1$} & \multicolumn{2}{|c|}{ B-index $>1$} \\
\hline & $\mathrm{n}$ & $\%$ & $\mathrm{n}$ & $\%$ \\
\hline Teat end index $=4 \ldots \ldots \ldots \ldots \ldots$ & 102 & 65.0 & 174 & 51.5 \\
\hline 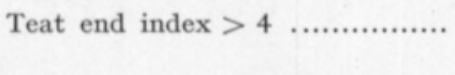 & $\frac{55}{157}$ & 35.0 & $\frac{164}{338}$ & 48.5 \\
\hline
\end{tabular}

$\chi^{2}=7.41^{* *}, 1 \mathrm{df}, \mathrm{n}=495$

Table 20. Herd B-index grouped according to the occurrence of injury to the teat end (herd teat end index).

\begin{tabular}{llcccc}
\hline Herd teat end index & $4.0-4.5$ & $4.6-5.0$ & $5.1-5.5$ & $5.6-$ \\
\hline Herd B-index $\ldots \ldots \ldots \ldots \ldots \ldots \ldots \ldots \ldots \ldots \ldots .$. & 1.69 & 1.85 & 2.35 & 2.02 \\
Number of herds ................................. & 7 & 9 & 6 & 10 \\
\hline
\end{tabular}

$\mathrm{F}=5.53^{* *}, 3$ and $28 \mathrm{df}$ 
occurrence of flat warts seemed to increase the likelihood of the incidence of subclinical mastitis $\left(\chi^{2}=5.11^{*}, 1 \mathrm{df}\right)$.

The incidence of clinical mastitis $(1975-77)$ did not correlate statistically significantly with the herd skin index, or correspondingly with the herd teat end index, although the numerical values of the correlation coefficient were clearly positive $\left(\mathrm{r}=0.22^{\mathrm{ns}}\right.$ and $\left.0.24^{\mathrm{ns}}\right)$.

A regression equation of the incidence of mastitis during the years $1975-77$ (y) on the incidence of teat diseases $(\mathrm{x})$ took the form of $\mathrm{y}=0.26+2.01 \mathrm{x}$, $\mathrm{r}=0.28^{\mathrm{ns}}$. When the incidence of teat diseases is calculated as a mean value for the period of ten years $(1968-77)$, the equation takes the form of $\mathrm{y}=0.20+3.00 \mathrm{x}, \mathrm{r}=0.42^{\mathrm{ns}}$, but the correlation coefficient does not even then deviate significantly from zero. The incidence of mastitis treated by farm visits during the 10-year-period correlates highly significantly with the incidence of teat diseases, $\mathrm{r}=0.62 * * *$.

\section{3. Discussion}

The mean percentage of mastitis $(36.5 \%)$ obtained from the milk sample examinations corresponds quite well to the result published by KoIranen $1976(34.8 \%)$. When $61.2 \%$ of the cows suffered from at least one case of subclinical mastitis during the study year based on the milk sample examinations, the duration of infections can be calculated to be $60 \%$ of the study period or 6-7 months on the basis of the formula presented by KINGwILL et al. 1977 (page 269). The average duration of infection in the material on 721 cows and 14 herds presented by KINGwILL's research group was 9 months, but the infection percentage was also higher, an average of $60 \%$ at each sampling time.

The milk sample diagnosis "presence of bacteria" may be caused by contaminated samples, but in this study it clearly proved an increased risk of mastitis. When the following samples were taken, a greater part of those cows with bacteria present was affected by mastitis than those belonging to the group "CMT $\geq 3$ " (Fig. 4), and when the previous sample had been taken, the share of healthy cows among those with bacteria present was less than among the other groups (Fig. 7). An explanation for this observation can be a great daily fluctuation of the cell content even in an infected udder (NEAvE 1975). Because "mastitis of economic importance is generally of bacterial origin and mainly caused by bacteria that are readily isolated by relative simple methods" (NEAVE 1975), there is every reason to emphasise the significance of the presence of bacteria as proof of the risk of mastitis. This matter has been emphasised in a report previously published and connected with this study (KoIrAnen et al. 1978).

Great changes in udder health were present already during the first $\mathbf{5}-\mathbf{8}$ weeks (Fig. 4), greater than those presented by GriFfin (1975) and also greater than those established in a Danish therapy experiment (JENSEN et al. 1979). There is no way of explaining whether the difference is due to the cow material, a difference in definition by the International Dairy Federation and the Nordic countries, or to other reasons. At any rate the great variation in the diagnoses 
emphasises those marked fluctuations of cell and bacterial content which can be detected in subclinical mastitis (NEAve 1975). A single milk sample examination, although establishing the momentary state of udder health, fails to give more than an approximate picture for the long term period. Examinations of milk samples at regular intervals, however, do give a quite good description.

The bacteriological findings were very similar to those obtained from an examination carried out by KoIRANEN (1976), involving the whole country. Of the 1430 bacteriological findings from this examination $38.0 \%$ were streptococcal, $59.9 \%$ staphylococcal or micrococcal and $2.2 \%$ miscellaneous. As a result of treatment the cases of Streptococcus agalactiae had clearly decreased by the third sampling time. In the operation area of the ambulatory clinic the bacteriological distribution of acute febrile mastitis showed a marked difference from the distribution of subclinical mastitis as stated above, the proportion of coliforms was $29.8 \%$, streptococci $28.1 \%$ and staphylococci $12.3 \%$ (Roine and Munsterhjelm 1974).

The figures denoting the incidence of clinical mastitis on the farms studied were higher than those in the statistics for the whole country, 0.18 in 1975 , 0.26 in 1976 and 0.25 in 1977 . The greater incidence of the disease in the study herds is partly due to the more exact registration of cases and partly due to a greater utilization of the treatment services, the availability of veterinary services being better than the average for the whole country. The number of mastitis cases treated in 1977 was increased to a small extent by the additional number of subclinical cases from the milk sample examinations. The method of preparing statistical information being more exact in the whole country in 1978, the incidence of mastitis in Finland based on the official statistics was as high as 0.32 (AnoN. 1979 a) in that year. The incidence of mastitis in the study herds does not differ essentially from the average incidence of the disease throughout the country.

The better availability of veterinary services for the study herds, compared with the situation for the whole country, is shown by the relationship between the cases of mastitis treated by farm visit and those treated by phone prescription. For each case in the study herds treated by farm visit 1.7 cases were treated by phone prescription, the corresponding figure in the whole country being 2.8 in 1978 (AnoN. 1979 a). Although in the case of individual herds the number of mastitis cases treated by farm visit and by phone prescription correlate statistically highly significantly, $r=0.61^{* * *}$, the correlation is, however, so small that the mastitis situation cannot be followed by filing statistical information on one of these groups only.

Statistical information on the incidence of clinical mastitis prepared on the basis of remembered information from the owner can give some indication of the actual number of mastitis cases contracted by the herd. Compared with the disease incidence based on the number of cases treated, however, the average incidence calculated from owner information proved to be so much less that it may not be possible to use this information, which is dependent on owner memory, for example for the purpose of breeding. If suitable auxiliary means are used when filing information the reliability of owner information 
increases. In Norway it has been possible to file information with an average of $70-95 \%$ of the actual cases by a health card system used on the farms (Solbu 1977).

On the basis of milk sample examinations the occurrence of subclinical mastitis has been found to be common. As already stated, $60 \%$ of the cows suffered from it during the study period. A degree of explanation obtained from a correlation coefficient denoting the connection between the incidence of sublinical mastitis (expressed by B-index for individual herds) and the incidence of clinical mastitis was, however, only $31 \%$ (Fig. 11), for which reason information is needed both on the cases of clinical and subclinical mastitis in order to assess the udder health of herds.

There was a marked annual fluctuation in the incidence of teat diseases treated by veterinarians. It is difficult to explain this observation, but the employment of treatment services probably varies from year to year. A considerable portion of the teat injuries are treated without veterinary assistance, for the incidence of the disease calculated on the basis of owner information was greater than that based on the information of the clinic.

Serious traumatic injuries to the udder and teat skin as well as to the teat ends were few; these were found only in about $2 \%$ of the cows examined, although most of the traumatic injuries demanding treatment generally occur in May, when the inspection of the udders and teats for this study was carried out (SAloniemi and Rorne, to be published). This result is in accord with the incidence of thelitis and teat wounds calculated in Table $10(2.9 \%$ of the cows in 1977), if the seasonal fluctuation is taken into consideration and the formula presented by Kingwill et al. (1977) is used. There is no reason, however, to arrive at any definite conclusions on the basis of one single farm visit as to the general occurrence of teat trampling in herds of under 20 cows, which are typical in Finland, because of the small mean frequency.

Using the same inspection method with cowsheds which had undergone primary renovation, the number of slight cases of trauma detected in such cowsheds in May after the primary renovation has been found to be tenfold the number of injuries detected in this study, the number of serious injuries, however, not being as many (SALONIEMI $1977 \mathrm{c}$ ). Two years after the primary renovation there was a marked decrease in the number of injuries (SALONIEMI $1978 \mathrm{c}$ ).

No significant correlation could be established statistically between skin injuries of the udder and teat and clinical or respectively subclinical mastitis in this material. The significance of skin injury as a medium for the increase of mastitis is generally known (ToLle et al. 1977). The long duration of subclinical mastitis, fluctuation in cell and bacterial content, small number and slightness of skin injuries and only one observation of them having been made, explain the insignificant correlation between these factors in this study.

An injury to the teat end makes it easier for pathogenic bacteria to penetrate into the udder through the teat canal. It is possible that the method used for judging the teat ends in this study does not give the best possible picture numerically of the extent of infection risk, but the risk of infection caused by teat end injury - in comparison with the healthy teat end - is, however, shown. 
A possible explanation for the correlation between the occurrence of flat warts and the B-index is the fact that these both increase with age (see next chapter). Wheather the occurrence of flat warts in itself is a factor which increases cases of infection remains unproved. Very few nodular warts or papillomas occurred in the teats. It is obvious that the occurrence of the papilloma virus (BVP) is less common in Finland than in Great Britain, for instance (MEISCHKE 1979), where $50 \%$ of the material of 328 cows were affected.

\section{Effect of cow's characteristics on udder health}

\section{1. Methods}

The parity of the cow, the time from the calving until the sampling date and the daily yield were noted.

In conjunction with the clinical examination the following information was obtained for each cow: the breed, the age in full years, the length from the angulus cervicalis of the os scapulae to the tuber ischiadicum, the girth length behind the shoulders, the conformation of the udder and teats as classified by the Finnish Society for Animal Breeding (MYLLYL 1977), the distance of the rear teat ends from the floor, the occurrence of supernumerary teats, the condition of the hooves, the health of the hocks, stifles, fore fetlocks and knees, any foot lameness, the position of the fore and hind legs and the cleanness of the animal. The result from each object which was observed was expressed with a code number the point value of which can be seen in the results section. The codes have been selected so that an increase in number implies a corresponding increase in the degree of injury or other similar factor. The codes were used as a mathematical measure to denote the health of the object observed. Mean values were then calculated from these to describe the quality in question in the individual herds.

The average milk flow rate was calculated on the basis of the time needed for the milking operation and was measured at the evening milking. The actual time measured was that from the moment the milk flow started until the moment it stopped, as exactly as is possible with eye observation. The results for the quantity of milk were corrected using the following formula: $\mathrm{y}_{\mathrm{c}}=\mathrm{y}_{\mathrm{o}}-0.134\left(\mathrm{x}_{\mathrm{o}}-7.42\right)$, where $\mathrm{y}_{\mathrm{c}}=$ corrected mean flow rate, $\mathrm{y}_{\mathrm{o}}=$ observed mean flow rate and $x_{0}=$ measured quantity of milk. The owners were questioned about each cow as to whether she had better, average or worse milkability qualities than the other cows in the herd.

\section{2. Effect of cow's age and parity}

\section{2.1. Results}

The average age of the cows was $5.2 \pm 2.2$ years. The average age of the different herds varied from 4.3 years to 7.1 years $(5.3 \pm 0.7)$. At the first sampling the cows had calved $3.2 \pm 1.9$ times, at the second $3.1 \pm 1.9$ times and the third $3.8 \pm 2.0$. 
Table 21. The A-index and mastitis percentage for cows grouped according to parity. The results from the different sampling times combined. The total of 1165 observations on 495 cows.

\begin{tabular}{|c|c|c|c|c|c|c|c|}
\hline Parity & 1 & 2 & 3 & 4 & 5 & 6 & $7-$ \\
\hline A-index & 1.57 & 1.80 & 2.15 & 2.04 & 2.18 & 2.43 & 2.11 \\
\hline Mastitis percentage ........ & 20.8 & 31.1 & 43.5 & 37.6 & 43.3 & 53.1 & 37.6 \\
\hline 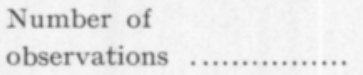 & 192 & 299 & 207 & 149 & 127 & 98 & 93 \\
\hline
\end{tabular}

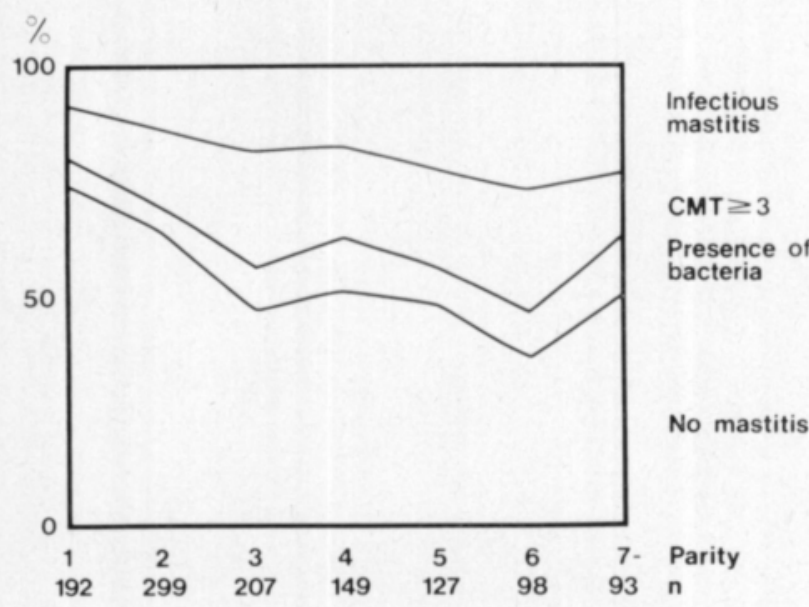

Fig. 12. Percentual proportion of milk sample diagnoses according to parity. 1165 observations.

With the increase in parity, the proportion of those cows suffering from subclinical mastitis increased, as can be seen from Table 21. This increase is due to an increase both in the incidence of a high cell content and in the cases of infectious mastitis. The increase in the proportion of cows with mastitis ends after the third stage of lactation. The proportion with bacteria present also increased with the increase in the number of lactation times up to the fourth time of lactation (Fig. 12). The distribution of observations on udder health differs highly significantly in the case of first calved cows $\left(\chi^{2}=24.3^{* * *}\right.$, $2 \mathrm{df})$ and significantly in the cows calved twice $\left(\chi^{2}=11.46^{* *}, 2 \mathrm{df}\right)$ from the average distribution. Healthy cows have calved on average 3.0 times, cows with bacteria present 3.9 times, "CMT $\geq 3$ " cows 3.5 times and cows with infectious mastitis 4.0 times.

The correlation coefficient between the age of the cow and the B -index is $0.23^{* * *}$. The B-index for the first calved cows was 1.56 , for the cows calved twice 1.81 and for the cows calved more than twice 2.17.

No correlation was established between the occurrence of udder and teat skin injury and age in this material. As far as teat end injury is concerned, cows of $2-3$ years of age (119 cows) differ from the others (381 cows), in that $35.3 \%$ of them had injuries compared with $46.9 \%\left(\chi^{2}=45.02 *, 1 \mathrm{df}\right)$. There is no further increase in the occurrence of teat end injury nor in the degree of injury with an increase in age. 
There is an increase in the occurrence of flat warts with age. Cows in which no flat warts were detected (373 cows) were on average 4.8 years of age, and cows in which flat warts were detected (127 cows) 6.3 years of age.

There was no statistically significant correlation between the mean age of herds and the herd B-index, $\mathrm{r}=0.22^{\mathrm{ns}}$, neither was there a significant correlation between the mean age of herds and the incidence of udder diseases in 1977, $\mathrm{r}=0.30^{\mathrm{ns}}$.

According to the owner information, the proportion of cows which had contracted mastitis was $17.6 \%$ in the case of two-and-three-year-old cows and $38.6 \%$ in the case of cows over 3 years of age. In the case of young cows the incidence of mastitis as previously defined was also very significantly less $\left(\chi^{2}=17.84^{* * *}, 1 \mathrm{df}\right)$. The cows who had contracted mastitis were on average 6.0 years old and the healthy ones 4.8 years old. The correlation coefficient between the incidence of the disease and age did not deviate statistically significantly from zero $\left(\mathrm{r}=0.07^{\mathrm{ns}}\right)$.

According to owner information the proportion of cows which had suffered teat trampling was $4.2 \%$ in the cows aged two and three years and on average $10.0 \%$ in the older cows. 4-year-old cows are, however, an exception in this group, only in $3.6 \%$ of them had teat trampling been detected. The occurrence of teat trampling is not significantly less in 3-year-old cows, compared with the others, $\chi^{2}=3.56,1 \mathrm{df}, 0.10>\mathrm{P}>0.05$. The average age of cows affected by trampling was 6.5 years and that of the others 5.1 years.

\section{2. 2. Discussion}

The occurrence of subclinical mastitis in older cows is greater than in younger ones. This may almost solely be due to the fact that the likelihood of the onset of infection increases linearly as a function of time. If susceptibility to the onset of a new infection were influenced by age, an increase in the incidence of mastitis would be accelerated as a function of time. No exact observation can be made, however, in field material because of the culling of cows. In this material the increase in the mastitis percentage became slower and stopped after the third lactation. This is probably mainly due to the culling of cows with mastitis. Moreover, since it is known that a cow which had once contracted mastitis succumbs again easily (DoDD et al. 1977), it would seem that a healthy cow - when getting older - does not run any greater risk of contracting mastitis than in the first stages of lactation.

No significant correlation could be established between the incidence of clinical mastitis and age in this study. The need for culling is still more obvious in those cows who have suffered from clinical mastitis than in those who have suffered subclinical mastitis. According to Scandinavian studies the proportion of the cows treated for mastitis has increased with lactation periods. However, the increase percentage clearly decreases with an increase in age (B̈̈cKSTRöm 1975, Solbu 1979). According to some researchers the significance of age in the onset of acute mastitis is actually small (WALSER et al. 1972). A critical study - lasting throughout the life span of a previously healthy cow - noting the incidence of clinical or subclinical mastitis at each stage of lactation would be needed in order to find out the predisposing effect age may exercise. 


\section{3. Effect of breed}

\section{3.1. Results}

Of the cows $431(86.9 \%)$ were of the Finnish Ayrshire, 16 (3.2\%) of the Finncattle and only one cow pure Friesian. The other $52(10.4 \%)$ were crossbreedings. The mean age of the Ayrshire cows was 5.4 years and that of the others 4.8 years. The difference is not significant statistically.

The average B-index for the Ayrshire cows was 1.98 and for the others 2.08. The difference is not significant statistically.

As far as the occurrence of injury to udder and teat skin is concerned, there was no difference between the Ayrshire cows and the others. The occurrence of injury to the teat end was more numerous in Ayrshire cows (index 5.5) than in the others (index 4.9), $\mathrm{F}=4.59 *, 1$ and $498 \mathrm{df}$, a deviation from the other observations. Injury to the teat end was found in $46 \%$ of the Ayrshire cows and in $33 \%$ of the other cows. This finding is strongly influenced by a herd of 15 Finncattle cows with exceptionally healthy teat ends (index 4.1).

According to the owner information, 149 or $35 \%$ of the Ayrshire cows had suffered from mastitis and 19 or $28 \%$ of the other cows. The difference was not significant $\left(\chi^{2}=0.93,1 \mathrm{df}, 0.8>\mathrm{P}>0.7\right)$. The cases of mastitis reported to have occurred in the Ayrshire cows had affected older ones, and the cases per cow were fewer in number, the incidence of the disease calculated from the information being the reverse of the distribution expressed in percentage $(0.176$ cases per production year in the case of Ayrshire cows and 0.215 cases per production year, as far as the cows of other breeds are concerned). This difference is not significant, either. According to the owner information cases of teat trampling had been detected in 32 (7\%) Ayrshire cows and in 11 cows of other breeds $(16 \%)$. Statistically the difference is significant at the $5 \%$ level, $\chi^{2}$ having the value of 5.49*, 1 df. The corresponding incidence calculated per year of production were 0.032 and 0.062 . The difference is not significant statistically.

\section{3. 2. Discussion}

Most of the cows examined were of Ayrshire breed, which is also the case for the whole country. The number of cows of other breeds was so small that the results of this study concern almost only the Ayrshire breed. Differences between the Ayrshire cows and other cows were in most cases not statistically significant, either.

\section{4. Effect of stage of lactation and that of daily yield}

\subsubsection{Results}

The distribution of calving months for the $\mathbf{5 0 0}$ cows examined is shown in Fig. 13. This corresponds fairly well to the distribution of calvings in 1975 in those cows participating in the milk recording system in the same area (the Agricultural Centre of Uusimaa). When the first sample was taken, the average period of time elapsed from calving was $5.4 \pm 3.6$ months, when the 
second sample was taken, $5.0 \pm 3.1$ months, and from the third sampling $6.4 \pm 3.6$ months. The average daily milk yield of the cows at the different sampling occasions were $14.9 \pm 6.4,16.0 \pm 5.8$ and $14.1 \pm 5.9 \mathrm{~kg}$.

The correlation between the incidence of subclinical mastitis and the time elapsed from calving is described in Table 22. When the observations from the different sampling occasions were combined, the A-index and mastitis percentage were decreased up to the fifth month, after which there was an increase during the $6-8$ months.

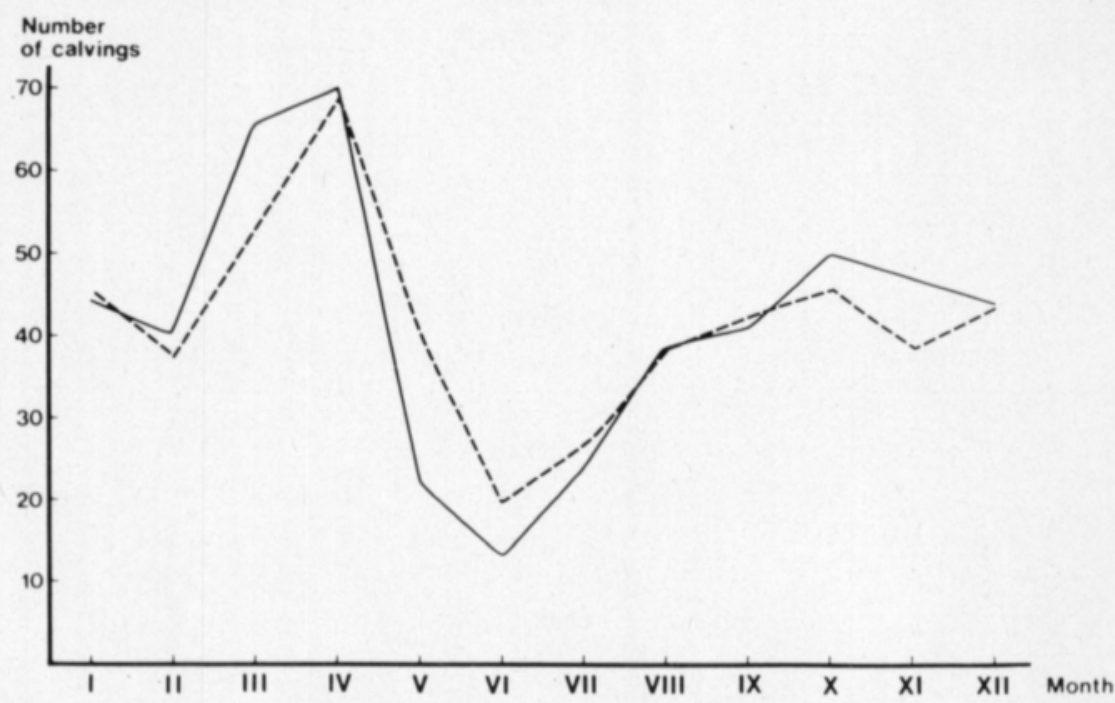

Fig. 13. Monthly distribution of calvings for examined cows (solid line) and the theoretically calculated distribution based on calvings in the area of the Agricultural Centre of Uusimaa in 1975 (dotted line).

Table 22. The A-index and mastitis percentage at different stages of lactation. The results from the different sampling times combined. 1180 observations.

\begin{tabular}{lccccccccc}
\hline Months after calving & 1 & 2 & 3 & 4 & 5 & 6 & 7 & 8 & $9-$ \\
\hline $\begin{array}{l}\text { A-index ...................... } \\
\text { Mastitis percentage .......... }\end{array}$ & 39.8 & 41.4 & 39.5 & 37.1 & 31.4 & 44.6 & 45.9 & 45.7 & 30.1 \\
\hline $\begin{array}{l}\text { Number of } \\
\text { observations .................. }\end{array}$ & 88 & 111 & 119 & 132 & 121 & 101 & 98 & 81 & 329 \\
\hline
\end{tabular}

In samples taken at the end of the milking period and during the dry period (58 observations) the proportion of subclinical mastitis cases is again decreased. No linear correlation was established between the A-index and the time elapsed from calving at any sampling occasion. The values of the correlation coefficients were $-0.05^{\mathrm{ns}},-0.02^{\mathrm{ns}}$ and $-0.04^{\mathrm{ns}}$.

The relations between the daily yield and the A-index are shown in Table 23. No linear correlation was established between these, $r=0.05^{\mathrm{ns}}, 0.01^{\mathrm{ns}}$ and $0.03^{\mathrm{ns}}$, and the slight differences between the daily yields in the different classes of the A-index were not significant on the basis of analysis of variance. 
Table 23. The A-index and mastitis percentage for cows grouped according to daily milk yield. The results from different sampling times are combined. 1183 observations.

\begin{tabular}{lccccccc}
\hline Daily yield, kg & 0 & $1-5$ & $6-10$ & $11-15$ & $16-20$ & $21-25$ & $26-$ \\
\hline A-index ...................... & 1.53 & 1.93 & 1.96 & 2.13 & 1.93 & 2.13 & 2.00 \\
Mastitis percentage .......... & 13.8 & 31.5 & 36.8 & 44.7 & 34.0 & 39.9 & 33.3 \\
\hline Number of observations & 58 & 92 & 220 & 264 & 374 & 148 & 27 \\
\hline
\end{tabular}

\section{4. 2. Discussion}

According to an examination carried out in the study area $23 \%$ of the febrile clinical mastitis cases were detected in the week following calving, the total percentage being 43 during the first month (RoIne and Munsterhjelm 1974). The occurrence of subclinical mastitis, however, is divided fairly evenly among the different phases of the milking period according to the findings submitted in this study. The long duration of subclinical mastitis explains this even division. At the end of the milking period and at the beginning of the dry period (most of the samples taken during the dry period were taken at the beginning) the indexes and mastitis percentage are lowest, although according to NIRD's researchers the rate of new infection should be highest (KIngwill et al. 1977, Thомas et al. 1972). Milking is undoubtedly factor in the prevention of mastitis because a great deal of bacteria which have entered the teat are removed at the milking. Dry cow therapy used in many study herds has a preventive effect, too. According to this study the dry period did not seem to have such a dramatic effect on udder health as NIRD's researchers have stated. Findings corresponding to those in this study have also been obtained from certain examinations made by NIRD's study group (OLIVER et al. 1956).

\section{5. Effect of cow's size}

\section{5.1. Results}

The average length of the cows from the angulus cervicalis of the os scapulae to the tuber ischiadicum was $157 \pm 7 \mathrm{~cm}$ ranging from $130 \mathrm{~cm}$ to $175 \mathrm{~cm}$. The mean figure of the chest girth length was $184 \pm 9 \mathrm{~cm}$, range 149 to $212 \mathrm{~cm}$. The regression equation of the body length $(y)$ on the chest girth length $(x)$ took the form of $y=69.7+0.45 x,\left(r=0.56^{* * *}\right)$. Finncattle cows in the material were a little, but not statistically significantly smaller than the others.

As can be seen from Table 24, there was an increase in the length of the cows up to the sixth year of age, the value of the correlation coefficient being $\mathrm{r}=0.32^{* * *}$. A corresponding observation was made for age and chest girth length, $\mathrm{r}=0.26^{* * *}$.

Table 24. The length of cows in different age groups.

\begin{tabular}{lrrrrrr}
\hline Age in years & -3 & 4 & 5 & 6 & $7-9$ & $10-$ \\
\hline Length, cm & 148 & 153 & 154 & 157 & 156 & 154 \\
Cows & 119 & 112 & 82 & 67 & 103 & 17 \\
\hline
\end{tabular}


According to the milk sample examinations the average body length of healthy cows $(\mathrm{n}=157)$ was $151.8 \mathrm{~cm}$ and that of cows suffering from subclinical mastitis $154.0 \mathrm{~cm}(\mathrm{n}=338)$. The correlation coefficient between length and B-index, $\mathrm{r}=0.08$, does not show any statistically significant deviation from zero. The chest girth of healthy cows was $182 \mathrm{~cm}$ and that of the other cows $185.6 \mathrm{~cm}$. The correlation between the B-index and chest girth $\left(\mathrm{r}=0.14^{* *}\right)$ showed a statistically significant deviation from zero, but an increase of one index unit corresponded to an increase of only $1.5 \mathrm{~cm}$ in chest girth.

According to the findings obtained from a milk sample examination which preceded the measuring of the cows, a variation in chest girth length was a statistically significant explanation fo udder health, Table 25.

Table 25. The chest girth length of cows grouped according to the results obtained from the milk sample examination (second sampling).

\begin{tabular}{|c|c|c|c|}
\hline & Diagnosis & $\begin{array}{c}\text { Number of } \\
\text { cows }\end{array}$ & $\begin{array}{l}\text { Chest girth } \\
\text { length, } \mathrm{cm}\end{array}$ \\
\hline \multirow[t]{4}{*}{, } & No mastitis . & 184 & 182.7 \\
\hline & Presence of bacteria ........ & 30 & 185.4 \\
\hline & $\mathrm{CMT} \geq 3 \ldots \ldots \ldots \ldots \ldots \ldots \ldots$ & 99 & 185.4 \\
\hline & Infectious mastitis .......... & 80 & 186.8 \\
\hline
\end{tabular}

$\mathrm{F}=4.60^{* *}, 3$ and $389 \mathrm{df}$

There was a slight increase in the occurrence of udder and teat skin injury with an increase in the length of the cow $\left(1.6 \mathrm{~cm} /\right.$ index class, $\left.\mathrm{r}=0.09^{*}\right)$. Cows in which cases of injury were detected were $156.9 \mathrm{~cm}$ in length (20 cows) and the others $153.1 \mathrm{~cm}$ (480 cows). No significant correlation was established between chest girth and the occurrence of injury $\left(r=0.04^{n s}\right)$.

The occurrence of injury to the teat end was found to be slightly more numerous in long cows $\left(\mathrm{r}=0.13^{* *}\right)$.

The length of cows with injury to the teat end (221 cows) was $154.5 \mathrm{~cm}$ and that of the other cows (279 cows) $152.3 \mathrm{~cm}$. A similar observation was made as to chest girth $\left(\mathrm{r}=0.12^{* *}\right)$, the chest girth of cows with injury to the teat end being $186.2 \mathrm{~cm}$ and that of the others $183 \mathrm{~cm}$.

Since there was an increase in body length and chest girth length with the age of the cow, it follows that the cows with mastitis according to owner information were longer $(154.5 \mathrm{~cm} / 152.6 \mathrm{~cm})$ with a larger chest girth $(187.1 \mathrm{~cm} / 183.1 \mathrm{~cm})$ than the other cows. The incidence of mastitis calculated per year of production did not, however, correlate significantly with either of these qualities, $\mathrm{r}=0.02^{\mathrm{ns}}$ and $0.06^{\mathrm{ns}}$.

A corresponding observation was made in the cases of teat injury detected by the owner. Cows with teat injury were longer $(156.3 \mathrm{~cm} / 153.0 \mathrm{~cm})$ with a larger chest girth $(187.6 \mathrm{~cm} / \mathbf{1 8 4 . 1} \mathrm{cm})$ than the other cows. The incidence did not correlate significantly with either of the qualities, $r=0.07^{\mathrm{ns}}$ and $0.05^{\mathrm{ns}}$. 


\section{5. 2. Discussion}

The average live weight of the cows was $510-520 \mathrm{~kg}$ calculated from tables by Kenttämies et al. (1974). The size of the cows corresponds well with previous Finnish findings (Kenttämies et al. 1974). When the same method of measuring was employed, NyGAARD (1973) found, in a Norwegian material of about 700 cows, that the regression equation of the body length (y) on the chest girth length $(\mathrm{x})$ was $\mathrm{y}=69+0.47 \mathrm{x}$. The correlation coefficient was almost the same numerically as in this study, $\mathrm{r}=0.61^{* * *}$.

There was no significant correlation statistically between the length of the cows and the occurrence of subclinical mastitis. A slight degree of positive tendency between the body length of the cow and the B-index is caused by an increase in size with age. When, however, the effect of age was eliminated in a least square analysis, this tendency no longer existed, either. The chest girth of the cow, which besides the phase of growth also indicates the degree of obesity, with any possible associated stiffness of movement, had a more definite connection with the incidence of mastitis than the body length.

With regard to mastitis the proportional size of the cow in relation to the stall construction is a more important factor than the absolute size of the cow (SALONIEmi $1977 \mathrm{c}$ ). A stall of a certain length causes damage to a long cow more easily than to a short one. This explains the slightly greater occurrence of udder and teat skin injury in longer cows irrespective of age, detected in this study.

\section{6. Effect of udder shape}

\subsubsection{Results}

The findings from the assessment of udder shape are shown in Table 26. The proportion of cows with dish-shaped and rounded udders was $77 \%$. The average distance from floor to teat ends was $43.9 \pm 6.8 \mathrm{~cm}$, the range being from $16 \mathrm{~cm}$ to $62 \mathrm{~cm}$. The mean of this distance varied from $39.9 \mathrm{~cm}$ to 48.1 $\mathrm{cm}(44.4 \pm 2.4 \mathrm{~cm})$ in different herds. On average, a rounded udder was $4 \mathrm{~cm}$ lower than a dish-shaped udder, and a pendulous one $3 \mathrm{~cm}$ lower than a rounded one. The teat-floor distance varied statistically highly significantly in the different classes of udder shape.

Table 26. The average distance between the rear teat end and floor as well as the average age of cows when grouped according to udder shape.

\begin{tabular}{|c|c|c|c|c|}
\hline Udder shape & $\begin{array}{c}\text { Number of } \\
\text { cows }\end{array}$ & $\%$ & $\begin{array}{c}\text { Teat-floor }{ }^{\mathbf{1}} \text { ) } \\
\text { distance, } \mathrm{cm}\end{array}$ & Age in years $^{2}$ ) \\
\hline Dish-shaped ................... & 181 & 36.2 & 47.1 & 4.2 \\
\hline Rounded ..................... & 203 & 40.6 & 43.2 & 5.3 \\
\hline Pendulous ..................... & 34 & 6.8 & 40.5 & 6.2 \\
\hline Rear-heavy .................... & 59 & 11.8 & 39.5 & 6.4 \\
\hline Divided ....................... & 18 & 3.6 & 42.8 & 7.2 \\
\hline Distended milk cisterns ... & 5 & 1.0 & 36.8 & 8.6 \\
\hline
\end{tabular}

1) $\left.\mathrm{F}=19.52^{* * *},{ }^{2}\right) \mathrm{F}=19.77^{* * *}, 5$ and $494 \mathrm{df}$ 
Table 27. The teat-floor distance of cows when grouped according to age.

\begin{tabular}{rrccc}
\hline $\begin{array}{c}\text { Age in } \\
\text { years }\end{array}$ & $\begin{array}{c}\text { Number of } \\
\text { cows }\end{array}$ & $\begin{array}{c}\text { Teat-floor } \\
\text { distance }\end{array}$ & $\begin{array}{c}\text { Difference between } \\
\text { age groups }\end{array}$ \\
\hline-3 & 119 & 50.2 & - \\
4 & 112 & 45.8 & -4.4 \\
5 & 82 & 43.2 & -2.6 \\
6 & 67 & 40.4 & -2.8 \\
$7-9$ & 103 & 38.9 & -1.5 \\
$10-$ & 17 & 35.4 & -3.5 \\
\hline
\end{tabular}

$\mathrm{F}=72.87^{* * *}, 5$ and $494 \mathrm{df}$

The effect of age on udder shape and above all on the teat-floor distance was strong, as shown in Tables 26 and 27. A regression equation of the teatfloor distance $(\mathrm{y})$ to the age $(\mathrm{x})$ took the form of $\mathrm{y}=53.7-1.87 \mathrm{x}, \mathrm{r}=0.62 * * *$. On the basis of the equation, teat ends are lowered by $1.9 \mathrm{~cm}$ with each additional year.

Of the Ayrshire cows $79 \%$ had a dish-shaped or rounded udder, while the proportion of these shapes was only $61 \%$ in the other cows. The distribution of udder shapes between Ayrshire and the others was highly significantly different $\left(\chi^{2}=20.55^{* * *}, 4 \mathrm{df}\right)$.

The shape of teats was cylindrical in $53.8 \%$ of the cows, conical in $45.6 \%$ and bottle-shaped in $0.6 \%$. As to the position of the teats, $71.3 \%$ of them were vertical, $17.4 \%$ turned inwards and $11.2 \%$ outwards (scattered teats).

Table 28. The occurrence of supernumerary teats in cows grouped according to udder shape.

\begin{tabular}{|c|c|c|c|c|c|c|c|c|c|c|}
\hline \multirow{2}{*}{$\begin{array}{l}\text { Occurrence of } \\
\text { supernumerary } \\
\text { teats }\end{array}$} & \multicolumn{2}{|c|}{ Dish-shaped } & \multicolumn{2}{|c|}{ Rounded } & \multicolumn{2}{|c|}{ Pendulous } & \multicolumn{2}{|c|}{ Rear-heavy } & \multicolumn{2}{|c|}{ Others } \\
\hline & $\mathrm{n}$ & $\%$ & $\mathrm{n}$ & $\%$ & $\mathrm{n}$ & $\%$ & $\mathrm{n}$ & $\%$ & $\mathrm{n}$ & $\%$ \\
\hline Yes ................. & 35 & 19.3 & 44 & 21.7 & 7 & 20.6 & 18 & 30.5 & 7 & 30.4 \\
\hline \multirow[t]{2}{*}{ No } & 146 & 80.7 & $\underline{159}$ & 78.3 & $\underline{27}$ & 79.4 & $\underline{41}$ & 69.5 & $\underline{16}$ & 69.6 \\
\hline & $\overline{181}$ & & $\overline{203}$ & & $\overline{34}$ & & $\overline{59}$ & & $\overline{23}$ & \\
\hline
\end{tabular}

$\chi^{2}=4.20,4 \mathrm{df}, 0.4>\mathrm{P}>0.3, \mathrm{n}=500$

One or more supernumerary teats were detected in 111 cows or $22 \%$ of the material. Relatively, as can be seen from Table 28, the occurrence of supernumerary teats was almost the same irrespective of udder shape. Cows with supernumerary teats were on average as old as the other cows, $5.2 \pm 2.2$ years.

The B-index for cows classified according to udder shape is shown in Table 29. The incidence of subclinical mastitis in cows with dish-shaped udders was less than in the others. Of the cows with healthy udders (B-index $=1$ ) $52 \%$ had dish-shaped udders. The relationship between the B-index and the teat-floor distance is described in Table 30. A regression equation of the B-index (y) on the teat-floor distance $(\mathrm{x})$ took the form of $\mathrm{y}=3.24-0.029 \mathrm{x}, \mathrm{r}=-0.21^{* * *}$. In this material the mastitis percentage in a single milk sample examination decreases about $12 \%$-units when floor-teat distance increases $5 \mathrm{~cm}$. 
Table 29. The B-index for cows grouped according to udder shape.

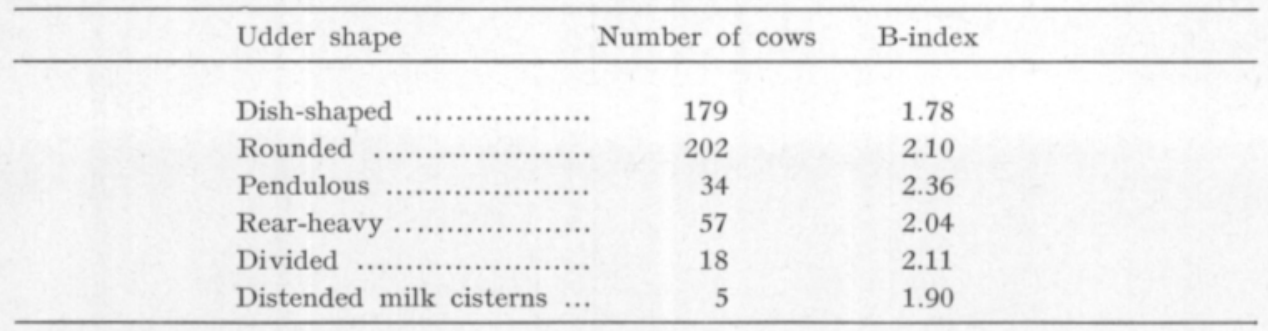

$\mathrm{F}=3.99^{* *}, 5$ and $489 \mathrm{df}$

Table 30. The relation of the teat-floor distance to the B-index.

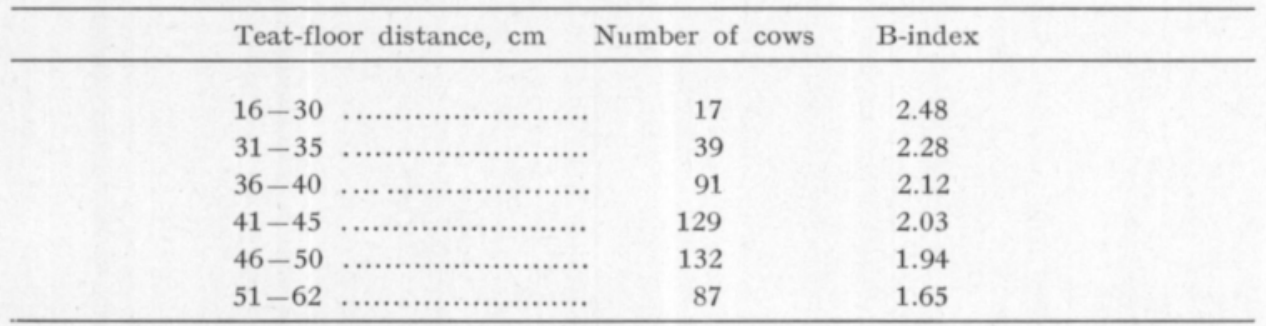

$\mathrm{F}=4.90^{* * *}, 5$ and $489 \mathrm{df}$

According to an analysis of variance $\left(\mathrm{F}=1.10^{\mathrm{ns}}, 2\right.$ and $\left.29 \mathrm{df}\right)$ the variation in teat-floor distance between the different herds did not give any explanation for the occurrence of mastitis in 1977, or that of udder diseases $\left(F=1.04^{\mathrm{ns}}\right)$. The values of the correlation coefficients between the average values of teatfloor distance and the incidence of mastitis and respectively that of the udder diseases were negative, in both cases -0.27 and -0.27 , yet showing no significant deviation from zero.

Although cows with dish-shaped udders seem to have slightly less injury to the udder and teat skin, no statistically significant differences could be found. A significant correlation at the $5 \%$ level can be established between teat-floor distance and the incidence of skin injury $\left(r=-0.09^{*}\right)$. The difference is, however, very small, the teat-floor distance in the case of healthy cows being $44.1 \mathrm{~cm}$ and $43.9 \mathrm{~cm}$ as far as the cows with skin injury are concerned.

Table 31. The occurrence of injury to the teat end in cows grouped according to udder shape.

\begin{tabular}{|c|c|c|c|}
\hline Udder shape & Number of cows & Teat end index & $\begin{array}{l}\text { Cows with injury } \\
\text { in percentage }\end{array}$ \\
\hline 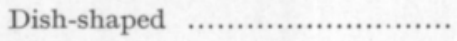 & 181 & 5.1 & 35 \\
\hline 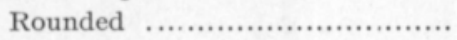 & 203 & 5.8 & 53 \\
\hline 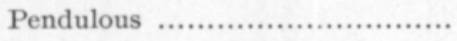 & 34 & 5.3 & 41 \\
\hline Rear-heavy ........................... & 59 & 5.5 & 49 \\
\hline 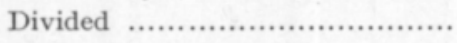 & 18 & 4.8 & 53 \\
\hline Distended milk cisterns ............ & 5 & 4.8 & 20 \\
\hline
\end{tabular}

$\mathrm{F}=2.49^{*}, 5$ and $494 \mathrm{df}$ 
The incidence of injury to teat ends in the different classes of udder shape is shown in Table 31. Most cases on injury, and injury of more serious nature, occurred in cows with rounded udders. There is an increase in the cases of injury to the teat end as soon as the teat-floor distance is decreased, $r=$ $-0.15^{* * *}$, but this increase is numerically small. In the case of cows with healthy teat ends the average teat-floor distance was $45.0 \mathrm{~cm}$ and in the case of cows with injury to the teat end $42.6 \mathrm{~cm}$.

Table 32. The incidence of udder diseases as reported by the owners in cows grouped according to udder shape.

\begin{tabular}{llllll}
\hline Udder shape & Dish-shaped & Rounded & Pendulous & Rear-heavy & Others \\
\hline Mastitis cows, $\% \ldots \ldots \ldots \ldots \ldots \ldots \ldots \ldots \ldots \ldots$ & 20 & 38 & 35 & 53 & 48 \\
Incidence of mastitis $\ldots \ldots \ldots \ldots \ldots \ldots \ldots \ldots$. & 0.137 & 0.182 & 0.231 & 0.307 & 0.131 \\
Cows with teat trampling, $\% \ldots \ldots \ldots \ldots \ldots$ & 5 & 9 & 21 & 8 & 13 \\
Incidence of trampled teats $\ldots \ldots \ldots \ldots \ldots \ldots$ & 0.037 & 0.033 & 0.066 & 0.036 & 0.020 \\
\hline Number of cows $\ldots \ldots \ldots \ldots \ldots \ldots \ldots \ldots \ldots$ & 181 & 203 & 34 & 59 & 23 \\
\hline
\end{tabular}

Table 32 shows the incidence of udder diseases as reported by the owners for the different classes of udder shape. Relatively few cows with dish-shaped udders could be found among the cows which had suffered mastitis The tendency is marked even after age correction, although the differences between the mean values did not quite reach the probability level of $5 \%$ $\left(\mathrm{F}=2.20^{\mathrm{ns}}, 5\right.$ and $\left.494 \mathrm{df}\right)$. The findings in the cases of teat injury reported by the owners are analogous. As soon as there is a decrease in teat-floor distance, there is a correspondingly marked increase in the proportion of cows affected by mastitis, Table 33 . The average teat-floor distance was $45.4 \mathrm{~cm}$ in the case of healthy cows and in those with mastitis $40.9 \mathrm{~cm}$. The proportion of cows with teat injury is doubled as soon as the teat-floor distance goes below $40 \mathrm{~cm}$. For the cows which have avoided teat injury, the teat-floor distance was 44.3 $\mathrm{cm}$ and for the cows with teat trampling $39.7 \mathrm{~cm}$.

The B-index for the cows with cylindrical teats was 1.98 , for the cows with conical teats 2.00 , and for the three cows with bottle -shaped teats on average

Table 33. The percentage of cows affected by mastitis and teat trampling according to owner information, when grouped according to teat-floor distance.

\begin{tabular}{cccc}
\hline $\begin{array}{c}\text { Teat-floor } \\
\text { distance, cm }\end{array}$ & $\begin{array}{c}\text { Number of } \\
\text { cows }\end{array}$ & $\begin{array}{c}\text { Mastitis cows } \\
\%\end{array}$ & $\begin{array}{c}\text { Cows with teat } \\
\text { trampling, \% }\end{array}$ \\
\hline $16-30$ & 18 & 83 & 28 \\
$31-35$ & 40 & 60 & 22 \\
$36-40$ & 92 & 48 & 12 \\
$41-45$ & 129 & 27 & 5 \\
$46-50$ & 132 & 24 & 5 \\
$51-62$ & 89 & 21 & 6 \\
\hline
\end{tabular}


$2.50(\mathrm{~F}<1)$, so teat shape does not have any significant effect on the incidence of subclinical mastitis. There is no significant difference in the B-index for the cows classified according to teat position, either, although the cows with scattered teats have a tendency to contract subclinical mastitis more often. The B-index for the cows with vertical teats $(n=353)$ was 1.97 , for the cows with teats close to each other $(n=87)$ also 1.97 and for the cows with scattered teats $2.16(\mathrm{n}=55)\left(\mathrm{F}=1.04^{\mathrm{ns}}\right)$.

$5 \%$ of the cows with cylindrical teats and $3 \%$ of the cows with conical teats had injury to the teat skin. The difference is not significant.

The teat position has a certain significance, because $13 \%$ of the cows with scattered teats but only $3 \%$ of the other cows had injury. To employ an $\chi^{2-}$ test in order to show the statistical significance of the observation is not reliable because of the small expected values.

Table 34. The effect of teat position on the occurrence of injury to the teat end.

\begin{tabular}{|c|c|c|c|c|c|c|}
\hline \multirow{2}{*}{ Teat position } & \multicolumn{2}{|c|}{ Vertical } & \multicolumn{2}{|c|}{ Inwards } & \multicolumn{2}{|c|}{ Outwards } \\
\hline & $\mathrm{n}$ & $\%$ & $\mathrm{n}$ & $\%$ & $\mathbf{n}$ & $\%$ \\
\hline Teat end index $=4$ & 202 & 56.6 & 50 & 57.5 & 27 & 48.2 \\
\hline Teat end index $>4$ & $\underline{155}$ & 43.4 & $\underline{37}$ & 42.5 & $\underline{29}$ & 51.8 \\
\hline & 357 & & 87 & & 56 & \\
\hline
\end{tabular}

$\chi^{2}=1.47,2 \mathrm{df}, 0.5>\mathrm{P}>0.4, \mathrm{n}=500$

The occurrence of injury to the teat end in cows with cylindrical teats is as common $(44 \%)$ as in cows with conical teats $(43 \%)$. It can be seen from Table 34 that the occurrence of injury to the teat end in cows with scattered teats is greater than in the other cows. Statistically there is, however, no significant difference between frequency distribution.

No connection was established between the teat shape and the incidence of mastitis reported by the owners. $32 \%$ of the cows with cylindrical teats and $35 \%$ of the cows with conical teats had suffered from mastitis. The corressponding figures were for the cows with vertical teats $32 \%$, the cows with teats turned inwards $30 \%$ and the cows with teats turned outwards (scattered teats) $46 \%$. The Chi-square test shows that scattered teats increase the risk of mastitis $\left(\chi^{2}=4.67^{*}, 1 \mathrm{df}\right)$.

According to the owner information $9 \%$ of the cows with cylindrical teats and $8 \%$ of the cows with conical teats had suffered from teat injury. The corresponding figures were for the cows with vertical teats $8 \%$, the cows with teats turned inwards $8 \%$ and the cows with teats turned outwards $13 \%$ as far as teat trampling is concerned.

The mean value of the B-index for the cows with supernumerary teats and the other cows was the same, 1.99. Skin index was $\mathbf{5 . 0 7}$ for both the cows with supernumerary teats and the other cows. The occurrence of injury to the teat end was slightly greater in the cows with supernumerary teats, teat end indexes were 5.64 and 5.40. As regards distribution, the difference, however, was not significant statistically $\left(\chi^{2}=4.46,5 \mathrm{df}, 0.5>\mathrm{P}>0.4\right)$. Ac- 
cording to the owner information $38 \%$ of the cows with supernumerary teats and $32 \%$ of the other cows had contracted mastitis. On the basis of an $\chi^{2}$ -test the presence of a supernumerary teat, however, does not mean any significant increase in the risk of mastitis $\left(\chi^{2}=1.30,1 \mathrm{df}, 0.8>\mathrm{P}>0.7\right)$.

After age correction the mastitis incidence in cows with supernumerary teats was 0.166 and in the others 0.185 . A similar observation could be made for cases of trampling observed by the owner. Cases of trampling were observed in $9.9 \%$ of the cows with supernumerary teats and in $8.2 \%$ of the other cows $\left(\chi^{2}=0.31,1 \mathrm{df}, 0.6>\mathrm{P}>0.5\right)$.

\section{6. 2. Discussion}

The assessment of udder construction has in Finland bcen employed by the Finnish Society for Animal Breeding, but no particular results have been published. These results have been used to some extent in progeny testing of bulls in artificial insemination (MYLLYLÄ 1978). Therefore, it is not possible to make any comparison as to how representative the results from this study are, as regards the whole cow population in Finland.

The correlation established in this study between the age and the teat-floor distance of the udder $(-0.62)$ is greater than that established by BurNSIDE et al. (1963) on the basis of a material of almost the same size, consisting of Holstein-Friesian cows $(-0.44)$, and slightly smaller than that obtained by NygaARD (1973) from cows of the Norwegian Red breed $(r=-0.69)$. A yearly decrease in teat-floor distance corresponds to the observations made by others (Aehnelt et al. 1969, Andreae 1963, Burnside et al. 1963, Johansson 1957, Witt et al. 1967, NygaARd 1973).

The smallest B-index value could be noted in the cows with dish-shaped udders or where the teat-floor distance was high. That a dish-shaped and rounded udder are emptied more completely in the machine milking than other udders (PAIzs 1973) may be a part explanation for the better health of these udder shapes, owing to the fact that residual milk which is left in the udder adds to the incidence of mastitis (Paizs 1973). Proof that the udder shape and the floor-teat distance have a connection with the incidence of subclinical mastitis has also been obtained from another Finnish material (SALONIEMI 1978 b).

There is also an increase in the incidence of clinical mastitis (cases reported by the owners) when udder conformation is poor. Proof for this can be found in other studies as well (Young et al. 1960, Paizs 1973). The combined effect on udder health of age and udder shape is discussed in chapter 5.9.

The observation that cases of teat trampling are increased when the teatfloor distance goes below $40 \mathrm{~cm}$ is in accord with other observations, for example those published by Grommers et al. (1971) and Kubicek and Meinecke (1978). KARLSSON and Gustafsson (1977) have also discovered that the occurrence of trampling is influenced by the floor-teat distance and udder shape. WITT et al. (1967) have set a teat-floor distance of $40 \mathrm{~cm}$ at the third lactation as a criterion for breeding selection. According to this study $24 \%$ of the cows at the third lactation had a teat-floor distance of $\leq 40 \mathrm{~cm}$. 
According to the findings obtained from this study udder health is not influenced by teat shape, which is in agreement with the previous observations published in Finland (Saloniemi $1977 \mathrm{c}$ ). Observations made by Hickman (1964) and RATHore $(1976,1977)$ that cows with cylindrical teats are more susceptible to mastitis are not valid in this material because of breed difference or other reasons.

Scattered teats are exposed to external injury. In the cow with scattered teats, a lot of residual milk is left in the udder in machine milking (PAIzs 1973), which may be contributive to the onset of infection.

According to this study relatively few supernumerary teats can be found in Finnish Ayrshire cows. Since hypermastia is rare, it is understandable that the udder health of cows with supernumerary teats did not differ from that of other cows. According to JoHansson (1957) the heritability of supernumerary teats is rather high, $\mathrm{h}^{2}=0.23$, but the site of the supernumerary teat is not hereditary. There is good reason to decrease by means of breeding the incidence of supernumerary teats so that such supernumerary teats in the immediate vicinity of normal teats which hinder milking as well as hypermastia can be eliminated.

\section{7. Effect of milkability}

\subsubsection{Results}

The milkability was measured in 424 cows, whose mean flow rate of milk was $1.44 \pm 0.59 \mathrm{~kg} / \mathrm{min}$. Milk quantity $(\mathrm{x})$ had a marked influence on the mean flow rate $(y), y=0.45 \pm 0.134 x, r=0.63^{* * *}$. After correction had been made on the basis of the milk quantity, the mean flow rate was $1.44 \pm$ $0.46 \mathrm{~kg} / \mathrm{min}$, the distribution of which can be seen in Fig. 14. The corrected mean flow rate in this material was independent of breed, age, udder shape or teat shape of the cow.

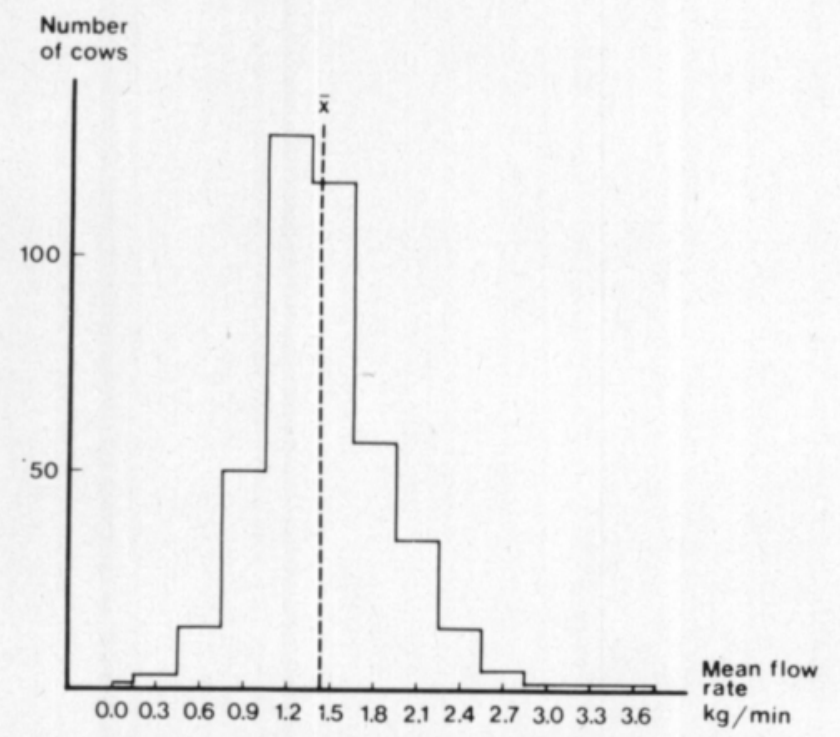

Fig. 14. Milkability of examined cows. Mean flow rate corrected according to milk yield. 424 cows. $\bar{x}=1.44 \mathrm{~kg} / \mathrm{min}$. 
The corrected mean flow rate was $1.50 \mathrm{~kg} / \mathrm{min}$ for cows $(\mathrm{n}=271)$ whose milkability was above average according to owner information. For cows which were estimated to have an average milkability the mean flow rate was $1.41 \mathrm{~kg} / \mathrm{min}$ (104 cows), and for cows whose milkability was below average $1.19 \mathrm{~kg} / \mathrm{min}$ (49 cows). There is a highly significant difference between the milkability of the different groups ( $\mathrm{F}=9.78^{* * *}, 2$ and $\left.421 \mathrm{df}\right)$.

No correlation was established between the uncorrected mean flow rate and the B-index. The incidence of mastitis in cows grouped according to the corrected mean flow rate is shown in Table 35. The B-index or the incidence of mastitis as reported by the owners had no bearing on milkability.

Table 35. The B-index and the incidence of mastitis as reported by the owners for cows grouped according to the mean flow rate of milk. The influence of milk yield on flow rate is eliminated.

\begin{tabular}{|c|c|c|c|c|c|}
\hline Corrected & milk flo & ow rate & Number of cows & B-index & Incidence of mastitis \\
\hline-0.9 & $\mathrm{~kg} / \mathrm{min}$ & n.................. & 44 & 1.83 & 0.145 \\
\hline $1.0-12$ & , & 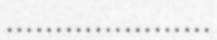 & 105 & 1.98 & 0.184 \\
\hline $1.3-1.5$ & , & n.................... & 127 & 2.03 & 0.207 \\
\hline $1.6-1.8$ & , & 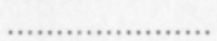 & 73 & 2.19 & 0.206 \\
\hline $1.9-3.6$ & - & …................. & 71 & 1.96 & 0.115 \\
\hline
\end{tabular}

Table 36. The mean flow rate of milk in cows grouped according to the teat end index. The influence of milk yield on flow rate is eliminated.

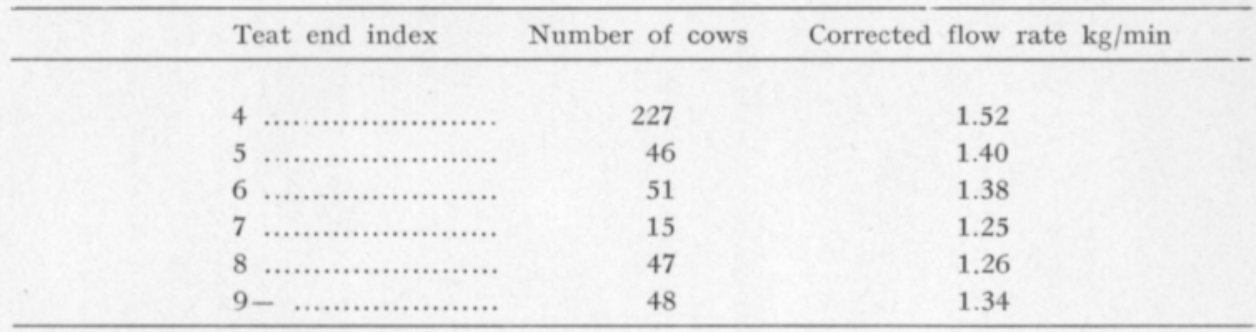

$\mathrm{F}=3.88^{* * *}, 5$ and $418 \mathrm{df}$.

As soon as there was an increase in cases on injury to the teat end, the milkability was decreased, Table 36 . The correlation coefficient between the corrected mean flow rate and the teat end index was $-0.17 * * *$. A corresponding correlation, statistically not significant, however, was found between the corrected mean flow rate of milk and the incidence of trampling cases as reported by the owners, $\mathrm{r}=-0.07^{\mathrm{ns}}$.

\subsubsection{Discussion}

The average of the mean flow rate $(1.44 \mathrm{~kg} / \mathrm{min})$ in this material is smaller than the result of $1.71-1.78 \mathrm{~kg} / \mathrm{min}$ obtained from a progeny testing of bulls for first-calved cows carried out in Finland (Lindholm 1978). The smaller 
quantity of milk produced at the evening milking and the fact that observation is difficult at the end of milk flow as well as the poor condition of the milking machines on the study farms (chapter 6.2) explain the low mean flow rate of milk.

The correlation between the milk quantity and the mean flow rate as established in this study is slightly greater $(0.63)$ than that established in an extensive Danish study (Nielsen 1970, 0.55 for Danish Reds and 0.54 for Danish Black and Whites).

No connection was established between milkability and subclinical or clinical mastitis. This observation is in accord with the results presented in Denmark (Nielsen et al. 1970) and in Finland (Lindholm 1978, Lindström and SYVÄJÄRVI 1978).

This material does not confirm a Danish observation according to which suffering from mastitis leads to worsening in milkability (NIELSEN et al. 1970). That teat injury is a factor which decreases milkability has been established also in another Finnish material (SALONIEMI $1977 \mathrm{c}$ ).

\section{8. Effect of leg condition}

\subsubsection{Results}

Observations on the state of hoof wearing have been specified in Table 37. $44.6 \%$ of the cows were judged to have normal hooves in shape and position.

Observations made on the legs are shown in Table 38. Both hocks were found to be without traumatic injury in $23.6 \%$ of the cows. Cicatrices were common, but the number of acute or more serious injuries of chronic nature was extremely small. No signs of stifle injury were detected in $83.0 \%$ of the cows, and the area of fore fetlocks was free from any visible injury in $93.2 \%$ of the cows. Cicatrices in the skin of a fore knee was the most usual observation, only $19.4 \%$ of the cows were found to have the skin of fore knees unchanged.

Leg soreness was detected in 67 cows or in $13.4 \%$ of the material, Table 39.

If the hooves were not trimmed, there was an increase in lameness. However, the correlation coefficient between the observations was small, $\mathrm{r}=$ $0.10^{*}$. More lameness was observed when the cases on injury to hocks increased $\left(\mathrm{r}=0.13^{* *}\right)$.

Table 37. The condition of hooves, percentage distribution, 500 cows (LF $=$ left front, RF $=$ right front, $\mathrm{LH}=$ left hind, $\mathrm{RH}=$ right hind).

\begin{tabular}{|c|c|c|c|c|c|}
\hline Observation & Score & LF & RF & LH & LH \\
\hline Satisfactory degree of wearing $\ldots \ldots \ldots \ldots \ldots \ldots$ & 1 & 52.2 & 53.6 & 54.2 & 54.6 \\
\hline 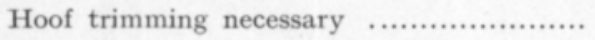 & 2 & 44.4 & 43.0 & 41.6 & 41.0 \\
\hline Digital axis bent ................................... & 3 & 3.2 & 3.2 & 4.0 & 4.0 \\
\hline Excessive wearing of hoof sole $\ldots \ldots \ldots \ldots \ldots$ & 4 & 0.2 & 0.2 & 0.2 & 0.4 \\
\hline \multirow{2}{*}{\multicolumn{2}{|c|}{$\begin{array}{r}\text { Score } \operatorname{mean}(\ldots \ldots \ldots \ldots \\
\text { S.D. }\end{array}$}} & 1.51 & 1.50 & 1.50 & 1.50 \\
\hline & & 0.57 & 0.57 & 0.58 & 0.60 \\
\hline
\end{tabular}


Table 38. The injury to the foot, percentage distribution, 500 cows.

\begin{tabular}{|c|c|c|c|c|c|c|c|c|c|}
\hline \multirow[b]{2}{*}{ Observation } & \multirow[t]{2}{*}{ Score } & \multicolumn{2}{|c|}{ Hock } & \multicolumn{2}{|c|}{ Stifle } & \multirow{2}{*}{$\begin{array}{r}\text { Fore } \\
\text { left }\end{array}$} & \multirow{2}{*}{$\begin{array}{c}\text { fetlocks } \\
\text { right }\end{array}$} & \multirow{2}{*}{$\begin{array}{l}\text { Fore } \\
\text { left }\end{array}$} & \multirow{2}{*}{$\begin{array}{l}\text { knee } \\
\text { right }\end{array}$} \\
\hline & & left & right & left & right & & & & \\
\hline No injury ... & 1 & 36.4 & 36.2 & 86.4 & 90.2 & 93.6 & 94.8 & 24.6 & 26.8 \\
\hline Cicatrices ............................. & 2 & 62.0 & 62.0 & 12.6 & 8.4 & 6.4 & 5.0 & 70.0 & 65.6 \\
\hline Acute skin injury $. . . \ldots \ldots \ldots \ldots . . . . .$. & 3 & 0.4 & 0.6 & 1.0 & 1.4 & - & 0.2 & 0.2 & 0.4 \\
\hline Bursitis without skin injury ... & 4 & 0.2 & - & - & - & - & - & 4.2 & 6.2 \\
\hline Bursitis with skin injury $\ldots . .$. & 5 & 1.0 & 1.0 & - & - & - & - & 1.0 & 1.0 \\
\hline 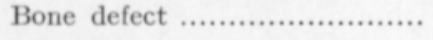 & 6 & - & - & - & - & - & - & - & - \\
\hline Bone defect and other injury & 7 & - & - & - & 一 & - & - & - & - \\
\hline \multirow{2}{*}{ Score } & & 1.67 & 1.67 & 1.15 & 1.11 & 1.06 & 1.06 & 1.87 & 1.89 \\
\hline & & 0.60 & 0.60 & 0.38 & 0.36 & 0.24 & 0.25 & 0.70 & 0.77 \\
\hline
\end{tabular}

Table 39. The observations on foot lameness.

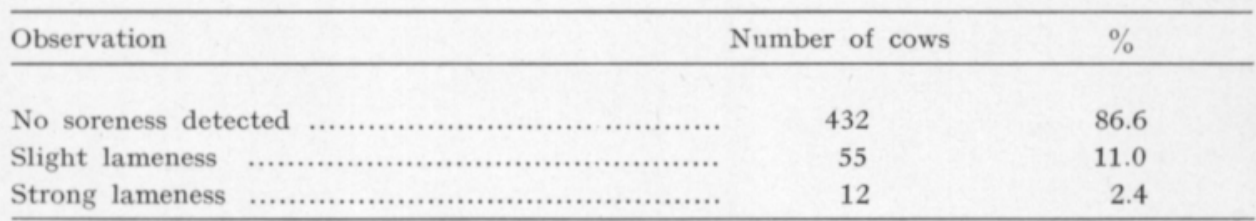

It was discovered that observations on the state of hooves and on cases of leg injury were not significantly dependent on the age of the cows. With the exception of stifle injury, correlation coefficient between the indexes of age and observations were positive, the values being, however, less than 0.1 .

As regards the individual cow, observations made on the condition of the hooves had no connection with the B-index, the correlation coefficient between this and the hoof index being -0.01 . The B-index for cows which were free from injury to hock and stifle was slightly below the average (1.86 and 1.97), whereas the index was slightly above the average $(2.03)$ for cows which were free from injury to the fore knee. The differences were not statistically significant. The effect on the B-index of injury to the fore fetlocks can be seen from Table 40. It is apparent that cases of slight injury to the fore fetlocks have a connection with the incidence of subclinical mastitis, $\mathrm{r}=0.13^{* *}$.

Table 40. The B-index and skin index for cows grouped according to injury to the fore fetlocks.

\begin{tabular}{lcccc}
\hline Degree of injury & Number of cows & B-index $\left.{ }^{1}\right)$ & Number of cows & Skin index $\left.{ }^{2}\right)$ \\
\hline No injury ................... & 462 & 1.96 & 466 & 5.1 \\
Cicatrices in one foot ....... & 10 & 2.37 & 10 & 5.0 \\
Cicatrices in both feet .... & 23 & 2.46 & 23 & 5.3 \\
Acute skin injury ......... & - & & 1 & 7.0 \\
\hline
\end{tabular}

1) $\mathrm{F}=4.07^{*}, 2$ and $\left.492 \mathrm{df}^{2}\right) \mathrm{F}=10.88^{* * *}, 3$ and $496 \mathrm{df}$ 
Observations made on leg soreness had no connection with the B-index. However, it was discovered that the herd B-indexes were greater for herds with more cases of lameness than average. The correlation coefficiant was positive $\left(\mathrm{r}=0.25^{\mathrm{ns}}\right)$, but did not show any statistically significant deviation from zero.

The occurrence of injury to the udder and teat skin had no significant connection with the observations made on the shape and wearing of hooves $\left(\mathrm{r}=-0.07^{\mathrm{ns}}\right)$ nor with the occurrence of injury to the hock $\left(\mathrm{r}=0.06^{\mathrm{ns}}\right)$ and injury to the fore knee $\left(r=0.07^{n s}\right)$. Instead, in this respect injury to the fore fetlocks had a statistically significant correlation $\mathrm{r}=0.17^{* * *}$, Table 40 .

With regard to the position of the fore legs, $71.2 \%$ of the cows were judged to have straight legs and $27.6 \%$ of the cows had out-toed feets.

In the mean cases of the hind legs the corresponding figures were $27.6 \%$ and $70.0 \%$. There was no connection between the position of the fore legs and age, but out-toed feets in hind legs hade a tendency to increase with age. In the case of hind legs, the marked occurrence of out-toed feets and "cow hocks" were more common in cows with long and untrimmed hooves. Only $19 \%$ of the latter had a normal hoof shape, whereas $48 \%$ of the cows with straight legs had a normal hoof shape.

It can be noticed from the material that the B-index has a tendency to increase with the occurrence of out-toed feets in the hind legs and the associated "cow hocks". With regard to the fore legs, no connection was discovered. A corresponding tendency was found to exist in the mean values for individual herds in the case of fore and hind legs, but the incidence of clinical udder diseases (in 1977) had no connection with their position.

\section{8.2. Discussion}

The judgement of the hooves and leg condition must be considered rather subjective. However, as the judgement of all herds was performed by the same person, comparisons can be made in spite of the subjectiveness of the "method of measuring».

The need for hoof trimming was rather great in the herds of this material, but marked changes were fewer than those detected in other Finnish studies (SAloniemi 1979). As is typical for cows in tying stalls, a great deal of skin injury cicatrices, especially to hocks, were detected, but the small number of acute skin injuries showed that the cows had adapted themselves quite well to stall conditions. Observations made on leg lameness (cases of soreness detected in $13.4 \%$ of the cows) are in accord with those observations made on cows after two years' adaptation time in short stalls which had undergone primary renovation (cases of soreness detected in $13 \%$ of the cows, SALONIEMI $1978 \mathrm{c}$ ).

According to this study cases on mild injury to the hoof and leg have no effect on udder health. A minor exception was an injury to the dorsal side of the fetlock joint in the case of fore legs. Whether the injury was caused by one or more environmental factors which cause simultaneous damage to udders or whether the increase in udder injury was caused by a difficulty of movement due to this injury to the leg, could not be ascertained in this study. It may be 
concluded that because of an absence of actual "stall hooves» i.e. hooves of excessive length, and cases of serious injury to legs in this material there is no reason to underestimate the significance of leg health and hoof trimming on udder health.

\section{9. Simultaneous effects on udder health of the characteristics of cow and herd}

\subsubsection{Results}

When the effect on the B-index of age, udder shape, injury to udder skin, injury to teat and fore fetlocks was examined by the least squares analysis, taking into consideration the variation between the different herds, the results as stated in Table 41 were obtained.

It was discovered that the variation in the B-index was explained very significantly by the variation between age groups and herds and almost significantly by udder shape. When the floor-teat distance of the rear teats or the body length of the cows was included, the degree of explanation in the model was not increased. With the exception of the mean values for herds, the least squares means are shown in Table 42. The LS-means for herds varied between 1.23 and 2.72 , the average error varying between 0.19 and 0.45 .

When factors influencing the owner reported number of clinical mastitis cases were analysed by means of the least squares method, it was discovered that the number of clinical mastitis cases reported by the owner was explained significantly by age, almost significantly by udder shape and highly significantly by the B-index (regression) and variation between the different herds, all the factors stated above being included in the same model.

Table 41. Least squares analysis of the effect on the B-index of some somatic factors and of the herds.

\begin{tabular}{|c|c|c|c|c|}
\hline Source of variation & Sum of squares & df & Mean square & F \\
\hline 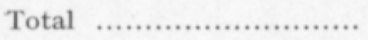 & 2366.34 & 500 & & \\
\hline 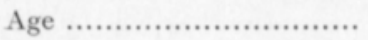 & 23.42 & 5 & 4.683 & $6.59^{* * *}$ \\
\hline Udder shape ................... & 7.85 & 4 & 1.962 & $2.76^{*}$ \\
\hline Skin index $\ldots \ldots \ldots \ldots \ldots \ldots . . . . . .$. & 0.00 & 1 & 0.000 & $0.00^{\mathrm{ns}}$ \\
\hline Teat end index ............. & 1.33 & 2 & 0.664 & $0.93^{\text {ns }}$ \\
\hline Injury of fetlocks .......... & 0.70 & 1 & 0.702 & $0.99^{\text {ns }}$ \\
\hline 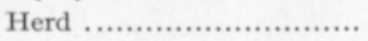 & 52.06 & 31 & 1.679 & $2.36 * * *$ \\
\hline Error ........................... & 5323.52 & 455 & 0.711 & - \\
\hline
\end{tabular}

\section{9. 2. Discussion}

Besides the effect of herds, age remains the most significant of those factors which can explain the incidence of subclinical mastitis.

The effect of udder shape is also an important factor, although it is difficult to find an explanation for the small LS-mean values for a rear-heavy udder 
Table 42. Least squares mean values for the B-index on the basis of the model presented in Table 41 , overall mean $=2.03$, standard error of the mean (S.E.M.) $=013$.

\begin{tabular}{|c|c|c|c|c|c|c|}
\hline 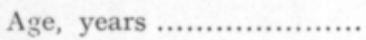 & 2 & 3 & 4 & 5 & 6 & $7-$ \\
\hline 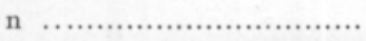 & 29 & 90 & 112 & 82 & 67 & 120 \\
\hline LS-mean ...................... & 1.64 & 1.77 & 1.97 & 2.37 & 2.11 & 2.30 \\
\hline 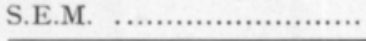 & 0.22 & 0.16 & 0.15 & 0.15 & 0.16 & 0.14 \\
\hline Udder shape & & dish-shaped & rounded & pendulous & rear-heavy & others \\
\hline $\mathrm{n} \quad \ldots \ldots \ldots \ldots \ldots$ & & 181 & 203 & 34 & 59 & 23 \\
\hline LS-mean . .................... & & 1.94 & 2.02 & 2.45 & 1.93 & 1.80 \\
\hline 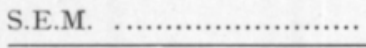 & & 0.14 & 0.13 & 0.19 & 0.17 & 0.24 \\
\hline $\begin{array}{l}\text { Skin index } \\
\mathrm{n} \ldots \ldots \ldots \ldots \ldots . . .\end{array}$ & & . & \multicolumn{2}{|c|}{$\begin{array}{c}\text { skin index }=5 \\
480\end{array}$} & \multicolumn{2}{|c|}{ skin index $>5$} \\
\hline LS-mean ....................... & & & \multicolumn{2}{|c|}{2.03} & \multicolumn{2}{|c|}{2.03} \\
\hline S.E.M. ........................ & & & \multicolumn{2}{|c|}{0.10} & \multicolumn{2}{|c|}{0.21} \\
\hline Teat end index ............... & & index $=4$ & \multirow{2}{*}{\multicolumn{2}{|c|}{$\begin{array}{l}\text { index } \\
\qquad 113\end{array}$}} & \multicolumn{2}{|c|}{ index $=7-12$} \\
\hline 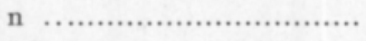 & & 279 & & & 108 & \\
\hline LS-mean ........................ & & 1.96 & \multicolumn{2}{|c|}{2.09} & \multicolumn{2}{|c|}{2.04} \\
\hline 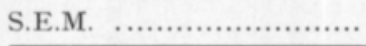 & & 0.14 & \multicolumn{2}{|c|}{0.15} & \multicolumn{2}{|c|}{0.15} \\
\hline Injury of fore fetlocks & & & \multicolumn{2}{|c|}{ no injury } & \multicolumn{2}{|c|}{ injuries observed } \\
\hline 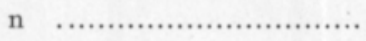 & & & \multicolumn{2}{|c|}{466} & \multicolumn{2}{|l|}{34} \\
\hline LS-mean.$\ldots \ldots \ldots \ldots \ldots \ldots \ldots \ldots$ & & & \multicolumn{2}{|c|}{1.95} & \multicolumn{2}{|c|}{2.11} \\
\hline S.E.M. . .............. & & & \multicolumn{2}{|c|}{0.12} & \multicolumn{2}{|c|}{0.18} \\
\hline
\end{tabular}

shape and for the group mother udder shapes». It has been discovered that cases of mild injury to the udder and teat skin has no effect. It was stated in chapter 4.2.4. that the B-index has a tendency to increase for cows with skin injury. This tendency disappears entirely in this least squares model (mean square $=0$ ). The statistically significant connection of teat end index (chapter 4. 2. 4.) and an injury to the fore fetlocks (chapter 5.8.) with the B-index remains so small in this model that no statistical significance can be obtained.

The owner reported number of clinical mastitis cases is influenced by the same factors as those in the case of the B-index.

\section{Effect of environmental factors on udder health}

\section{1. Methods}

The examination of factors in the production environment was carried out in three phases. Milking machines were tested in January 1977, ventilation was measured in February and March and factors relating to the environment and management of cows were examined in May 1977. 
Table 43. The milking machine index, the objects of testing and the classification of results.

1. Vacuum level with all units in operation.

1. normal $=50.7 \pm 0.7 \mathrm{kPa}$ (or $44 \pm 0.7 \mathrm{kPa}$ )

2. below normal

3. above normal

2. Evacuation time from $33 \mathrm{kPa}$ to normal vacuum level with all units in operation and the vacuum regulator closed.

1. bucket machines below $7 \mathrm{sec}$, pipe line machines below $6 \mathrm{sec}$
2.
$7-8 \mathrm{sec}$
$6-7 \mathrm{sec}$
3.
above $8 \mathrm{sec}$
above $7 \mathrm{sec}$

3. Pump capacity ( $1 / \mathrm{min})$ measured from the pump outlet of the vacuum pipeline.

1 bucket 2 buckets 2 clusters 3 cluster 4 clusters*)

1. above 85 above 150 above 230 above 305 above 400

2. $85-70 \quad 150-125 \quad 230-220 \quad 305-285 \quad 400-370$

3. below 70 below 125 below 220 below 285 below 370

4. Reserve capacity, measured from the connection of the regulator (all units in operation)

1 bucket 2 bucket 2 clusters 3 clusters 4 clusters*)

1. above 55 above 85 above 145 above 180 above 235

2. $55-45 \quad 85-70 \quad 145-135 \quad 180-165 \quad 235-215$

3. below 45 below 70 below 135 below 165 below 215

*) two milkers

5. Air flowrate of vacuum taps. Bucket machines: the vacuum regulator closed (differences below 15 liters between the taps acceptable). Pipe line machines: the vacuum regulator in operation, the vacuum level $50 \mathrm{kPa}$ (differences below $10 \%$ between the taps acceptable).

1. variation between the taps acceptable

2. not more than $25 \%$ of the taps outside acceptable variation

3. over $25 \%$ of the taps outside acceptable variation

6. Performance of vacuum regulator over a range between 10 to $100 \%$ of the pump capacity controlled from the regulator connection.

1. decrease in vacuum level below $2.7 \quad \mathrm{kPa}$

2. decrease in vacuum level between $2.7-5.3 \mathrm{kPa}$

3. decrease in vacuum level over $5.3 \quad \mathrm{kPa}$

7. Pulsation rate, deviation of 3 pulsation cycles per minute is acceptable. Normal rate: diaphragm pulsators $38-44$ cycles per minute, pneumatic pulsators 50 cycles per minute and hydrostatic pulsators 60 cycles per minute.

1. normal

2. below normal

3. above normal

8. Faltering of pulsation expressed in percentage and calculated from the pulsation chamber vacuum record as a difference between the cluster halves.

1. below $4 \%$

2. $4-5 \%$

3. over $5 \%$

9. Suction ratio, in percentage. $5 \%$ deviation from the suction ratio recommended by the manufacturer is acceptable.

1. normal

2. below normal

3. above normal 
The testing of milking machines was carried out and the results judged in accordance with the instructions for testing as fixed by the Finnish Co-operative Dairies' Association "Valio» (Anon. 1975). The regulations for evacuation time, pump capacity and reserve capacity are lower than the Nordic recommendations for milking machines published by the joint committee from the Dairies' Association in the Nordic countries (Anon. 1971). An index was formed to describe the condition of milking machines, incorporating the results from 9 separate objects of testing. The objects of testing included in the index and their three-part classification are shown in Table 43.

The Lambrecht thermohygrograph was used for measuring the ventilation in the cowsheds. It was suspended from the middle of the cowshed ceiling for a total of 2240 hours, an average of 70 hours in each cowshed (48-94 hours). In addition, there were a minimum-maximum thermometer and a separate hair hygrometer in the cowshed. A minimum-maximum thermometer was placed on the outside wall, in the shade. The readings were recorded by a cow tender at 7.00 and $\mathbf{1 8 . 0 0}$ hours. The values of temperature and relative humidity were read from the curve of the thermohygrograph at two hours intervals; mean values and the range of values were calculated. The readings from the thermometer and hygrometer placed in the cowsheds were used to control the operation of the thermohygrograph. There was no need, however, to correct the thermohygrograph readings, because the differences in temperature were below $2^{\circ} \mathrm{C}$ and those of relative humidity below $5 \%$.

The lighting of the areas where milking takes place was measured at the same time as the examination of milkability.

Factors relating to the cowshed construction and cow management were examined on the farm visit made in May 1977. Observations were made on the age and general condition of the cowsheds; on the type, dimensions and condition of the stalls; types on tying, stall partities, the dimensions and condition of the feeding tables, the type and place of the drinking bowls as well a the constructions employed in the removal of manure. The operation of the ventilation system was judged by sensory evaluation. The cattle tender was asked about milking, the hygiene of the udders and the service of milking equipment, which was also subjected to ocular inspection. The type of feeding, the average feeding amounts of hay, silage and concentrates were ascertained by making inquiries - as well as the level of milk yield and the age of the cattle tenders.

\section{2. Condition of milking machines}

\section{2.1. Results}

All the study farms were equipped with a milking machine, 20 farms having a bucket machine and 12 farms a milk pipeline machine. The average age of the machine was $11.5 \pm 7.5$ years, the bucket machines $14.8 \pm 8.2$ years (ranging between $2-26$ years) and the pipeline machines $5.9 \pm 3.7$ years (ranging between $2-13$ years).

The average capacity of the vacuum pumps measured was $115 \pm 70$ litres/ min (range $48-300$ ) in the bucket machine and $420 \pm 115$ litres/min (range 
$300-600)$ in the pipeline machines. There was no measurable reserve capacity in the vacuum equipment of three bucket machines, and only in the case of six bucket machines $(30 \%)$ was the volume of reserve capacity in the vacuum equipment acceptable. Nine of the pipeline machines (75\%) had sufficient reserve capacity. The lack of sufficient reserve capacity was due to the inefficiency of the pumps in 12 bucket machines, and in the case of two bucket machines and three pipeline machines the lack was due to leaks in the vacuum lines and the great consumption of air in the clusters and the pipeline machine releasers. The average loss of capacity taking place in the vacuum line between the vacuum pump and the vacuum regulator connection which indicated the poor condition of the vacuum equipment, amounted to $17 \%$ in the bucket machines and to $15 \%$ in the pipeline machines. It is recommended that the loss should not exceed $5 \%$. Besides air leakage, the small size of the air pipeline also explains its small capacity. The size of the vacuum pipeline was $15 \mathrm{~mm}$ on three farms, $19 \mathrm{~mm}$ on 12 farms and $25 \mathrm{~mm}$ on 17 farms. It is recommended that the minimum size be $25 \mathrm{~mm}$ (Anon. 1971).

The average vacuum level in the machines tested was $49.3 \pm 3.5 \mathrm{kPa}$ (37 $\pm 2.6 \mathrm{cmHg}$, all clusters being in operation). The vacuum level in the bucket machines was $48.2 \pm 4.3 \mathrm{kPa}(36.3 \pm 3.2 \mathrm{cmHg})$. The vacuum level was too high in five machines (above $51.3 \mathrm{kPa}$ ). Twelve machines had a vacuum level of below $50 \mathrm{kPa}$, for four of them a vacuum level of $44 \mathrm{kPa}$ was recommended. The measured vacuum level of the bucket machines varied between $40.7 \mathrm{kPa}(30.5 \mathrm{cmHg})$ to $57.3 \mathrm{kPa}(43.0 \mathrm{cmHg})$. Five of the bucket machines had in addition a spring-controlled vacuum regulator. The vacuum level was too low in two of these machines and too high in the remaining three, the fluctuations of vacuum in all the machines being over $2.7 \mathrm{kPa}(2 \mathrm{cmHg})$ within the operation area of the regulator.

The vacuum level of the pipeline machines, when all units were in operation, was $50.8 \pm 0.8 \mathrm{kPa}(38.1 \pm 0.6 \mathrm{cmHg})$. Only one of the machines had a vacuum level below the recommended level $(49.2 \mathrm{kPa}$ or $36.9 \mathrm{cmHg})$ and two of the machines above, $52.0 \mathrm{kPa}(39.0 \mathrm{cmHg})$ in both of them. All the pipeline machines were equipped with a dead weight controlled vacuum regulator (three machines of 600 litres capacity had in addition a spring regulator), the operation of which met the recommendations with the exception of one machine.

The total number of pulsators on the farms was 63. There were several kinds of pulsators: an old Benco piston-diaphragm pulsator (on 2 farms), a diaphragm pulsator of the Alfa-Laval, Senior or Strangko type (on 11 farms), a Unisoft pneumatic pulsator (on 2 farms) and a liquid pulsator of the Hydropulse or Lactapulse type (on 17 farms). $70 \%$ of the pulsators functioned defectively. The greatest degree of faltering measured in the pulsators was $14.9 \%$. Only 6 farms had pulsators which worked well.

The testing results included in the milking machine index are shown in Table 44. The average machine index for the bucket machines was $1.93 \pm 0.42$ (ranging between 1.22 and 2.67) and for the pipeline machines $1.40 \pm 0.24$ (ranging between 1.00 and 1.78, Fig. 15). The difference between the index means was highly significant, $\mathrm{t}=4.54^{* * *}$, $30 \mathrm{df}$. 
Only one of the machines met the requirements in all nine objects of testing. No testing observation, classified as belonging to the worst group, was made on five of the machines. There was an annual increase of 0.05 units in the machine index, the correlation between age and the machine index being highly significant, $\mathrm{r}=0.77 * * * \quad$ (Fig. 16).

Table 44. The distribution of results obtained from the different testing objects included in the milking machine index.

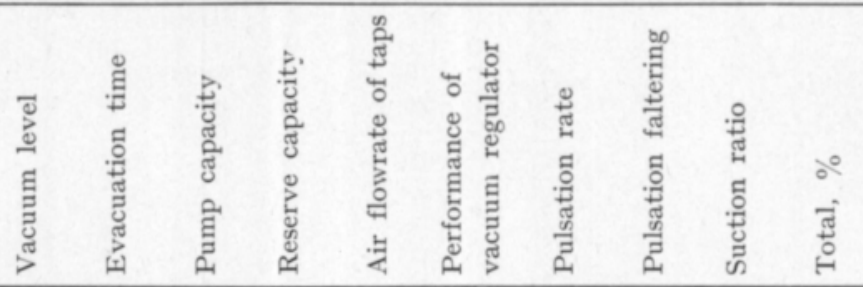

Bucket machines

$\begin{array}{rrrrrrrrrrr}\text { class } 1 . & 5 & 9 & 5 & 6 & 10 & 11 & 9 & 10 & 14 & 44 \\ \text { class } 2 . & 10 & 2 & 5 & - & 7 & 5 & 2 & 2 & 2 & 19 \\ \text { class 3. } & 5 & 9 & 10 & 14 & 3 & 4 & 9 & 8 & 4 & 37\end{array}$

Pipeline machines

\begin{tabular}{rrrrrrrrrrr} 
class 1. & 9 & 8 & 12 & 9 & 10 & 11 & 5 & 7 & 7 & 72 \\
class 2. & 1 & 2 & - & 1 & 1 & 1 & 4 & 5 & 2 & 16 \\
class 3. & 2 & 2 & - & 2 & 1 & - & 3 & - & 3 & 12 \\
\hline
\end{tabular}

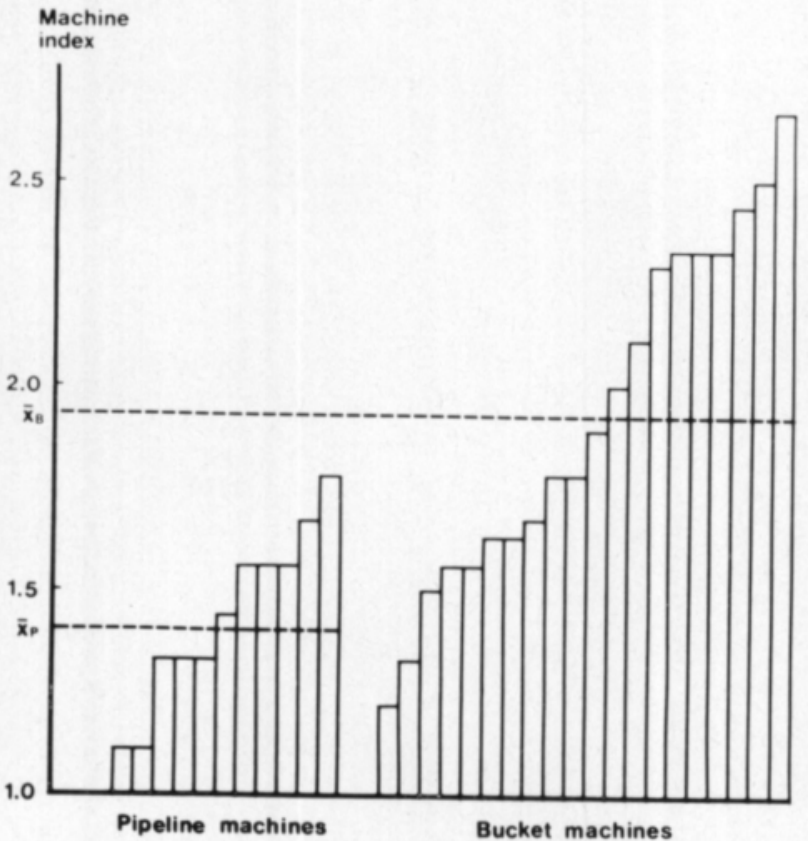

Fig. 15. Distribution of milking machine indexes of the farms equipped with milk pipeline machines (12 farms) and bucket machines (20 farms). $\bar{x}_{\mathrm{p}}=$ 1.40 and $\bar{x}_{\mathrm{B}}=1.93$. 


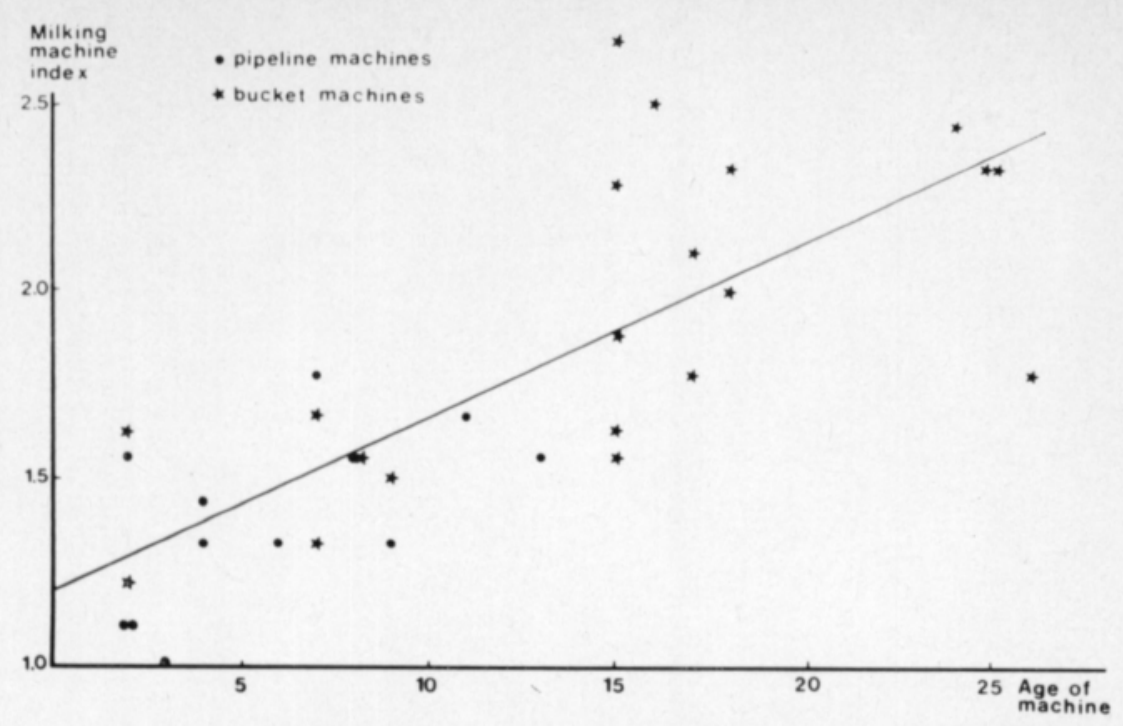

Fig. 16. Relationship between milking machine index and age of machines. The regression equation is $\mathrm{y}=120+0.046 \mathrm{x}, \mathrm{r}=0.77 * * *$.

\section{2. 2. Discussion}

The testing of milking machines has been carried out in Finland since 1967 (PERTtil $\ddot{A}$, to be published), but few results of the testing have been published (SAloniemi 1973, HaAnpä̈ 1978, SaARI 1978). On the basis of this study and other reports the condition of milking machines has been found to be extremely poor in Finland. Cases of serious disturbance have been detected in the function of milking machines which have been in use only for two years, which indicates the careless installation of the machine and that the machine user lacks both the knowledge and the ability to use it. The recurrent and continuous use of a milking machine twice a day naturally leads to the deterioration of its condition, and the machine index was not actually below $\mathbf{1 . 5}$ for any of the machines which were over 10 years old (Fig. 16). The better condition of the pipeline milking machines compared with that of the bucket machines is probably due more to the shorter period of use and not to the better quality of technical equipment.

The results strongly support the proposal made in Finland that new milking machines should be tested before actual use. It is apparent on the basis of the regression line in Fig. 16 that as far as newly installed machines are concerned, defects can be found already in two out of the nine objects of testing.

\section{3. Effect of condition of milking machine}

\section{3. 1. Results}

The average herd B-index for farms with a bucket milking machine was $1.96 \pm 0.43$ and similarly $1.96 \pm 0.27$ for farms with a pipeline milking machine. The correlation coefficient between the herd B-index and the machine index was positive in the whole material, but did not show any statistically sig- 
nificant deviation from zero $\left(\mathrm{r}=0.18^{\mathrm{ns}}\right)$. A more distinct tendency could be noted on farms with bucket machines $\left(r=0.29^{n s}\right)$, again there is no statistical significance. No connection was detected between the age of a milking machine and the herd B-index $\left(\mathrm{r}=0.02^{\mathrm{ns}}\right)$.

On those five farms where the vacuum regulator was controlled by a spring the herd B-index was only 0.2 units greater than that for the group of milking machines whose regulator was controlled by a dead weight system. The difference has no significance. When the machines were divided into three groups according to the size of the vacuum pipelines, a difference between the mean values of the herd B-indexes for the different groups was only 0.15 . The greatest herd B-index value (2.19) could be noted for the group of old piston pulsators and the smallest value for the pulsators of the Unisoft type (1.78). This difference is not significant, either $(\mathrm{t}=3.99,2 \mathrm{df}, 0.10>\mathrm{P}>0.05)$.

The evacuation time, measured pump capacity, reserve capacity, air flowrate of vacuum taps, performance of the vacuum regulator, pulsation rate and average faltering percentage of the pulsator were found to have no connection with the herd B-index. When the vacuum was at the right level, the herd Bindex showed a smaller value (1.89) than in those cases where the level was too low (2.03) or too high (2.00). The differences are not significant $(\mathrm{F}<1)$. On those seven farms where one of the pulsators had too high a suction ratio, the herd B-index was found to be almost significantly greater (2.37) than on those 21 farms where the suction ratio was kept at the level recommended by the manufactures $(1.86, \mathrm{t}=2.37 *, 26 \mathrm{df})$.

The incidence of clinical mastitis in the years $1975-1977$ was $0.369 \pm 0.239$ on the farms which were equipped with bucket milking machines and $0.225 \pm$ 0.141 on the farms equipped with pipeline machines. The difference is statistically significant, $\mathrm{t}=2.41^{*}, 30 \mathrm{df}$. A regression equation of the incidence of clinical mastitis $(y)$ on the machine index $(x)$ is $y=-0.12+0.25 x$, $\mathrm{r}=0.52 * * *$ (Fig. 17). The correlation coefficient between the variable stated did not show any statistically significant deviation from zero on the farms with bucket milking machines $\left(\mathrm{r}=0.38^{\mathrm{ns}}\right)$, but did on those farms with pipeline milking machines $\left(\mathrm{r}=0.66^{* *}, \mathrm{y}=-0.32+0.39 \mathrm{x}\right)$. The correlation coefficient between age of a milking machine and the incidence of clinical mastitis was significant, $\mathrm{r}=0.41^{*}$, but age had a rather small effect. There was an increase of 0.012 cases per cow per annum in the incidence of the disease with

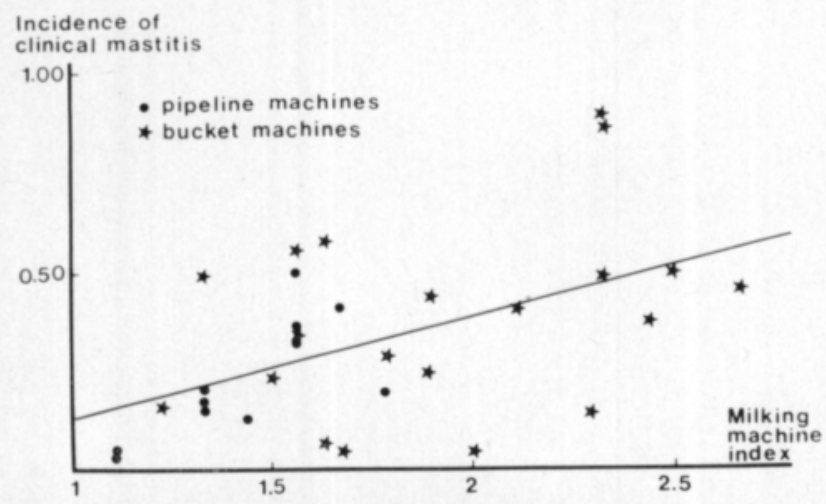

Fig. 17. Relationship between the incidence of clinical mastitis in $1975-77$ and the milking machine index. The regression equation is $\mathrm{y}=-$ $0.12+0.25 \mathrm{x}, \mathrm{r}=0.2 * *$. 
the yearly increase in the age of the machine. The combined effect of the machine age $(x)$ and the machine index $(y)$ on the incidence of clinical mastitis (z) expressed by a multiple regression equation was $\mathrm{z}=-0.18+0.02 \mathrm{x}+$ $0.21 \mathrm{y}, \mathrm{R}=0.78$ in the case of pipeline machines and $\mathrm{z}=-0.07-0.003 \mathrm{x}$ $+0.25 \mathrm{y}, \mathrm{R}=0.38$ in the case of bucket milking machines. A multiple regression equation for the whole material took the form of $\mathrm{z}=-0.11+$ $0.001 \mathrm{x}+0.24 \mathrm{y}, \mathrm{R}=0.52$.

The combined degree of explanation obtained from the age of the machine and the machine index amounts to $61 \%$ in the case of the pipeline milking machines, but as far as the bucket milking machines and the combined material are concerned, the degree of explanation obtained from the machine index is not increased by an age factor.

The incidence of clinical mastitis on the farms which had a spring controlled vacuum regulator was $0.475 \pm 0.230$ and on the other farms $0.285 \pm 0.206$. The difference is not statistically significant $(\mathrm{t}=1.72,30 \mathrm{df}, 0.10>\mathrm{P}>0.05)$. The incidence of the disease was $0.333 \pm 0.239$ on the farms which had a bucket machine equipped with a vacuum regulator controlled by a dead weight system. The average incidence of clinical mastitis was smaller on the farms with a $25 \mathrm{~mm}$ air pipeline $(0.259)$, the mean value for the others being 0.378. When the farms were grouped according to the type of pulsator, the greatest incidence was found to be in the group of piston pulsators $(0.665)$, consisting of two machines of 25 years of age, and the smallest in the group of Unisoft machines (0.044), consisting of two machines of two years of age. Differences between the mean values of incidence occurring in the groups divided according to pulsator type are significant at the $5 \%$ level $\left(\mathrm{F}=3.89^{*}\right.$, 3 and $28 \mathrm{df})$.

A tendency for an increase in the occurrence of clinical mastitis was noticed when there was an increase in vacuum level. On those seven farms where the vacuum was above the normal level, the average incidence was $0.437 \pm 0.227$. On the farms where the vacuum level was normal (14 farms), the incidence was $0.226 \pm 0.150$, and on the farms where the vacuum was below the normal level (11 farms) $0.350 \pm 0.252$. A difference between the mean values for the high vacuum level and the normal vacuum level was significant at the $5 \%$ level ( $\left.\mathrm{t}=2.23^{*}, 19 \mathrm{df}\right)$. The pump capacity, reserve capacity and evacuation time had no connection with the incidence of clinical mastitis. On four farms where the air flow rate of the vacuum taps differed from the normal flow in over $25 \%$ of the taps, the incidence was $0.584 \pm 0.209$, on the farms belonging to the second group ( 8 farms) $0.303 \pm 0.178$ and on the farms where the air flowrate was normal (20 farms) $0.266 \pm 0.202$. The difference between the mean values for the best and worst group is not significant, $t=1.74,22 \mathrm{df}$, $0.10>\mathrm{P}>0.05$. When the machines were grouped according to the performance of the vacuum regulators, the corresponding mean values for the incidence were as follows: $0.544 \pm 0.197$ for the worst group ( 4 farms), $0.415 \pm$ 0.112 for the middle group ( 6 farms) and $0.245 \pm 0.206$ for the group where the performance was normal ( 22 farms). The group with the worst vacuum regulators differs statistically almost significantly from that with the regulators with a normal performance, $\mathrm{t}=2.77 *, 24 \mathrm{df}, \mathrm{P}<0.02$, and similarly 
the middle group from the normal one $\mathrm{t}=2.68^{*}, \mathrm{P}<0.02$. The pulsation rate was found to have no statistically significant effect on the incidence of clinical mastitis in this material. The incidence of the disease was smallest in the group where the pulsation rate was lower than normal. If there was a lot of faltering in the action of the pulsator and the suction ratio was greater than normal, there was an increase in the incidence of clinical mastitis, but the differences have no statistical significance.

The occurrence of injury to the teat end was greater on the farms equipped with pipeline machines (the mean value of the herd teat end index $5.58 \pm 1.15$ ) than on the farms equipped with bucket machines $\left(5.07 \pm 0.84, t=1.34^{\mathrm{ns}}\right.$, $30 \mathrm{df})$. When there was an increase in the machine index, there seemed to be an increase in the herd teat end index in both machine groups. The correlation coefficients, however, did not show any significant deviation from zero. The effect of the vacuum level on the occurrence of injury to the teat end is shown in Table 45. In the case of the bucket machines the herd teat end index mean for the normal vacuum level shows a significant difference from the mean for both the level below normal $\left(\mathrm{t}=5.49^{* * *}, 13 \mathrm{df}\right)$ and for the level above normal $(\mathrm{t}=$ $2.62 *, 8 \mathrm{df})$. When the machines were grouped according to evacuation time (Table 46), it was discovered that an increase in evacuation time added to the number on injury cases. In the case of the bucket machines, the difference between the herd teat end index means for class 1 and class 3 was significant at the $5 \%$ level ( $\left.\mathrm{t}=2.23^{*}, 16 \mathrm{df}\right)$, similarly between class 1 and class 3 of the pipeline machines $\left(\mathrm{t}=2.43^{*}, 8 \mathrm{df}\right)$.

The herd teat end index was influenced by the air flowrate of taps on the farms equipped with bucket machines, class $1=4.79 \pm 0.73(\mathrm{n}=10)$, class $2=4.99 \pm 0.65(\mathrm{n}=7)$ and class $3=6.17 \pm 0.95(\mathrm{n}=3), \mathrm{t} 1 / 3=2.33^{* *}$, $11 \mathrm{df}$. The occurrence of injury to the teat end was not influenced by the pulsator function in this material.

Table 45. The effect of vacuum level on the teat end index for herds ( $\mathrm{n}=$ number of herds).

\begin{tabular}{|c|c|c|c|c|c|c|}
\hline \multirow{3}{*}{ Vacuum level } & \multicolumn{6}{|c|}{ Herd teat end index } \\
\hline & \multicolumn{3}{|c|}{ Bucket machines } & \multicolumn{3}{|c|}{ Pipeline machines } \\
\hline & $\overline{\mathbf{x}}$ & S.D. & $\mathrm{n}$ & $\overline{\mathbf{x}}$ & S.D. & n \\
\hline Normal ........ & 4.18 & 0.19 & 5 & 5.64 & 1.23 & 9 \\
\hline Below normal ................ & 5.29 & 0.58 & 10 & 4.6 & & 1 \\
\hline Above normal ................... & 5.50 & 1.11 & 5 & 5.75 & 1.06 & 2 \\
\hline
\end{tabular}

Table 46. The teat end index for herds grouped according to evacuation time.

\begin{tabular}{|c|c|c|c|c|c|c|}
\hline \multirow{3}{*}{$\begin{array}{l}\text { Evacuation time } \\
\text { classification }\end{array}$} & \multicolumn{6}{|c|}{ Herd teat end index } \\
\hline & \multicolumn{3}{|c|}{ Bucket machines } & \multicolumn{3}{|c|}{ Pipeline machines } \\
\hline & $\overline{\mathbf{x}}$ & S.D. & $\mathrm{n}$ & $\overline{\mathbf{x}}$ & S.D. & $\mathrm{n}$ \\
\hline Class 1. ...................... & 4.58 & 0.72 & 9 & 5.31 & 0.96 & 8 \\
\hline 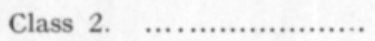 & 5.35 & 0.35 & 2 & 5.00 & 0.57 & 2 \\
\hline 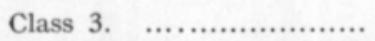 & 5.49 & 0.81 & 9 & 7.20 & 0.99 & 2 \\
\hline
\end{tabular}




\section{3. 2. Discussion}

The udder health of a herd became worse with the increase of defects in the functioning of a milking machine. The most conspicuous exceptions were 3 or 4 farms equipped with bucket machines. On these farms the defective functioning of the old machines was compensated by the special care observed in the process of milking and in the management of the cows, and the incidence of mastitis remained small. This could not be noted on the farms equipped with pipeline machines. It is known that the general tendency is to increase work efficiency by obtaining a milk pipeline equipment which results in a decrease of the time needed for the care of an individual cow.

Variables which show the condition of the milking machine clearly have a more marked connection with the incidence of clinical mastitis than that of subclinical mastitis. The testing of the milking machines was carried out one month before the first milk sample examination was made. Measures taken in conjunction with the testing, and thereafter, probably led to a better functioning of some of the machines. Any error detected at this time effects the comparison of the incidence of subclinical mastitis examined during 1977 more strongly than the comparison of the incidence of clinical mastitis, because in the latter case the material originates from the two years prior to the testing and from one year thereafter. It was discovered also in a Norwegian examination (BAKKEN 1978) that the condition of a milking machine had a more distinct influence on the incidence of clinical mastitis. The observation can partly be explained by the fact that the incidence of subclinical mastitis is at a certain time period influenced by the duration of infection, on which treatment has again a marked effect (KINGwILL et al. 1977). The effect of the milking machine therefore seems to show itself in the occurrence of new infections, in the onset of clinical mastitis.

Defects in the functioning of the milking machine increase with the age of the machine, which adds to the incidence of mastitis. Of the constructional factors of the machine the type of the vacuum regulator, the type of pulsator and the diameter of the vacuum pipeline influence udder health, although the differences were not statistically significant at all points in this study. The vacuum conditions prevailing in the clusters are influenced by the function of the vacuum regulator and the diameter of the vacuum pipeline. Marked changes in the vacuum level in liners, which contribute to the onset of new infections, may be caused by the factors stated above. A spring vacuum regulator - even if this works well - is more dependent on the steady capacity of the vacuum pump than a vacuum regulator controlled by a dead weight system (RABOLD et al. 1974), furthermore, disturbances in the functioning of the spring regulator become frequent with age. A decrease in the diameter of the vacuum pipeline means a strong decrease in capacity. Only five bucket machines in this material were equipped with a $25 \mathrm{~mm}$ vacuum pipeline as recommended, so the constructional premisses for the perfect functioning of the machine were in most cases small.

The care and cleaning of the machines are generally neglected. Leaks in the different parts of the vacuum equipment are not rare. It was also usual that the functioning of the vacuum regulators and pulsators was hindered by dirt. 
The results from these operative defects were manifested in worsened udder health. Although observations made from a single object of testing did not always have a statistically significant connection with the measurement of udder health, the observations were not at any point in disagreement with those results most commonly published in literature. Since the testing and servicing of milking machines improve the udder health of the herds (HofF and Skoglund 1977), and the quality of milk (SAloniemi and Auvinen 1979), the state authorities should also pay more attention to the matter. Because a disturbance in the functioning of the machine quickly leads to a worsening of udder health (JACKSON 1970), the machines should be tested every year.

\section{4. Effect of ventilation in the cowshed}

\subsubsection{Results}

Six cowsheds in this material had an automatic ventilation system, regulated by a thermostat, and the remaining 26 cowsheds had natural ventilation. The ventilation was judged with sensory evaluation to work well in 7 (3) cowsheds, fairly well in 18 (2) and poorly in 7 (1) cowsheds. The number of cowsheds with automatic ventilation are stated in brackets.

The thermohygrograph readings showed the mean indoor temperature in the cowsheds to be $14.4 \pm 2.2^{\circ} \mathrm{C}$, the herd mean values ranging between $9-18^{\circ} \mathrm{C}$. The change in temperature in the cowsheds was $5.8 \pm 1.2^{\circ} \mathrm{C}$ during the 24 hours, ranging from $3^{\circ}$ to $8^{\circ} \mathrm{C}$ in the individual cowsheds. During the examination period the outdoor temperature ranged from $-19^{\circ} \mathrm{C}$ to $+5^{\circ} \mathrm{C}$, the mean temperature being $-5.0 \pm 6.8^{\circ} \mathrm{C}$. The average relative humidity in the cowsheds was $80.3 \pm 7.3 \%$, the herd mean value ranging between $65-$ $95 \%$. The maximum values of relative humidity measured ranged from $75 \%$ to $99 \%$.

The herd B-index for cows kept in the cowsheds with automatic ventilation was 1.98 and for cows kept in the cowsheds with natural ventilation 1.96. When the ventilation was judged to work well, the mean value of the herd B-index was 1.89 , when the ventilation worked fairly well, the mean value was 1.95 and in the case of poor ventilation 2.05. According to an analysis of variance the differences are not statistically significant. When grouped in a corresponding manner, the incidence of clinical mastitis in the herds was as follows: $0.185,0.364$ and $0.322\left(F=1.77^{\mathrm{ns}}, 2\right.$ and $\left.29 \mathrm{df}\right)$. The incidence of the disease was $0.245 \pm 0.141$ in herds with automatic ventilation and $0.331 \pm$ 0.231 with natural ventilation. The difference between the mean values is not significant.

No connection was established between the indoor temperature measured and the herd B-index. When the indoor temperature changed within the limits of five degrees centigrade, the herd B-index was $1.77 \pm 0.31$ (14 herds), and when the range was over 5 degrees centigrade, the herd B-index was $2.11 \pm$ 0.35 (18 herds). The difference is significant, $t=2.93^{* *}, 30 \mathrm{df}$. The mean value and the maximum value of the relative humidity had no connection with the herd B-index. When the range in humidity did not exceed $20 \%$, the herd B-index was $1.90 \pm 0.37$ (21 herds), and when it ranged between $20-30 \%$, 
the herd B-index was $2.08 \pm 0.35$ (11 herds). The difference between means is not significant.

The incidence of clinical mastitis was $0.200 \pm 0.153$ (13 herds) in the years 1975-77 in cowsheds where the indoor temperature changed within the limits of five degrees centigrade. Similarly, when the range was over five degrees, the incidence was $0.393 \pm 0.223$ (19 herds). The difference between the means is significant, $\mathrm{t}=2.91^{* *}$, 30 df. No connection was established between the indoor temperature measured and the incidence of the disease. No connection was established between the mean and maximum values of relative humidity and the incidence of clinical mastitis, either. When the changes of humidity did not exceed $20 \%$ during the measuring period, the incidence of the disease was $0.303 \pm 0.202$ during the three-year-period, and when the change was between $20-30 \%$, the incidence was $0.338 \pm 0.252$. With $70 \%$ likelihood the difference of the mean values may be coinsidental.

\section{4. 2. Discussion}

The ventilation arrangement is often insufficient in old cowsheds. The poor heat insulation and the poor condition of the buildings add to the surface humidity and draught. It is obvious that these factors contribute to an increase in mastitis (SIMENSEN 1976 a, Madsen 1978). The marked changes in indoor temperature during the 24-hour-period, as discovered in this study, had a clear relation with the greater incidence of mastitis. These changes of temperature can be interpreted to be due to poor ventilation. The mean temperature as such, if staying within the limits of $9-18^{\circ} \mathrm{C}$ as observed, did not seem to have any effect. The same was the case with the mean value of relative humidity.

To judge ventilation on the basis of sensory evaluation gives only indicative information, therefore there is a good reason to use a thermohygrograph to show daily changes. It was possible to observe from the thermohygrogram, for example, the effect the use of ample wash water had on the air humidity.

\subsection{Effect of lighting}

\subsubsection{Results}

An average lighting capacity of 23 lux was noted at udder level beside the cow, the range being between 5-100 lux, according to the lighting measurements carried out during the process of the evening milking at the turn of April-May. For the lighting of areas where the milking takes place, the following distribution was obtained from an estimation of the lighting capacity made in May on the basis of sensory evaluation (the measurements and estimation were made by different persons): good lighting in 4 cowsheds, average in 8 cowsheds and poor in 20 cowsheds. When the cowsheds were grouped according to the estimated lighting capacity, the distribution of the measured lighting capacity was as follows: $66 \pm 35 \operatorname{lux}$ (4 farms), $21 \pm 9$ lux (8 farms) and $16 \pm 7$ lux (20 farms). The mean values for the good group and the average group differ from each other significantly at the $5 \%$ level $\left(t=2.53^{*}, 10 \mathrm{df}\right.$ ), but the difference between the mean values for the average and poor group is not significant $\left(\mathrm{t}=1.47^{\mathrm{ns}}, 26 \mathrm{df}\right)$. 
The herd B-index was $\mathbf{1 . 8 5}$ for herds on the farms where the lighting capacity was over 40 lux ( 3 farms), 1.97 in the case of farms where the lighting power was between $20-30$ lux (12 farms) and 1.98 where the lighting capacity was below 20 lux (17 farms). The differences between the mean values are not significant. When the farms were grouped according to estimated lighting capacity, the corresponding figures were: 1.87 in the case of good lighting, 1.89 in the case of average lighting and 2.01 where the lighting was poor $(\mathrm{F}<1)$.

The incidence of clinical mastitis in the years $1975-77$, when grouped according to estimated lighting capacity, was as follows: $0.248,0.254$ and 0.352 $(\mathrm{F}<1)$. When the measured capacity was not below $40 \mathrm{lux}$, the incidence was $0.167 \pm 0.142$, when between $20-39$ lux, the incidence was $0.354 \pm 0.231$ and when below 20 lux, $0.313 \pm 0.217$. The differences between these means are not significant, either.

\section{5.2. Discussion}

As regards udder health in tying stalls, the most important phase of work, milking, is carried out in a stall where it is difficult to have the udders adequately lighted. From the view of hygiene requirements the average lighting capacity measured was much too small, and even in the best cases the lighting was only adequate. Besides the small number and power of the bulbs, the dirtiness of the lighting equipment can also be a cause of the poor lighting (Nieminen et al. 1975). The poor state of hygiene in the care of cows is otherwise often associated with inadequate lighting. Results obtained from this study support the necessity of improving lighting in those areas where milking takes place. The estimation of lighting strength by sensory evaluation gives only a rough picture of the adequacy of lighting. In view of practical instruction work this is just about adequate.

On average, in this material udder health was better in those cowsheds which had the best lighting, although the differences between the groups cannot be considered as definite statistically. In the prevention of mastitis more attention should be paid to the improvement of lighting so that the state of hygiene in the care of cows can be raised.

\section{6. Effect of cowshed and stall constructions}

\section{6. 1. Results}

The frame work of the cowsheds in this material consisted of bricks in 21 cases, timber in 7 cases, stone in 2 cases and in 2 cases a combination of these.

No connection was established between the building material and those variables which describe udder health.

The mean age of the buildings was $34.5 \pm 17.9$ years (range $3-82$ years). The frame work was under 20 years of age in only four cowsheds. Eight of the cowsheds had undergone primary renovation, five of them not more than 10 years before. The age of the cowshed as such had no connection with udder health. 
The visible condition of the cowsheds was estimated to be good in 4 cases, average in 25 cases and poor in 3 cases. The herd B-index $(2.05,1.93,2.14)$ or the incidence of clinical mastitis $(0.192,0.392,0.580)$ did not differ statistically significantly in the different groups. Table 47 shows a relationship between the stall constructions and the incidence of mastitis. 23 of the cowsheds had long standing and 9 of them short standing. The occurrence of mastitis was slightly greater in long standing cowsheds. Skin injury to the udder and teat occurred slightly less (5.06/5.08) in long standing stalls, whereas the incidence of teat diseases was again slightly greater in the years $1975-77(0.027 / 0.026)$. The differences are of no statistical significance.

The average age of the short standing cowsheds was 5.8 years and that of the long standing cowsheds 32.4 years. No significant correlation was established between the age of the cowshed and the herd B-index in either of the cowshed types. The age of the short standing cowsheds $(x)$ correlated with the incidence of clinical mastitis $(\mathrm{y}), \mathrm{r}=0.67 *, \mathrm{y}=0.033+0.036 \mathrm{x}$. As far as the long standing cowsheds are concerned, no significant linear correlation was established $\left(\mathrm{r}=0.18^{\mathrm{ns}}\right)$.

The average stall length of the long standing cowsheds was $192 \pm 7 \mathrm{~cm}$ (range $180-200 \mathrm{~cm}$ ). No connection was established between the stall length of long standings and the herd B-index nor between the stall length and the incidence of clinical mastitis. The stall length of long standings had no connection with the incidence of teat diseases or with the skin index, either. The stall length of the short standing cowsheds was $152 \pm 9 \mathrm{~cm}$ (range 140$160 \mathrm{~cm})$. No connection was found between the length of short standing and the herd B-index. With a length $(\mathrm{x})$ increase of the short stall, the incidence of clinical mastitis (y) decreased by some 0.1 cases per cow and year for each 10 centimeters $\left(\mathrm{y}=2.01-0.012 \mathrm{x}, \mathrm{r}=0.64^{*}\right)$. The incidence of teat diseases was $0.020 \pm 0.033$ in the short stalls of under $150 \mathrm{~cm}(4 \mathrm{farms})$ and $0.024 \pm$ 0.021 in the short stalls of over $150 \mathrm{~cm}$ ( 5 farms). The difference is coincidental with $80 \%$ probability. A corresponding observation was made with regard to skin index, $5.10 \pm 0.20(\mathrm{n}=4)$ and $5.06 \pm 0.09(\mathrm{n}=5)$.

The average width of the stalls was $110 \pm 7 \mathrm{~cm}$. The stalls of the short standing cowsheds, which had been built later, were wider, $115 \pm 5 \mathrm{~cm}$. The width of the stalls in the long standing cowsheds was $107 \pm 7 \mathrm{~cm}$. The stall width had no connection with the herd B-index nor the incidence of clinical mastitis in this whole material. The same applies to the short or long standing stalls when treated separately. The same observation was made in the case of the skin index.

The stall surface in 30 cowsheds was of concrete, in 1 cowshed partly of concrete and partly rubber mats and in 1 cowshed of wood. The udder health in the two latter cases did not differ from that in the other cowsheds. Most cases of mastitis occurred in cowsheds with a broken stall surface (Table 47). The lack of insulation in the stalls also had a connection with the incidence of mastitis. The differences between the mean values for the groups are not statistically significant.

In all the long standing cowsheds the cows were tied with cross chain tying. There were several kinds of tying systems in the short standing cowsheds: 
Table 47. The relation of some stall constructions to the B-index and the incidence of clinical mastitis.

\begin{tabular}{|c|c|c|c|c|c|}
\hline \multirow[t]{2}{*}{ Environmental factor } & \multirow[t]{2}{*}{$\begin{array}{l}\text { Number of } \\
\text { cows }\end{array}$} & \multicolumn{2}{|c|}{ Herd B-index } & \multicolumn{2}{|c|}{$\begin{array}{c}\text { Incidence of clinical } \\
\text { mastitis }\end{array}$} \\
\hline & & $\overline{\mathbf{x}}$ & S.D. & $\overrightarrow{\mathbf{x}}$ & S.D. \\
\hline
\end{tabular}

Type of standing

- long standing ........... 23

- short standing

0.40

$0.343^{\mathrm{a}}$

0.233

- short standing

$1.93^{\mathrm{a}}$

0.29

$0.242^{\mathrm{a}}$

0.161

Condition of stall surface

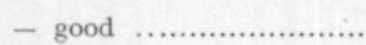

- worn ....................... 20

$\begin{array}{llll}1.98^{\mathrm{a}} & 0.46 & 0.291^{\mathrm{a}} & 0.270 \\ 1.95^{\mathrm{a}} & 0.35 & 0.307^{\mathrm{a}} & 0.205 \\ 2.00^{\mathrm{a}} & 0.34 & 0.525^{\mathrm{a}} & 0.225\end{array}$

- broken

$\begin{array}{rr}9 & 1.98^{\mathrm{a}} \\ 20 & 1.95^{\mathrm{a}} \\ 3 & 2.00^{\mathrm{a}}\end{array}$

0.34

0.225

Heat insulation of stall

- insulated ................... 8

$1.92^{\mathrm{a}}$

0.31

$0.222^{\mathrm{a}}$

0.159

- not insulated

24

$1.98^{\mathrm{a}}$

0.39

$0.346^{\mathrm{a}}$

0.228

Type of tying in short stalls

- vertical chain .............

collar ...................... 3

4

$2.06^{\mathrm{a}}$

0.39

$0.244^{\mathrm{a}}$

0.160

- cross chain and shoulder bows

$1.78^{\mathrm{a}}$

0.14

$0.300^{\mathrm{a}}$

0.277

- yoke tying

1

1.77

0.179

0.127

Height of neck bar

- below $100 \mathrm{~cm}$

- above $100 \mathrm{~cm}$........... 4

$1.99^{\mathrm{a}}$

0.42

$0.154^{\mathrm{a}}$

0.136

$4 \quad 1.85^{\mathrm{a}}$

0.17

$0.359 \mathrm{a}$

0.132

Stall partition

- yes .......................... 8

$\begin{array}{llll}1.94^{\mathrm{a}} & 0.55 & 0.207^{\mathrm{a}} & 0.150 \\ 1.97^{\mathrm{a}} & 0.40 & 0.351^{\mathrm{b}} & 0.227\end{array}$

Condition of feeding

table surface

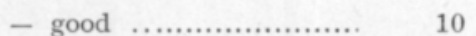

$\begin{array}{llll}1.91^{\mathrm{e}} & 0.29 & 0.189^{\mathrm{a}} & 0.119 \\ 1.94^{\mathrm{e}} & 0.42 & 0.374^{\mathrm{b}} & 0.240 \\ 2.26^{\mathrm{d}} & 0.08 & 0.306^{\mathrm{ab}} & 0.197\end{array}$

Type of drinking bowl

\begin{tabular}{lrrrrr} 
- automatic .................. & 20 & $1.90^{\mathrm{a}}$ & 0.40 & $0.244^{\mathrm{a}}$ & 0.185 \\
- with water container . & 12 & $2.07^{\mathrm{a}}$ & 0.31 & $0.432^{\mathrm{b}}$ & 0.256 \\
& & & & & \\
Place of drinking bowl & & & & & \\
- on the feeding table $\ldots$ & 6 & $2.00^{\mathrm{a}}$ & 0.34 & $0.273^{\mathrm{a}}$ & 0.173 \\
- above the stall ......... & 26 & $1.96^{\mathrm{a}}$ & 0.38 & $0.324^{\mathrm{a}}$ & 0.228 \\
\hline
\end{tabular}

Means with different letters are significantly different. $\mathrm{a} / \mathrm{b}(\mathrm{P}<0.05), \mathrm{c} / \mathrm{d}(\mathrm{P}<0.001)$ 
the vertical chain or Grabner tying with a neck bar (on 4 farms, neck bar height $94 \pm 8 \mathrm{~cm}$ ), the vertical chain with a collar connected to the neck bar (on 3 farms, neck bar height $101 \pm 15 \mathrm{~cm}$ ), the cross chain and shoulder supports with the addition of a neck bar (on 1 farm, neck bar height $110 \mathrm{~cm}$ ), and the yoke tying (on 1 farm). The average neck bar height on the different farms was $99 \pm 11 \mathrm{~cm}$. Because the short standing cowsheds were few in number it was difficult to examine the effect of the tying type on udder health (Table 47).

The incidence of teat disease in short standing cowsheds was as follows, when grouped according to tying type: $0.025 \pm 0.019,0.034 \pm 0.039,0.000$ and 0.036 , and similarly the skin index: $5.05 \pm 0.10,5.13 \pm 0.23,5.0$ and 5.1 .

There was a stall partition between each cow, at a maximum distance of $70 \mathrm{~cm}$ from the edge of the dung gutter, in five short standing cowsheds. In two other short standing cowsheds and in one long standing cowshed there was a stall partition between each cow, but at a distance of over $80 \mathrm{~cm}$ from the dung gutter. In the other cowsheds there were supporting pillars of the ceiling and in some stalls actual stall partitions placed irregularly, or there were no stall partitions between the cows. The herd B-index in cowsheds with stall partitions does not differ significantly from the average herd B-index (Table 47). The herd B-index in the five stalls with a maximum distance of $70 \mathrm{~cm}$ from the dung gutter was $1.85 \pm 0.11$, but this mean value does not differ from the herd B-index mean value for the other herds, either. The occurrence of clinical mastitis in the herds kept in cowsheds with stall partitions was slightly significantly less in number than in other herds, and in the case of the five herds the incidence for the disease was $0.177 \pm 0.186$. The corresponding figures describing the occurrence of injury to the teat were $0.019 \pm$ $0.019(\mathrm{n}=8), 0.016 \pm 0.016(\mathrm{n}=5)$ and $0.030 \pm 0.033(\mathrm{n}=24)$, and the skin index $5.09 \pm 0.15,5.10 \pm 0.17$ and $5.06 \pm 0.08$. There is no significant difference statistically between these mean values.

The surface of the feeding table was $31 \pm 6 \mathrm{~cm}(22-44 \mathrm{~cm})$ above the stall surface in long standing cowsheds, and $4 \pm 3 \mathrm{~cm}(0-8 \mathrm{~cm})$ above the stall surface in short standing cowsheds. No connection was found between the construction of the feeding table and udder health, but the incidence of clinical mastitis was influenced by the condition of the feeding table surface (Table 47).

The position of the drinking bowl had no significant connection with udder health, but it could be shown, however, that the occurrence of clinical mastitis was significantly less on farms which were equipped with automatic bowls (Table 47).

\section{6. 2. Discussion}

The number of cowsheds was too few in this material to prove the effect of stall constructions on health. The slight difference between the different types of stall may have a connection with the lesser age of the short standing cowsheds and any connecting factors, such as undamaged constructions (stall and feeding table surfaces) and more modern equipment (drinking bowls). The findings correspond fairly well with Scandinavian observations (BRATLIE 1966, Ekesbo 1966, Madsen 1978, Bakken 1978, NygaArd 1979) and with 
previous observations made in Finland (Nieminen et al. 1975, Saloniemi 1977 c). There is variation in statistical significance for details in field examination like this (MADSEN 1978, BAKKEN 1978), but the results obtained from this study were not contrary to those obtained from other Nordic studies. More definite results can be obtained for the connection between constructional environmental factors and the incidence of clinical mastitis than that for subclinical mastitis. The same observation has been made in a Norwegian study by BAKKEN (1978).

\section{7. Effect of manure removing system}

\subsubsection{Results}

The system of removing manure in solid form was employed on 29 farms, where the removal of manure was done mechanically in $\mathbf{5}$ cowsheds and by hand in 24 cowsheds. The average width of the dung gutter was $46 \pm 11 \mathrm{~cm}$ (range 27-65) and the average depth $14 \pm 5 \mathrm{~cm}$ (range 5-25).

A liquid manure system was employed on 3 farms, two of these without a gate valve (continuous removal) and one with a gate valve. The slits of the dung grid varied between $35-43 \mathrm{~mm}$ in width and the iron bars between 10-15 mm. The cowsheds with a liquid manure system, which had undergone primary renovation 8-11 years before, were of the short stalled type, the stall length varying between $140-145 \mathrm{~cm}$. Cows on these farms were younger than average.

In cowsheds with a solid manure system (those with long standing included), the herd B-index was $1.97 \pm 0.38$, in the six short standing cowsheds equipped with a solid manure system the herd B-index was $1.96 \pm 0.34$ and for the cowsheds with a liquid manure system the herd B-index was $1.87 \pm 0.20$. The differences between the means are not significant. The width of the dung gutter had no connection with the herd B-index, $r=0.11^{\text {ns }}$. The same applied to the gutter depth, $r=0.19^{\text {ns }}$.

The incidence of clinical mastitis was $0.289 \pm 0.228$ in the cowsheds with a solid manure system (the cowsheds with long standing included) and $0.419 \pm$ 0.069 in the cowsheds with a liquid manure system. The difference between the means is statistically significant at the $5 \%$ level, $\mathrm{t}=2.24 *, 30 \mathrm{df}$. The incidence was $0.154 \pm 0.107$ in the cowsheds of the short standing type with a solid manure system. The mean value differs significantly from that for the cowsheds with a liquid manure system, $\mathrm{t}=4.49^{* *}, 7$ df. The width $(\mathrm{r}=$ $\left.-0.25^{\mathrm{ns}}\right)$ or depth $\left(\mathrm{r}=-0.08^{\mathrm{ns}}\right)$ of the gutter had no statistically significant connection with the incidence of clinical mastitis.

The incidence of teat disease was $0.026 \pm 0.030$ in the cowsheds with a solid manure system and $0.038 \pm 0.034$ in the cowsheds with a liquid manure system. The difference may be due to coincidence with a $50 \%$ probability. The corresponding incidence in the short standing cowsheds with a solid manure system was $0.020 \pm 0.021$. The correlation coefficients between the incidence of teat diseases and the width and depth of the gutter did not show any significant deviation from zero, $\mathrm{r}=0.20^{\mathrm{ns}}$ and $0.21^{\mathrm{ns}}$. No injuries to the udder 
and teat skin were detected in the cowsheds with a liquid manure system. The same was the case with the 16 cowsheds with a solid manure system. The values of the skin indexes were $\mathbf{5 . 0 0}$ and $\mathbf{5 . 0 8}$. The skin index was $\mathbf{5 . 0 5} \pm 0.08$ (25 farms) when the depth of the gutter was below $20 \mathrm{~cm}$, and when the depth was between $20-29 \mathrm{~cm}$, the index was $5.20 \pm 0.14$ ( $4 \mathrm{farms})$. The difference is significant at the $5 \%$ level, $\mathrm{t}=2.09^{*}, 27 \mathrm{df}$.

More cases of injury to the teat end were detected in the cowsheds with a liquid manure system, the mean of the teat end index being $6.90 \pm 0.87$ and respectively $5.09 \pm 0.83$ for cowsheds with a solid manure system $(\mathrm{t}=$ $\left.3.45^{* *}, 30 \mathrm{df}\right)$.

\section{7. 2. Discussion}

A liquid manure system associated with a very short stall and a dung grid seems to constitute a risk to udder health. This result has been generally accepted also in other Nordic countries (EKESBo and Vilson 1978, BAKKeN 1978, Klastrup 1978 b). According to this study a short standing cowshed equipped with a solid manure system decreases the risk of mastitis when the stall is of sufficient length. The observation that a deep gutter for solid manure adds to the incidence of injury to the teat is in accord with those observations made by RAsbech and Jochumsen (1963).

\section{8. Effect of bedding and of stall and cow cleanness}

\section{8.1. Results}

Straw was used as bedding on 28 farms (the average amount was $1.5 \pm 0.6$ $\mathrm{kg}$ per each cow), more than $1 \mathrm{~kg}$ per day and cow was used on 22 farms, and only a little straw was used on 6 farms. Sawdust was used as bedding on one farm and no bedding was used on three farms. The latter three farms had cowsheds with a liquid manure system.

The effect of bedding was estimated by judging the cleanness and dryness of the stalls in connection with a farm visit. Stalls were judged to be dry and fairly clean in 3 cowsheds, damp and dirty to the usual extent in 20 cowsheds, wet and dirty in 8 cowsheds. A great deal of straw was used in the three cowsheds with dry and clean stalls. Of these cowsheds two had long standing and a neck bar, the third had short standing and yoke tying. Of the eight cowsheds which were judged to be dirtiest, two cowsheds were of a short standing type, where an average amount of straw was used. The stall lengths were $148 \mathrm{~cm}$ and $160 \mathrm{~cm}$ and both were equipped with a tying system strongly restricting the movements of the cow. A great deal of straw was used in four of the six long standing cowsheds, an average amount of straw in one cowshed, and sawdust was used in one cowshed. On the basis of what has been stated above, it could not be proved that the dryness and cleanness of a stall are connected with the stall type, the quality and amount of bedding material or the manure removal system employed.

$20.6 \%$ of the cows were judged to be clean (score $=1$ ), $60,0 \%$ dirty to some extent (score $=2$ ) and $19.4 \%$ very dirty (score $=3$ ). The mean values for the cleanness of the individual herds corresponded quite well to the results obtained for the cleanness of stalls, Table 48 . 
Table 48. The cleanness of cows, the herd B-index and the incidence of udder diseases in herds grouped according to stall cleanness and dryness.

\begin{tabular}{|c|c|c|c|c|}
\hline $\begin{array}{l}\text { Stall condition } \\
\text { Number of herds }\end{array}$ & & $\begin{array}{c}\text { Dry and clean } \\
3\end{array}$ & $\begin{array}{c}\text { Medium } \\
21\end{array}$ & $\begin{array}{l}\text { Dirty and wet } \\
8\end{array}$ \\
\hline \multirow[t]{2}{*}{ 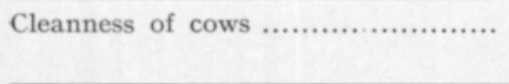 } & $\overline{\mathbf{x}}$ & $1.50^{\mathrm{ac}}$ & $1.90^{\mathrm{be}}$ & $2.44^{\mathrm{d}}$ \\
\hline & S.D. & 0.26 & 0.30 & 0.31 \\
\hline \multirow[t]{2}{*}{ 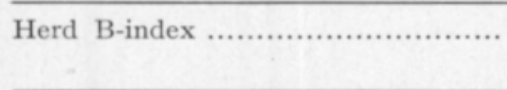 } & $\overline{\mathbf{x}}$ & $2.16^{\mathrm{a}}$ & $1.98^{\mathrm{a}}$ & $1.85^{\mathrm{a}}$ \\
\hline & S.D. & 0.41 & 0.37 & 0.36 \\
\hline \multirow{2}{*}{ Incidence of clinical mastitis ........... } & $\overline{\mathbf{x}}$ & $0.199^{\mathrm{a}}$ & $0.362^{b}$ & $0.178^{\mathrm{a}}$ \\
\hline & S.D. & 0.042 & 0.240 & 0.133 \\
\hline \multirow{2}{*}{ 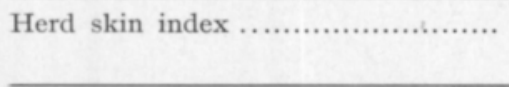 } & $\overline{\mathbf{x}}$ & $5.07 \mathrm{a}$ & $5.04^{\mathrm{a}}$ & $5.11 \mathrm{a}$ \\
\hline & S.D. & 0.12 & 0.07 & 0.15 \\
\hline \multirow[t]{2}{*}{ Incidence of teat diseases $1975-77$} & $\overline{\mathbf{x}}$ & $0.004^{\mathrm{a}}$ & $0.034^{\mathrm{b}}$ & $0.017 \mathrm{ab}$ \\
\hline & S.D. & 0.008 & 0.032 & 0.024 \\
\hline
\end{tabular}

Means with different letters are significantly different. a/b $(\mathrm{P}<0.05), \mathrm{c} / \mathrm{d}(\mathrm{P}<0.001)$

The quality or amount of bedding material had no significant connection with the herd B-index in this material, nor with the skin index or the incidence of clinical mastitis or teat diseases.

As can be seen from Table 48, the B-index was greatest for the group with the cleanest stalls and smallest for the group with wet stalls, the differences, however, not being significant. The incidence of clinical mastitis was again significantly greater in the group of stalls which were judged to be dirty to an average extent than in the group of clean or dirty stalls.

No connection was detected between the skin index and the dryness and cleanness of the stall surface. The incidence of teat disease during the threeyear-period of $1975-77$ was smallest in the group of dry and clean stalls and greatest in the middle group. The testing of differences between the mean values by the $t$-method is questionnable because of the skewness of distribution.

\section{8. 2. Discussion}

The effect of the bedding material on udder health remains unproved by this study, which is in accord with the examinations made by MADSEN (1978) and BAKKEN (1978), and contrary to the results presented by EKEsBo (1966) and NygaARD (1979). It is probable that a single observation on the use of bedding and on the cleanness of cows does not give a reliable picture for the whole period of indoor feeding. On the other hand, it is possible that a small amount of straw or sawdust may even increase the risk of mastitis because moisture is then retained in the stall and sharpness of sawdust may cause mechanical injury to the skin (Saloniemi 1977 c, Koiranen 1979 b). Only a sufficient amount of bedding to provide a soft place to lie on protects udder health. As a rule, a sufficient amount of bedding can be used only in the loose housing conditions. No sufficient amounts of bedding were used in the cowsheds of this material. The use of soft stall mats makes it possible to arrange such a soft bedding in a tying stall which protects the udder from injury (SALONIEMI 1977 b). 


\subsection{Effect of milking hygiene and milking technique}

\subsubsection{Results}

On all the farms in this material udders were wiped with an udder cloth before the cluster was fastened. A separate cloth for each cow was used on six farms (on five of them the cloths were disposable), on the remaining 26 farms the udders of several cows were wiped with one or several cloths during the process of milking. A foremilk cup was used only in two herds. In 10 herds no foremilk was taken when preparing the udder for milking. According to owner information overmilking occasionally took place in 9 herds, no overmilking took place in 23 herds. As a rule, stripping was carried out by machine (in 25 herds), by hand only in one herd, and in the case of 6 herds the cluster was unfastened without touching the udder. Teat dipping was performed in 4 herds after each milking and daily teat smearing was carried out in two herds. Neither of these treatments were given in 17 herds. As far as could be estimated, proper care of the milking equipment was taken on 10 farms, someway insufficient on 20 farms, and entirely neglected on 2 farms.

Information on the herd B-index and the incidence of mastitis, grouped according to the quality and condition of udder cloths, is shown in Table 49. The good condition of the cloths and their disinfection between milking times seem to improve udder health.

Table 49. The effect on milking hygiene on udder health.

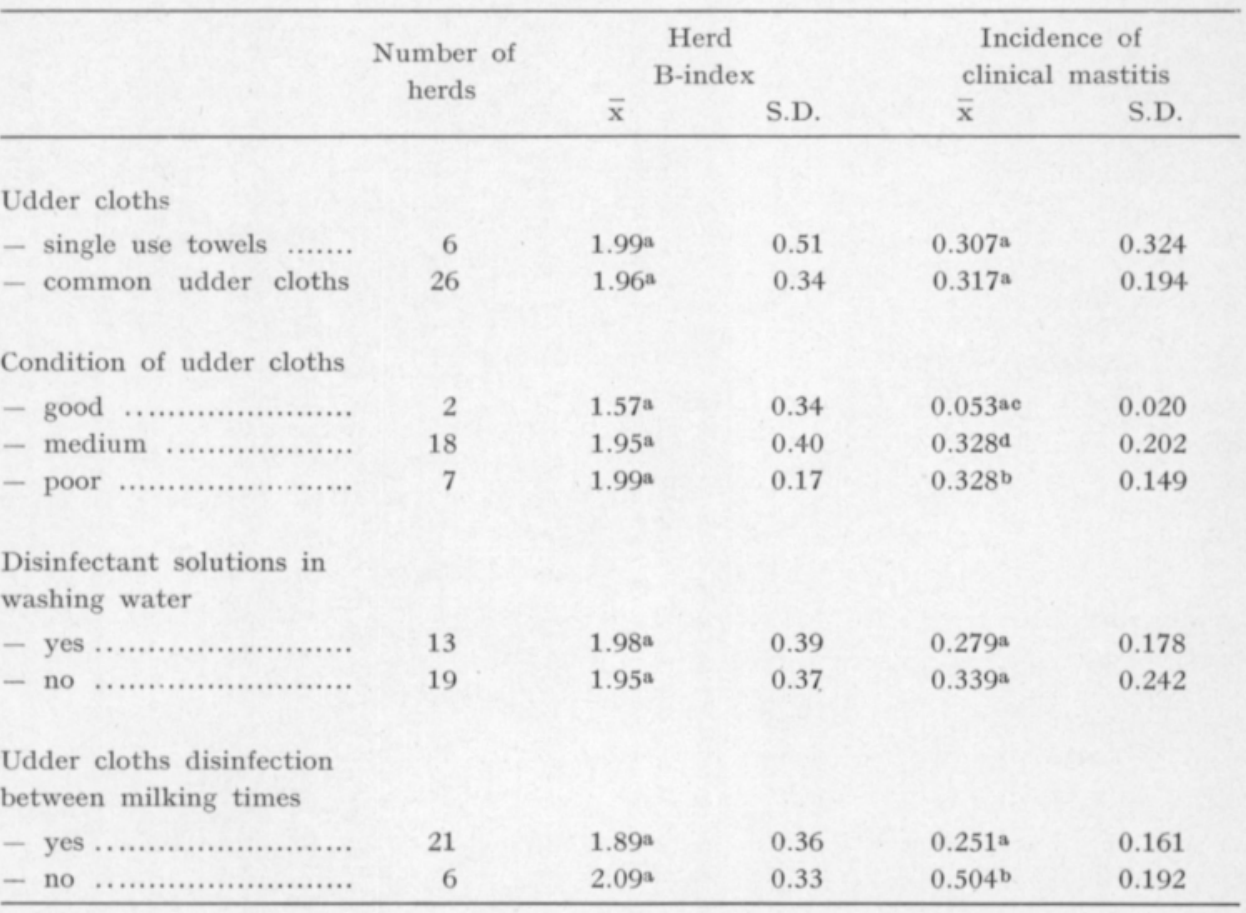

Means with different letter are significantly different. $\mathrm{a} / \mathrm{b}(\mathrm{P}<0.01), \mathrm{c} / \mathrm{d}(\mathrm{P}<0.001)$ 
Table 50. The effect of the milking routine on udder health ( $\mathrm{n}=$ number of herds).

\begin{tabular}{|c|c|c|c|c|c|c|c|}
\hline & \multirow[b]{2}{*}{$\mathrm{n}$} & \multicolumn{2}{|c|}{$\begin{array}{c}\text { Herd } \\
\text { B-index }\end{array}$} & \multicolumn{2}{|c|}{$\begin{array}{c}\text { Incidence of } \\
\text { clinical mastitis }\end{array}$} & \multicolumn{2}{|c|}{$\begin{array}{l}\text { Herd teat } \\
\text { end index }\end{array}$} \\
\hline & & $\bar{x}$ & S.D. & $\overline{\mathbf{x}}$ & S.D & $\overline{\mathbf{x}}$ & S.D. \\
\hline \multicolumn{8}{|l|}{ Foremilking } \\
\hline - in foremilking cup .... & 2 & 187 & 0.08 & 0266 & 0.321 & 6.45 & 2.05 \\
\hline- in stall ....................... & 20 & 2.02 & 0.35 & 0.304 & 0201 & 5.33 & 0.80 \\
\hline - no foremilking $\ldots . . . . . .$. & 10 & 1.87 & 0.44 & 0.347 & 0.254 & 4.88 & 1.00 \\
\hline \multicolumn{8}{|l|}{ Overmilking } \\
\hline 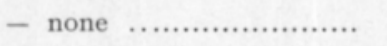 & 23 & 1.95 & 0.37 & 0.319 & 0.249 & 5.13 & 0.90 \\
\hline - occasionally ................. & 9 & 2.01 & 0.38 & 0.298 & 0.114 & 5.59 & 1.14 \\
\hline \multicolumn{8}{|l|}{ Stripping } \\
\hline - by machine ................ & 25 & 1.95 & 0.38 & 0.339 & 0.223 & 5.16 & 1.02 \\
\hline - by hand .................. & 1 & 1.96 & & 0.430 & & 5.2 & \\
\hline - none $\ldots \ldots \ldots \ldots \ldots \ldots \ldots$ & 6 & 2.02 & 0.37 & 0213 & 0174 & 5.48 & 0.80 \\
\hline
\end{tabular}

Table 51. The effect on udder health of teat dipping and smearing ( $\mathrm{n}=$ number of herds).

\begin{tabular}{|c|c|c|c|c|c|c|c|}
\hline & \multirow[b]{2}{*}{$\mathrm{n}$} & \multicolumn{2}{|c|}{$\begin{array}{c}\text { Herd } \\
\text { B-index }\end{array}$} & \multicolumn{2}{|c|}{$\begin{array}{c}\text { Incidence of clinical } \\
\text { mastitis }\end{array}$} & \multicolumn{2}{|c|}{$\begin{array}{l}\text { Herd teat } \\
\text { end index }\end{array}$} \\
\hline & & $\overline{\mathbf{x}}$ & S.D. & $\bar{x}$ & S.D. & $\bar{x}$ & S.D. \\
\hline \multicolumn{8}{|l|}{ Teat dipping } \\
\hline - always ...................... & 4 & 1.98 & 0.28 & 0.372 & 0.158 & 5.85 & 1.71 \\
\hline - occasionally ............. & 3 & 1.86 & 0.28 & 0.272 & 0.140 & 5.43 & 0.85 \\
\hline - never .......................... & 25 & 1.97 & 0.40 & 0.311 & $0 ; 236$ & 5.14 & 0.86 \\
\hline \multicolumn{8}{|l|}{ Teat smearing } \\
\hline - always ...................... & 2 & 2.04 & 0.72 & 0.427 & 0.204 & 5.75 & 1.63 \\
\hline - occasionally ............... & 12 & 1.91 & 0.37 & 0.349 & 0.235 & 5.32 & 1.18 \\
\hline - never ..................... & 18 & 1.99 & 0.35 & 0.279 & 0.210 & 5.17 & 0.82 \\
\hline $\begin{array}{l}\text { Neither teat dipping nor } \\
\text { smearing } \ldots \ldots \ldots \ldots \ldots \ldots \ldots\end{array}$ & 17 & 1.99 & 0.36 & 0.286 & 0.124 & 5.18 & 0.84 \\
\hline
\end{tabular}

The mean values are shown in Table 50 for the herd B-index, the incidence of clinical mastitis and the teat end index, grouped according to the factors associated with the performance of milking. No significant differences in the mean values could be detected.

Neither teat dipping nor teat smearing had any statistically significant connection with udder health, Table 51. Neither the herd B-index $(1.99 \pm 0.29$, $1.94 \pm 0.35$ and $2.10 \pm 0.26)$ nor the incidence of clinical mastitis $(0.289 \pm$ $0.262,0.327 \pm 0.208$ and $0.328 \pm 0.228$ ) seemed to be dependent on the care of the milking equipment. 


\section{9. 2. Discussion}

Information on the milking hygiene and the process of milking was mainly obtained by interviewing the cattle tender the reliability of which is decreased by the fact that the tender had difficulty in assessing his own performance, and by the human inclination to conceal any action known or believed to be imperfect. On the basis of this study milking hygiene does not seem to have any effect on udder health, but this finding must be considered of little significance because of the inefficient observation method. In the practical control work with mastitis, observations on milking hygiene and technique must be made during the milking process. The importance of milking hygiene and the correct milking technique has been shown in several reports (KoIRANEN and Nurmi 1973, Kingwill et al. 1977, Toille et al. 1977).

\section{10. Effect of size of herd, participation in milk recording, level of milk yield and cattle tender}

\section{10.1. Results}

The total number of cows in the herds of this material was 500 in May 1977 or $15.6 \pm 7.4$ per herd, ranging between 4 and 38 cows per herd. When the incidence of mastitis was calculated for the years $1975-1977$, the average size of the herds was $15.1 \pm 6.7,15.3 \pm 6.7$ and $16.1 \pm 7.2$ cows per annum.

11 of the herds participated in the milk recording system, the average number of cows in these being 21.3 cows $( \pm 7.9$ cows). The average yield of the milk recording herds was $5470 \pm 670 \mathrm{~kg}$ of $4 \%$ milk per cow per annum. The information of the milk yield for 19 farms was based on the quantities of milk delivered to the dairy, the average amount being $4460 \pm 690 \mathrm{~kg}$ per cow per annum.

Hired labour was used on two farms, on the others the herds were tended by the owners. The age of the cattle tenders ranged between 25 years and 75 years, the mean age being $47 \pm 11$ years.

The information on the udder health of the herds, when grouped according to the number of cows, is given in Table 52. The udder health seems to be slightly better in the largest and the smallest herds, but no significant differences can be found between the groups.

Table 52. The udder health in herds grouped according to herd size.

\begin{tabular}{|c|c|c|c|c|c|c|c|}
\hline \multirow[t]{2}{*}{ Size of herds } & \multirow[b]{2}{*}{$\mathrm{n}$} & \multicolumn{2}{|c|}{ Herd B-index } & \multicolumn{2}{|c|}{$\begin{array}{c}\text { Incidence of clinical } \\
\text { mastitis }\end{array}$} & \multicolumn{2}{|c|}{$\begin{array}{c}\text { Incidence of teat } \\
\text { diseases }\end{array}$} \\
\hline & & $\overline{\mathbf{x}}$ & S.D. & $\overline{\mathbf{x}}$ & S.D. & $\overline{\mathbf{x}}$ & S.D. \\
\hline $4-10$ & 7 & 1.80 & 0.37 & 0.218 & 0.184 & 0.017 & 0.033 \\
\hline $11-15$ & 12 & 2.04 & 0.45 & 0.320 & 0.261 & 0.022 & 0.034 \\
\hline $16-20$ & 7 & 1.89 & 0.18 & 0.422 & 0.207 & 0.041 & 0.026 \\
\hline $21-38$ & 6 & 1.84 & 0.86 & 0.293 & 0.147 & 0.033 & 0.023 \\
\hline
\end{tabular}


The herd B-index was $1.87 \pm 0.27$ for the milk recording herds and $2.01 \pm$ 0.41 for the other herds. The incidence of clinical mastitis was $0.303 \pm 0.153$ in the milk recording herds and $0.321 \pm 0.248$ in the other herds, the corresponding figures for the incidence of teat disease were $0.030 \pm 0.027$ and $0.025 \pm 0.032$. The differences between the mean values are not significant in any of the variables describing udder health. For each case of clinical mastitis treated by farm visit 1.48 cases were treated by phone prescription on milk recording herds. The corresponding relationship was 1.98 on the other farms.

Table 53. The udder health in herds grouped according to the milk yield of the milk recording herds $(n=11)$ and according to the quantities of milk delivered to dairy $(n=19)$.

\begin{tabular}{|c|c|c|c|c|}
\hline & Her & d B-index & $\begin{array}{c}\text { Incidence of } \\
\text { clinical mastitis }\end{array}$ & $\begin{array}{l}\text { Incidence of } \\
\text { teat disease }\end{array}$ \\
\hline $\mathrm{n}$ & $\overline{\mathbf{x}}$ & S.D. & $\overline{\mathrm{x}} \quad$ S.D. & S.D. \\
\hline
\end{tabular}

Lactation yield in

the milk recording

herds

\begin{tabular}{llllllll} 
below $5000 \mathrm{~kg}$ & 3 & $1.83^{\mathrm{a}}$ & 0.11 & $0.246^{\mathrm{a}}$ & 0.172 & $0.018^{\mathrm{a}}$ & 0.031 \\
$5000-6000 \mathrm{~kg}$ & 6 & $1.79^{\mathrm{a}}$ & 0.31 & $0.384^{\mathrm{ac}}$ & 0.125 & $0.035^{\mathrm{a}}$ & 0.032 \\
above $6000 \mathrm{~kg}$ & 2 & $2.15^{\mathrm{a}}$ & 0.19 & $0.147^{\mathrm{ad}}$ & 0.208 & $0.034^{\mathrm{a}}$ & 0.003 \\
\hline
\end{tabular}

Quantities of milk

delivered to dairy

$\mathrm{kg} /$ cow $/$ year

\begin{tabular}{lrllllll} 
below 4000 & 4 & $1.62^{\mathrm{a}}$ & 0.27 & $0.151^{\mathrm{a}}$ & 0.124 & $0.013^{\mathrm{a}}$ & 0.026 \\
$4000-5000$ & 11 & $1.99^{\mathrm{b}}$ & 0.30 & $0.386^{\mathrm{bd}}$ & 0.219 & $0.022^{\mathrm{a}}$ & 0.024 \\
above 5000 & 4 & $2.04^{\mathrm{ab}}$ & 0.59 & $0.163^{\mathrm{be}}$ & 0.032 & $0.010^{\mathrm{a}}$ & 0.017 \\
\hline
\end{tabular}

Means with different letters are significantly different. $a / b \quad(P<0.05), c / d(P<0.01)$

Table 54. The udder health in herds when grouped according to age of cattle tender.

\begin{tabular}{cccccccc}
\hline Age & $\begin{array}{c}\text { Number } \\
\text { of herds }\end{array}$ & \multicolumn{2}{c}{ Herd B-index } & \multicolumn{2}{c}{$\begin{array}{c}\text { Incidence of } \\
\text { clinical } \\
\text { mastitis }\end{array}$} & \multicolumn{2}{c}{$\begin{array}{c}\text { Herd teat } \\
\text { end index }\end{array}$} \\
& & $\overline{\mathrm{x}}$ & S.D. & $\overline{\mathrm{x}}$ & S.D. & $\overline{\mathrm{x}}$ & S.D. \\
\hline-39 & 8 & 1.85 & 0.36 & 0.276 & 0.196 & 5.04 & 0.92 \\
$40-49$ & 10 & 2.08 & 0.40 & 0.320 & 0.166 & 5.59 & 1.01 \\
$50-59$ & 11 & 1.99 & 0.38 & 0.373 & 0.285 & 5.25 & 1.06 \\
$60-$ & 3 & 1.80 & 0.24 & 0.185 & 0.130 & 4.77 & 0.76 \\
\hline
\end{tabular}

The connection of the information available on the milk yield with udder health is shown in Table 53. An increase in the level of the milk yield seems to add to the incidence of subclinical mastitis, but on the other hand, it was discovered that the incidence of clinical mastitis was less in the herds with the best yield than in the other herds. 
The udder health of those herds tended by hired labour did not differ from that of the other herds.

The information on the influence of the age of the cattle tender is given in Table 54. Although the udder health of the herds tended by younger and older persons seems to be slightly better, the differences, however, between the groups are not of any statistical significance.

\subsubsection{Discussion}

The incidence of udder disease was not influenced by the size of the herd in this material. It would appear that the effect of the cattle tender is so great on herds on the farms run by the members of one family that it levels the possible increase in the risk of disease caused by any rationalization of work.

The udder health of the herds participating in the milk recording was better, although not statistically significant. The richer yield of the milk recording herds (a difference of about 1500 kilos per cow per annum in Finland) does not appear to worsen udder health. It may be that the risk caused by the increased milk yield is compensated by the possibly better professional skill of the cattle tender. As was discovered in a previous study (SALONIEMI and RoINE 1976), the greater number of visits made to the milk recording farms for the treatment of mastitis is due to the fact that veterinary services are used to a greater extent on these farms and not to the greater incidence of mastitis.

According to this material an increase in the level of the milk yield adds to the incidence of subclinical mastitis. Cows with the richest yield in the milk recording herds are slightly older, but on the other hand the mean age of those herds delivering less than 4000 kilos to the dairy was higher than that of the other herds. According to this material a high milk yield cannot be achieved if the incidence of clinical mastitis is high.

\section{11. Effect of feeding on udder health}

\subsubsection{Results}

Hay was given to the cows on all the farms, the average quantity being $8.1 \pm 3.2 \mathrm{~kg} /$ cow (range $3-16 \mathrm{~kg}$ ). Silage was given on $22 \mathrm{farms}$, the average quantity being $19 \pm 7 \mathrm{~kg} /$ cow (range $5-30 \mathrm{~kg}$ ). Concentrates were given $6.1 \pm 1.3 \mathrm{~kg} /$ cow (range $4-10 \mathrm{~kg}$ ).

Table 55 shows the herd B-index and the incidence of clinical mastitis in the herds grouped according to fodder use. The intensity of feeding had a connection with poor udder health; a statistically significant manifestation of this was obtained only when observations were made on the use of concentrates. The udder health on the farms where silage was given to the cows was worse than that on the farms where only hay was given as coarse fodder, the herd B-index being 2.00 (22 herds) and 1.87 (10 herds), and the incidence of clinical mastitis 0.352 and 0.233 . The differences are not significant. 
Table 55. The effect of feeding on udder health.

\begin{tabular}{|c|c|c|c|c|c|c|}
\hline & & \multirow[t]{2}{*}{$\begin{array}{l}\text { Number } \\
\text { of herds }\end{array}$} & \multicolumn{2}{|c|}{ Herd B-index } & \multicolumn{2}{|c|}{$\begin{array}{c}\text { Incidence of clinical } \\
\text { mastitis }\end{array}$} \\
\hline & & & $\bar{x}$ & S.D. & $\overline{\mathbf{x}}$ & S.D. \\
\hline \multicolumn{7}{|l|}{ Hay } \\
\hline $1-6 \mathrm{~kg} / \mathrm{cow}$ & ........... & 14 & $2.01^{\mathrm{a}}$ & 0.38 & $0.324^{\mathrm{a}}$ & 0.237 \\
\hline $7-12$ & ........... & 15 & $1.95^{\mathrm{a}}$ & 0.39 & $0.337^{\mathrm{a}}$ & 0.211 \\
\hline $13-16$ & .......... & 3 & $1.81^{\mathrm{a}}$ & 0.24 & $0.158^{\mathrm{a}}$ & 0123 \\
\hline \multicolumn{7}{|l|}{ Silage } \\
\hline $0 \mathrm{~kg} /$ cow & ........... & 10 & $1.87^{a}$ & 0.30 & $0.233^{\mathrm{a}}$ & 0.147 \\
\hline $1-15$ & ........... & 7 & $2.09^{\mathrm{a}}$ & 0.28 & $0.408^{\mathrm{a}}$ & 0.269 \\
\hline $16-20$ & ........... & 8 & $1.92^{\mathrm{a}}$ & 0.45 & $0.263^{\mathrm{a}}$ & 0.183 \\
\hline $21-30$ & ........... & 7 & $2.01^{\mathrm{a}}$ & 0.47 & $0.398^{\mathrm{a}}$ & 0.259 \\
\hline \multicolumn{7}{|l|}{ Concentrates } \\
\hline $4-6 \mathrm{~kg} / \mathrm{cow}$ & ............ & 22 & $1.81^{\mathrm{e}}$ & 0.30 & $0.242^{\mathrm{a}}$ & 0.163 \\
\hline $7-10$ & ........... & 10 & $2.30^{\mathrm{d}}$ & 0.30 & $0.453^{b}$ & 0.247 \\
\hline
\end{tabular}

Means with different letter are significantly different. $\mathrm{a} / \mathrm{b}(\mathrm{P}<0.05), \mathrm{c} / \mathrm{d}(\mathrm{P}<0.001)$

\section{11.2. Discussion}

The possible risk of indigestion increases with the intensity of feeding and with the use of silage (CARROL 1977). The worsening of the general condition associated with indigestion is reflected in a decreased resistance to udder infection. Diarrhoea associated with disturbances in digestion contributes to an increased risk of infection caused by coliform bacteria (BRAMLEY and NEAVE 1975). Disturbances in digestion are also regarded as a significant cause of toxic, non-bacterial mastitis (KоHz 1971).

Observations obtained from this study give support to the fact that intensive feeding and any associated more frequent disturbances of digestion have a negative effect on udder health.

\section{Conclusions}

There has been a marked increase in the incidence of udder disease in Finland during the past ten years. Considering the increased incidence and the inaccurate methods of gathering information from the whole country it would appear that the average number of clinical mastitis cases treated in Finland is already as high as $0.35-0.40$ cases per cow per annum. If the duration of clinical mastitis is calculated to be five days, $0.5 \%$ of the cows suffer from this disease daily.

According to a study published in 1976 about $35 \%$ of the cows suffered from subclinical mastitis (KoIRANEN 1976). According to this study the average percentage of mastitis based on a single milk sample examination was also about $35 \%$, but more than $60 \%$ of the cows of this material suffered from subclinical mastitis during 1977. The single milk sampe examination 
describes the momentary state of udder health, but it gives a too good estimate of udder health of a single cow or herd for a long time period. According to this study and that published by KoIranen at least half of the cows in Finland suffer from subclinical mastisis yearly.

A marked variation can be noted in the diagnosis made of udder health based on milk sample examinations of the cow at several weeks intervals, although the average duration of subclinical mastitis is about half a year. This observation, which agrees with the nature of subclinical mastitis, emphasises the need for repeated examinations when judging the condition of the udder. When udder health is assessed merely on the basis of cell content (milk recording in Finland), this need must be taken into consideration with even greater emphasis.

The diagnosis "presence of bacterian is interpreted by all Nordic countries and also by the International Dairy Federation, that the udder is not affected by mastitis. On the basis of this study the udder in which the presence of bacteria is detected has either previously suffered from mastitis or on reexamination is more likely to be suffering from it than the udder for which the diagnosis of mastitis has been made merely on the basis of an increased cell content. Therefore, if bacteria are found to be present in a milk sample taken in the usual way, it means quite often the existence of an infection and an increased risk of mastitis.

The correlation coefficient between the B-index for individual herds and the incidence of clinical mastitis in them was only 0.56 . The measurement of udder health in the individual herd must, therefore, be based on the incidence of both subclinical and clinical mastitis. The registration of those cases of clinical mastitis which have required a veterinary visit for treatment is not complete enough to enable the incidence of this disease to be measured, because the correlation coefficient between these cases and those treated by phone prescription was only 0.60 .

A reliable picture of the udder health of a herd can be obtained only if cases of clinical mastitis treated both by veterinarians and owners are filed, and the occurrence of subclinical mastitis is followed by means of repeated milk sample examinations.

Information based on owner memory gives an intimation of the udder health of a herd. However, this kind of information is not accurate enough for the purpose of selection. When the use of auxiliary means, such as health cards for the cows, are further developed, more exact information can be collected on herds. As information on disease in the case of a single cow constitutes a "threat" to her value as a breeding animal, the owner is naturally not always willing to file this kind of information. Clear proof of this has been obtained when registering cases of the disease in connection with milk recording. For this reason a veterinarian treating the herd must see that information on cases of the disease is collected. Even if he has to collect the information himself. In return for this, as a kind of sfeen, the veterinarian should be able to obtain information on the incidence of the disease concerning the herds in his area in the form of a monthly or at least an annual report, which he could use preparing official reports on sickness or when working out a programme for the 
control of health in herds, for example. The information collected in this way on the incidence of clinical udder diseases together with the information on the cell content of milk collected in connection with the milk recording, forms a basis for progeny testing of bulls as regards the susceptibility of their daughters to mastitis.

Among the somatic factors, the age of the cow and the udder conformation are those which have the strongest effect on udder health. According to this study age, as such, does not add to the risk of the disease in a healthy cow, but the likelihood of an infection naturally increases as a function of time, and the proportion of diseased cows is greater among old cows than among young ones. In order to compare the udder health of different herds, information on the average age of cows is needed. When the occurrence of clinical udder diseases within a short time period is examined, information on calving dates is also needed.

The judgement of the udder shape based on subjective measuring is not as recommendable as the measurement of the teat-floor distance of the rear teats, although a more definite connection with udder health could be established on the basis of the former method in this study. If the teat-floor distance of the rear teats is found to be less than $40 \mathrm{~cm}$ during the three first lactations, it is to be recommended that the cow in question should be culled from the herd. The teat shape is of no importance, but scattered teats constitute a risk to udder health. Because of the definite heritability of udder conformation more attention should be paid to the possibility of utilizing this information in breeding.

This study does not support the theory that good milkability is a factor which predisposes a cow to mastitis. In the control of mastitis, however, an examination of the milkability can provide information as to the performance of milking which is needed for the prevention of the disease. The observation that the occurrence of injury to the teat end has a diminishing effect on milkability can be used in the instruction work done for the promotion of udder health.

According to this study udder health was not influenced by the condition of hooves and legs, which was probably due to the absence of serious cases on injury in the material. There is every reason to observe the condition of hooves and legs on a farm visit associated with mastitis control, and if necessary, to give instructions for the care of hooves and for constructional improvements in stalls. It is possible to improve the general condition of the cows in this way and maybe to eliminate such environmental factors which besides being harmful to the health of legs also cause damage to the udder.

When a mastitis problem in an individual herd is being solved, the ascertainment of predisposing factors provides, primarily, the priorities for the culling of the cows, because most of these factors cannot be altered (age, breed, udder shape).

Factors in the production environment seemed to have a stronger effect on the incidence of clinical mastitis than on that of subclinical mastitis. Harmful factors in the environment cause such serious injury to those mechanisms which prevent microbes from entering the udder through the teat canal and 
which have a preventive effect against the onset of an infection that a case of clinical mastitis will develop. The existence of subclinical mastitis seems to be more dependent on the internal mechanisms of resistance in the udder and on the efficiency of the therapy used in the case of clinical mastitis. As is known, the frequency of clinical mastitis can only partly explain the variation in the incidence of subclinical mastitis.

Of the factors in the production environment the function of the milking machine has the most marked effect on the incidence of mastitis, especially on that of clinical mastitis. A single constructional or functional factor in the machine (with the probable exception of the vacuum regulator) did not prove to be more significant than the other factors, but udder health was strongly influenced by the very number of defective factors.

During the milking process the reflux of milk in the teat liners is probably the most important factor which contributes to the onset of an infection. Although no direct proof of this can be obtained by testing the machine, the occurrence of this can be hindered effectively by maintaining the working performance of the machine so that it meets the recommendations.

The regular service of milking machines and the checking of their function by testing are measures which belong to the good care of udder health and absolutely to the preventive work with mastitis.

In spite of the availability of the testing services in the study area the voluntary use of these had been rather small judging from the condition of the machines. As there is a distinct deterioration in the condition of machines with age, testing measures are necessary on all farms. The installation of new machines must also be supervised, and intensive instruction for their use must be given. Considering the effect which the condition of the milking machine has on udder health and on the quality of milk it is reasonable to expect that strong measures should be taken by the authorities concerning the matter.

Neither the temperature in the cowshed nor the humidity percentage as such was found to have a connection with the incidence of mastitis. A single act of measuring made on a farm visit in conjunction with the control work has proved to be of no use. To estimate the functioning of the ventilation system merely on the basis of sensory evaluation does not provide any useful information, either. Since it would appear, however, that defects in the ventilation (poor heat insulation, insufficient volume of ventilation) seem to add to the occurrence of mastitis, the use of a thermohygrograph would be justified. The use of smoke ampoules to show the existence of draughts, and the thermohygrogram are good ways of demonstrating existing defects in the ventilation to the cattle owner.

In a very great number of the cowsheds the lighting was not good enough to meet the requirements for udder and milking hygiene. Even on the basis of more sensory evaluation there is every reason to draw the cattle owners' attention to this fact.

It is difficult to establish any connection between the constructional details of the cowshed and udder health; this material was in most cases too small for the purpose. On the basis of previous findings and those obtained from this study there is a good reason, however, to include the inspection of the cowsheds 
and especially that of the stall constructions as regards dimensions and condition, in the programme of a farm visit in conjunction with the control work.

It is generally considered that milking hygiene and technique have an effect on udder health. The method employed in this study, that of interviewing, does not give realiable information, therefore, this must be obtained by observing the milking process. It is very likely that better results can be achieved if any mistakes and defects observed in the milking technique of the cattle tender are brought to his or here attention and the correct technique is then taught during the milking.

According to this study the size of the herd had no significant connection with udder health. Certain factors associated with the participation in a milk recording system (the follow-up of udder health, feeding according to a fixed plan, controlling of milk yield) contribute to the health of udders, because the occurrence of both subclinical and clinical mastitis was found to be less on those farms participating in this system.

Indigestion caused by changes in feeding and the poor quality of fodders is considered to be a factor predisposing a cow to the onset of mastitis. The intensity and type of feeding may have an effect to such an extent that there is a good reason to collect relevant information on farm visits connected with preventive work.

The significance of the cattle tender is as great as any factor in the production environment. It became evident from this study, when the milking machines were examined, that the cattle tender has the possibility to weaken the effect of any harmful factors in the environment on udder health. When preventive measures are being taken to control mastitis, the elimination of any predisposing factors detected on a farm is naturally dependent on the cattle tender or owner. When a programme for the control of mastitis is worked out and adapted practically, therefore, more attention should be paid to the ways in which the attitude of the cattle tender can be influenced and directed. At least one way is to show the state of health in a herd clearly and to demonstrate the existence of any predisposing factors detected on the farm (e.g. thermohygrograph, demonstration of defects in the functioning of the milking machine and the negligence of the machine care), and so emphasize the importance of the economical consequences involved in the prevention of the mastitis.

\section{REFERENCES}

Aehnelt, E., Grunert, E., Frerking, H. \& Ahlers, D. 1969. Ursachen und Verhütung von Zitzenverletzungen bei Leistungskühen. Dt. Tierärztl. Wschr. 76: 681-684.

Andreae, U. 1963. Altersbedingte Veränderungen von Euter- und Zitzenmassen bei Kühen. Z. Tierzücht. Züchtungsbiol. 78: 332-349.

- 1971. Die Euterform als züchterische Aufgabe. Tierzüchter 23: $370-372$.

ANoN. 1971. Lypsykoneiden mitoituksen, asennuksen ja toiminnan pääperiaatteet. Karjatalous 47: 203-214.

- 1975. Lypsykoneiden testausohjeita. Valio Meijereiden Keskusosuusliike. Mimeogr. 22 p. [Helsinki]. 
- 1977. Eläinlääkintölaitos 1971-1975. (Veterinary Service 1971-1975.) Suomen virallinen tilasto (Off. Statist. Finland) XXXIV: 42-46. 27 p. Helsinki.

— 1978 a. Eläinlääkintölaitos 1976. (Veterinary Service 1976). Suomen virallinen tilasto (Off. Statist. Finland) XXXIV: 47. 22 p. Helsinki.

- 1978 b. Tilastoa Suomen karjantarkkailusta tarkkailuvuonna 1977. (Statistics of activity of milk recording sosieties in Finland 1977). Maatilahall. Tied. 389: 1-48. Helsinki.

- 1978 c. Rapport fra vurderingskomiteen for helsekort. Helsekortordningen 1976-77. Norsk Vet. Tidsskr. 90: 451-458.

- 1979 a. Maa- ja metsätalousministeriön eläinlääkintöosasto. Tautitoimiston tiedote. Tammikuu. Mimeogr. 8 p. [Helsinki].

- 1979 b. Eläinlääkintölaitos 1977. (Veterinary Service 1977.) Suomen virallinen tilasto (Off. Statist. Finland) XXXIV: 48, 26 p. Helsinki.

- 1979 c. Djurhälsovård 1977-78. Medd. Sv. Husdjurskötsel 95:1-52. Eskilstuna.

- 1979 d. Mastitis hos køer - set fra en immunologisk synsvinkel. In: Modern immunterapi och immunprofylax. NKVet - symposium. Konsulentavd. Rapp. Allmänt 20. p. 60-62. Uppsala.

Appleman, R. D. 1973. Subjective evaluation of teat canal anatomy. J. Dairy Sci. 56: 411 -413. Asby, C. B., Ellis, P. R., Griffin, T. K. \& Kingwill, R. G. 1974: Mastitis control is good business. Dairy Farmer 21, 4:36-39, 44.

ВаккеN, G. 1978. Environment and mastitis frequence. Some results from a survey in Norwegian dairy farm. 29th Ann. Meet. Eur. Ass. Anim. Prod. Stockholm. M-C/3.06: 1-5.

Baumgartner, H. \& Tschappat, R. 1974. Udder health after surgical operation on the teats. XIX Int. Dairy Congr. Liebefeld-Berne. 1E: 151-152. (Ref. Mast. Lit. Survey 1975: 2).

Benson, R. J. \& Betrmann, E. B. 1977. The New South Wales mastitis control program. 3. The effect on production and economics. Austr. Vet. J. 53: 538-541.

Bramley, A. J. \& NeAve, F. K. 1975. Studies on the control of coliform mastitis in dairy cows. Brit. Vet. J. 131: 160-169.

Brandsma, S. \& MaAtJe, K. 1978. Mastitis prevention in conventional machine milking. 29th Ann. Meet. Eur. Ass. Anim. Prod. Stockholm. M-C/3.08:1-7.

Bratlie, O. \& Fodstad, F. H. 1955. Etiologi og patogenese ved akutt mastitis hos storfe. (Etiology and pathogenesis of acut bovine mastitis). Nord. Vet. Med. 7: 278-296.

- 1958. Betydningen av vakuumhøyden i mjølkemaskinene for mjølketeknikk og jurhygiene. (The importance of degree of vacuum in the milking machine for the milking technique and udder hygiene). Nord. Vet. Med. 10:128-142.

- , Slagsvold, P. \& Tollersrud, S. 1959. Pulseringshastigheten ved maskinmjølkning. (Significance of pulsation rate in machine milking). Nord. Vet. Med. 11: 759-779.

- , Gedde-Dahl, T., Slagsvold, P. \& Tollersrud, S. 1963. Forsök over mjølkemaskinens faseforhold og dets virkning på jurhelsen. (Experiments on the pulsation ratio of the milking machine and its effect on udder health). 9. Nord. Vet. Møde. Københaven 1962. Beretn. 2: 654-660.

- 1966. Miljø og mastitis. (Environment and mastitis). Nord. Vet. Med. 18: 366-375.

Brookbanks, E. O., Welch, R. A. S. \& Coup, M. R. 1969. Estrogen in pasture and a possible relationship with mastitis. N. Z. Vet. J. 17:159-160.

Buddle, B. M. \& Cooper, M. G. 1979. Aspects of the epidemiology of bovine staphylococcal mastitis. N. Z. Vet. J. 26: 296-298.

Burnside, E. B., McDaniel, B. T., \& Legates, J. E. 1963. Relationships among udder heigth, age, and milk production. J. Dairy Sci. 46: 157-158.

Bäскsтröm, L., Mattsson, J., Wallin, O. \& Vilson, B. 1975. Praktikjournalförsöket i Skaraborgs län 1971-1973. Svensk Vet. Tidn. 27: 238-250, 292-300.

Carroll, E. J. 1977. Environmental factors in bovine mastitis. J. Amer. Vet. Med. Ass. 170: $1143-1148$.

Cote, J. F. 1976. A preventive medicine programme for dairy cattle in Southern Ontario. Vet. Annual 16: 7-12.

Danko, G. \& Hengl, R. 1975. Diseases caused by mouldy straw. In: Kovícs, F. \& Rafai, P. (Ed.) 1975. Progress in animal hygiene. Budapest. p. 311-314. 
Davis, C. E. 1976. The effect of regression to the mean in epidemiologic and clinical studies.

Amer. J. Epidemiol. 104: 493-498.

Dijкhuizen, A. A. \& Renkema, J. A. 1978. Economic aspects of mastitis and mastitis control in the Netherlands. 29th Ann. Meet. Eur. Ass. Anim. Prod. Stockholm. M-C/3.10: 1-9.

Dobbins, C. N. 1977. Mastitis losses. J. Amer. Vet. Med. Ass. 170:1129-1132.

DodD, F. H. \& NeAve ,F. K. 1951. Machine milking rate and mastitis. J. Dairy Res. 18: 240245.

- 1975. Review of the seminar. In: DodD, F. H., Griffin, T. K. \& Kingwill, R. G. (Ed.) 1975. Proceedings of seminar on mastitis control 1975. p. 501-506.

- , GrJffin, T. K. \& Kingwill, R. G. (Ed.) 1975. Proceedings of seminar on mastitis control 1975. Reading. International Dairy Federation. Bulletin Document 85. 125 p. Bruxelles.

-, Westgarth, D. R. \& Griffin, T. K. 1977. Strategy of mastitis control. J. Amer. Vet. Med. Ass. 170: 1124-1128.

Ereland, E. 1963. Erfaringer med hensyn til rasemessige disposisjoner for mastitis hos storfe. (Experiences of race biological disposition to mastitis in cattle.) 9. Nord. Vet. Møde. København 1962. Beretn. 2: 700-705.

EкEsвo, I. 1966. Disease incidence in tied and loose housed dairy cattle. Acta Agric. Scand. Suppl. 15: 1-74.

- 1969. Veterinärmedicinska synpunkter på nötkreaturens stallmiljō. Svensk Vet. Tidn. 21: 235-246.

- 1973. Animal health, behaviour and disease prevention in different environments in modern swedish animal husbandry. Vet. Rec. 93: 36-39.

- \& Vilson, B. 1978. Comparison of different environmental factors on the incidence of mastitis. 29th Ann. Meet. Eur. Ass. Anim. Prod. Stockholm. M-C/3.03: 1-2.

Elleby, F., Jochumsen, P. \& Veirup, N. H. 1969. Forekomst af kvaægsygdomme i 6 danske kontrolforeninger i 1967/68. (Disease incidence within six Danish milk recording societies.) Kgl. Vet. Landbohøjsk. Inst. Sterilitetsforskn. Aarsber. p. 77-90.

Erb, H. N. \& Martin, S. W. 1978. Age, breed and seasonal patterns in the occurrence of ten dairy cow diseases: a case control study. Can. J. Comp. Med. 42: 1-9.

FELL, L. R. 1964. Machine milking and mastitis - a review. Dairy Sci. Abstr. 26: 55! - 596.

Fodstad, F. H. 1966. Biologiske faktorer som understøttende momenter ved visse patogene jurinfeksjoner hos kyr. 10. Nord. Vet. Mötet. Stockholm. Berett. 1: 404-415

Frank, N. A.. Sanger, V. L., Pounden, W. D., Pratr, A. D. \& Keuren, R. van. 1967. Forage estrogens and their possible influence on bovine mastitis. J. Amer. Vet. Med. Ass. 150: 503-507.

Funke, H. 1963. Predisponerade faktorer i samband med juverinflammationer. 9. Nord. Vet. Møde. København 1962. Beretn. 2: 718-728.

Garpman, I. 1958. Mastitis och olämpliga stallförhâllanden. (Mastitis and unsuitable stable conditions.) 8. Nord. Vet. Mötet. Helsinki. p. 1147-1152.

Greenough, P. R., MacCallum, F. J. \& Weaver, A. D. 1972. Lameness in cattle. 478 p. Edinburgh.

GrIFFIN, T. K. 1975. Communication in general discussion in session "Diagnosis of mastitis and intramammary infections. In: Dodd, F. H., Griffin, T. K. \& Kingwill, R. G. (Ed.) 1975. Proceedings of seminar on mastitis control 1975. p. 73.

Grommers, F. J. 1967. Veterinaire aspecten van de huisvesting van melkvee. (Dairy cattle housing and health.) Thesis. 124 p. Utrecht.

- , BraAk, A. E. van de \& Antonisse, H. W. 1971. Direct trauma of the mammary glands in dairy cattle. I. Variations in indicence due to animal variables. Brit. Vet. J. $127: 271-282$.

-- BraAk, A. E. van de \& Antonisse, H. W. 1972. Direct trauma of the mammary glands in dairy cattle. II. Variations in incidence due to housing variables. Brit. Vet. J. 128: 199-205.

Groor, J. C. de. 1966. Been- en speendeschadigingen bij melkkoeien bij toepassing van de drijfmestgrup met roosters. (Foot and teat traumas in dairy cattle in stalls with liquid manure and grid.) Landbouwvoorlichting 23: 35-41. 
Grootenhuis, G., Oldenbroek, J. K. \& Berg, J. van den. 1979. Differences in mastitis susceptibility between Holstein Friesian, Dutch Friesian and Dutch Red and White cows. Vet. Quarterly 1: 37-46.

Groth, W. \& Ejchler-Steinhauff, H. J. 1977. Haltungsbedingte Schäden beim Milchvieh. Fortscht. Vet. Med. 28: 34-43.

GrøndahL, J. 1975. Utmelkingsegenskap hos ku i relasjon til spenekanaldiameter. (Milkingout characteristics in the cow in relation to teat canal diameter.) Thesis. 125 p. Oslo.

Gudding, R. \& BAKKen, G. 1975. Jurhelsekontroll i klinisk veterinaærpraksis. Norsk. Vet. Tidsskr. 87: $785-789$.

Guidry, A. J., PaApe, M. J. \& Pearson, R. E. 1975. Effects of estrus and exogenous estrogen on circulating neutrophils and milk somatic cell concentration, neutrophil phagocytosis, and occurrence of clinical mastitis in cows. Amer J. Vet. Res. 36: 1555-1560.

HAANPäÄ, S. 1978. Lypsykoneen vuosihuolto välttämätön - kuka sen tekee? Karjatalous $54,5: 23-24$.

Harvey, W. R. 1966. Least squares analysis of data with unequal subclass numbers. Agric. Res. Service, US Dept. Agric. ARS 20-8.

Heeschen, W. 1978. Definition and diagnosis of mastitis. 29th Ann. Meet. Eur. Ass. Anim. Prod. Stockholm. M-C/3.01: 1-8.

HeIdrich, H. J. \& ReNK, W. 1963. Krankheiten der Milchdrüse bei Haustieren. 371 p. Berlin und Hamburg.

Heidrich, H.-D., Arcularis, K., Günther, M., Markan, W. \& Woll, E. 1968. Zur Entstehung einiger Gesundheitsschäden bei Kühen in Kotrostanbindeställen. Mh. Vet. Med. 23: $856-861$.

Ніскмал, C. G. 1964. Teat shape and size in relation to production characteristics and mastitis in dairy cattle. J. Dairy Sci. 47: 777-782.

Hinrichsen, J. F., Bahrini, S., Sölch, A \& Buchenauer, D. 1978. Der Einfluss des Haltungsverfahrens, der Rasse und der Fütterung auf die Milchleistung von Rindern. World Rev. Anim. Prod. 14, 3: 59-63.

HoAre, R. J. T. \& Roberts, E. A. 1972. Investigations in mastitis problem herds. II. Effect of herd size, shed type, hygiene and management practices. Austr. Vet. J. 48: 661-663.

- , Williams, L. G., Richards, R. J. \& Boutcher, L. G. 1977. The New South Wales mastitis control program. 1. Field aspects and their effect on clinical and subclinical mastitis. Austr. Vet. J. 53: 529-533.

Hoff, H. \& Skoglund, J. E. 1977. Melkemaskinens betydning for jurhelsa. Norsk. Vet. Tidsskr. 89: $465-469$.

JAckson, E. R. 1970. An outbreak of teat sores in a commercial dairy herds possible associated with milking machine faults. Vet. Rec. 87: 2-6.

Jensen, A. J. H., Madsen, J. A. \& Pedersen, P. S. 1979. Goldyverterapi. (Dry-cow therapy). Dansk Vet. Tidsskr. 62: $50-56$.

Johansson, I. 1957. Untersuchungen über die Variation in der Euter-und Strichform der Kühe. Z. Tierzücht. Züchtungsbiol. 70: 233-270.

- \& Malven, P. 1960. The influence of yield, udder pressure, size of teats and of the teat orifice on the rate of milking. Z. Tierzücht. Züchtungsbiol. 74: 1-13.

Jørgensen, M. 1970. Influence of environment on udder health of dairy cows. Rep. Int. Working Conf. The influence of the Environment in Animal Housing. C.I.G.R. Section II. Gent. Rep. 2, 46: 1-10.

Kallela, K. 1964. The incidence of plant oestrogens in Finnish pasture and fodder plants with special reference to their possible effects in cases of sterility in ruminants. Thesis. $132 \mathrm{p}$ Helsinki.

KaLtenböск, K. 1972. Vorschläge zur Verbesserung oder zum Neubau von Rinderställen. Wien. Tierärztl. Mschr. 59: 65-76.

Karhunen, J., Pyykkönen, M., Mykkänen, U., Nieminen, L. \& Saloniemi, H. 1979. Pihattotutkimus $1976 \ldots$... 1978. Vakolan tiedote 29/79. 34 p. Helsinki.

Karlsson, U. \& Gustafsson, B. 1977. Varför trampar korna på spenarna? Svensk Lantbr. Univ. Inst. Lantbr. Byggnadstekn. Specialmedd. 68:1-51. Lund.

Keller, P. 1977. The influence of the environment on the health of cows in cubicle stalls. C.I.G.R. Section II Seminar. Ås. Rep. 1: 118-124. 
Kenttämies, H., Taivalantti, P. \& Vehmaan-Kreula, E. 1974. Lehmien elopainon määrittäminen rinnanympäryksen avulla. Kehittyvä Maatalous 18: 3-15.

KıNG, J. O. L. 1967. The effect of mastitis on the yield and composition of heifers' milk. Vet. Rec. 80: 139-141.

Kingwill, R. G., Dodd, F. H. \& Neave, F. K. 1977. Machine milking and mastitis. In: Thiel, C. C. \& DodD, F. H. (Ed.) 1977: Machine milking. p. 231-285.

Klastrup, O. 1971. Forebyggende mastitiskontrol i Danmark. Suom. Eläinlääk. Lehti 77: $8-15$.

- \& Madsen, P. S. 1974. Nordiske rekommendationer vedrørende mastitisundersøgelser af kirtelprøver. Nord. Vet. Med. 26: 197-204.

- , Madsen, P. S., Olsen, SV. J. \& Pedersen. P. S. 1974 a. Kvaegets mastitis: Persisterende infektion, nyinfektion og udsætterfrekvens. 12. Nord. Vet. Kongr. Reykjavik. Foredr. Rapp. p. 269.

- , Madsen, P. S., Nielsen, SV. M., Klausen, K. G., Madsen, N. P., Jørgensen, K., DALSGÅRD, H. \& Jensen, V. 1974 b. Vaccuumvariationers inflydelse på yversundhed, ydelse, malkehastighed, og malkefedtets syregrad. (The influence of fluctuating vacuum on the udder health, the yield, milking rate, and acidity of the milk fat.) Nord. Vet. Med. 26: 702-712.

- 1978 a. Hvor står mastitisbekæmpelsen i dag? Dansk Vet.Tidsskr. 61: 273-281.

- 1978 b. The influence of housing and milking machines on mastitis. 29th Ann. Meet. Eur. Ass. Anim. Prod. Stockholm. M-C/3.02: 1-7.

Knezevic, P. 1971. Aufstallungsbedingte Klauenkrankheiten. Wien. Tierärztl. Mschr. 58: $121-126$.

Конz, E. 1971. Die Coli-Mastitis des Rindes. Problem und Therapie. Tierärztl. Umschau 26: $536-544$.

Kolranen, L. \& Nurmi, E. 1973. Utaretulehduksen ehkäisy. (Mastitis prevention.) Suom. Eläinlääk. Lehti 79: 303-319.

- 1976. Utaretulehduksen yleisyys Suomessa. (Incidence of bovine mastitis in Finland.) Suom. Eläinlääk. Lehti 82: 64-72, 185-189.

- 1977. Utaretulehduksesta karjanomistajalle aiheutuvat menetykset. Karjatalous 53, 12: $4-5$.

- 1978. Praktiska erfarenheter efter vaccinering mot mastit. 13. Nord. Vet. Kongr. Turku. Föredr. Rapp. p. 225-228.

- , Roine, K. \& Saloniemi, H. 1978. Om växlingarna i mastitfrekvensen och de bacteriologiska fynden i fältundersökningar. 13. Nord. Vet. Kongr. Turku, Föredr. Rapp. p. 313.

- 1979 a. Utaretulehduksen torjuntaan yhteistyöllä. Suom. Eläinlääk. Lehti 85: 287290.

- 1979 b. Kolimastiitit ja niiden ehkäisy. Eläinlääkeuutiset 1979, 1: 3-5.

Kovícs, F. \& Rafai, P. (Ed.) 1975. Progress in animal hygiene. Proc. First Intern. Congr. Anim. Hyg. 1973. 501 p. Budapest.

KUвiсек, J. \& MеiNecke, B. 1978. Frequenz und Schweregrad von Klauentrittverletzungen der Zitzen unter Berücksichtigung des Zitzenspitzen - Bodenabstandes. Z. Tierzücht. Züchtungsbiol. 94: 312-318.

LeFFeler, R. 1965. Beziehungen zwischen Melkbarkeit und Eutergesundheit beim Simmentaler Fleckvieh in der Schweitz. Diss. 103 p. München.

Lindногм, S. 1978. Suomalaisten lehmien lypsettävyys ja siihen vaikuttavat tekijät. Laudaturtyö. [Helsingin yliopisto, kotieläinten jalostıstieteen laitos.] Mimeogr. 51 p. [Helsinki.]

LindströM, U. B. \& SYVÄJÄRVI, J. 1978. Use of field records in breeding for mastitis resistance in dairy cattle. Livestock Prod. Sci. 5: 29-44.

Lrvoni, P. 1955. Mastitisbekzempelse. (Mastitis control.) Thesis. 115 p. Aarhus.

LundBerg, M. 1974. Sambandet mellan mjölkningsegenskaper och mastit. Examenarbete. Mimeogr. 57 p. [Uppsala.]

Madsen, P. S. Klastrup, O., Olsen, S. J. \& Pedersen, P. S. 1974. Herd incidence of bovine mastitis in four danish dairy districts. - I. The prevalence and mastitogenic effect of micro-organisms in the mammary glands of cows. Nord. Vet. Med. 26: 473-482. 
- , Klastrup, O., Olsen, S. J. \& Pedersen, P. S. 1975. Herd incidence of bovine mastitis in four Danish dairy districts. - II. Evaluation of the effect of the mastitis control scheme. Nord. Vet. Med. 27: 305-318.

- 1978. Milieudata in danske besætninger under mastitiskontrol. 13. Nord. Vet. Kongr. Föredr. Rapp. Turku. p. 208-211.

Maton, A. \& Moor, A. de. 1975. Een onderzoek naar de samenhang tussen de huisvestigsvoorwaarden en gedragingen van en letsels bij melkvee. Vlaams Diergeneeskunding Tijdschrift 44, 1: 1-18. (Ref. Mast. Lit. Survey 1975: 27.)

Meischке, H. R. C. 1979. A survey of bovine teat papillomatosis. Vet. Rec. 104: 28-31.

Miller, R. H., OWen, J. R. \& Moore, E. D. 1976. Incidence of clinical mastitis in a herd of Jersey cattle. J. Dairy Sci. 59: 113-119.

- , Pearson, R. E. \& Weinland, B. T. 1978. Relations of mastitis with milking rate and milking time. J. Dairy Sci. 61, Suppl. 1: 129.

Morris, R. S. 1973. The depression of quarter milk yield caused by bovine mastitis, and the response of yield to successful therapy. Austr. Vet. J. 49: 153-156.

- 1975. Criteria tor the desing and evaluation of bovine mastitis control systems. In: Dodd, F. H., Griffin, T. K. \& Kingwill, R. G. (Ed.) 1975. Proceedings of seminar on mastitis control 1975. p. 395-409.

Mortensen, B. 1971. Forsøg med bindsler til køer 1. SBI-Landbrugsbyggeri 33. 156 p. København.

Munch-Petersen, E. 1938. Bovine mastitis. Survey of the literature to the end of 1935. Imperial Bureau Animal Health. Review Series 1. (Ref. Sснацм et al. 1971.)

MYLlyLÄ, L. 1977. Jalostuksen mahdollisuudet torjua utaretulehdusta. Nautakarja 7, 1:1 7-18.

- 1978. Personal communication.

Mylrea, P. J., Hoare, R. J. T., Colquhoun, P., Links, I. J., Richards, R. J. \& Barton M. 1977. The New South Wales mastitis control program. 2. Effect upon bacterial infections. Austr. Vet. J. 53: 534-537.

Natzke, R. P., Oltennace, P. A. \& Schmut, G. H. 1978. Change in udder health with overmilking. J. Dairy Sci. 1: 233-238.

NeAve, F. K. 1975. Communication in general discussion in session pDiagnosis of mastitis and intrammary infection." In: Dodd, F. H., Griffin, T. K. \& KInGwill, R. G. (Ed.) 1975. Proceedings of seminar on mastitis control 1975. p. 75.

Nicolai, J. H., Cox, S., Laurglois, B. \& Hemken, R. 1977. The effect of vacuum level at the teat end on the incidence of mastitis. Ann. Meet. Nat. Mastitis Counsil, Feb. 21-23. Washington DC 20006, p. 73-77. (Ref. Mast. Lit. Survey 1977: 29.)

Nielsen, SV. M. 1970. Undersøgelser vedrørende køers malkbarhed. a. Malkbarhedens afhængighed af biologiske faktorer. Landøkon. Forsøgslab. Efterårmøde. Årbog 1970. p. 323-343. København.

- , Klausen, S., Neimann-Sørensen, A., Madsen, P. S. \& Klastrup, N. O. 1970. Undersøgelser vedrørende køers malkbarhed. b. Sammenhæng mellan malkbarhed og mastitis. Landøkon. Forsøgslab. Efterårmøde. Årbog 1970. p. 344-349. København.

Nieminen, L., Karhunen, J., Mүккӥnen, U., Pyykkönen, M. \& Saloniemi, H. 1975. Parsinavettatutkimus 1973-75. Vakolan tiedote 24/75. 41 p. Helsinki.

Nito, M., Shoda, Y., Kobayashi, H., Fukushima, Y. \& Nomura, S. 1965. Jap. Zootech. Sci. 36: 496. (Ref. LuNdBerg, M. 1974).

Nurmi, E. \& Kolranen, L. 1971 a. Utaretulehduksen merkitys ja vastustaminen. (Control of mastitis.) Suom. Eläinlääk. Lehti 77: 19-25.

- \& Kolranen, L. 1971 b. Betydning av spenedypping med jodofor lanolinpreparat. Norsk. Vet. Tidsskr. 83: $97-100$.

NygaARd, A. 1973. Omgivelsesstudier in hus for mjølkeproduksjon. II. Kroppsmål hos kyr. (Environmental studies in housing for milk production.) Norg. Landbr. Høgsk. Inst. Bygn. Tekn. Meld. 68: 1-21.

- \& Engan-SkeI, I. 1974. Omgivelsesstudier i hus for mjølkeproduksjon. III. Jurtilstanden hos kyr. (Environmental studies in housing for dairy cows. III. The udder condition in dairy cows.) Norg. Landbr. Høgsk. Inst. Bygn. Tekn. Meld. 73: 1-22.

- 1979. Omgivelsestudier $\mathrm{i}$ hus for mjølkeproduksjon. (Environmental studies in housing for milk producktion.) Meld. Norg. Landbr. Høgsk. 58, 19:1-64. 
Nyнan, J. F. 1968. The effect of vacuum fluctuation on udder disease. Proc. Symp. Machine Milking 1968. Reading. p. $71-82$.

NÄsı, M., Poutiainen, E. \& Brofeldt, E. 1977. Lypsytekniikan vaikutus lehmien lypsettävyyteen ja utareen terveydentilaan. Karjatalous 53, 10:35-38.

O'Shea, J., O' Callaghan, E., Meaney, W. \& Crowley, C. 1975. Liner slip, impacts and mastitis. Irish J. Agric. Res. 14: 372-375.

Oliver, J. 1955. The influence of environmental and physiological factors on udder health. Dairy Sci. Abstr. 17: 354-366, 447-460.

- , Dodd, F. H., Neave, F. K. \& Barley, G. L. 1956. Variations in the incidence of udder infection and mastitis with stage in lactation, age and season of the year. $\mathrm{J}$. Dairy Res. 23: 181-193.

Olsen, S. J. 1968. Fodringsbetinget mastitis. (Mastitis conditioned by feeding.) Nord. Vet. Med. 20: 562-575.

PAizs, L. 1971. Untersuchungen über den Einfluss von Melkmaschinenfehler auf die Eutergesundheit. Mitt. Tierhaltung 11: 14-22.

- 1973. Untersuchungen über die Beeinflussungen der Melkbarkeit und Eutergesundheit durch Exterieurmetkmale des Euters. Diss. 163 p. Hohenheim.

Pearson, J. K. L., Green, D. O., Spence, B. K.; McParland, P. J., McKinley, D. L., Dunlop, W. L. \& Acheson, A. W. 1972. Factors involved in mastitis control; a comparative study between high and low incidence herds. Vet. Rec. 91: 615-623.

Pedersen, P. S. 1975. Prevention of mastitis in cows. In: Dodd, F. H., Griffen, T. K. \& Kingwill, R. G. 1975. Proceedings of seminar on mastitis control 1975. p. 249-258.

Peterson, K. J. 1964. Mammary tissue injury resulting from improper machine milking. Amer. J. Vet. Res. 25: 1002-1009.

Phillips, D. S. M., Whiteman, D. P. \& Walker, H. T. M. 1969. Foremilk and bovine mastitis. N. Z. Vet. J. 17:90-91.

Pнilpot, W. N. 1972. Effect of milking machines equipped with automatic quarter-take-off devices on milk quality and health of the udder. J. Milk Food Technol. 35: 454-547.

- 1975. Provention of infection - hygiene. In: DodD, F. H., Griffin, T. K. \& KingwILL, R. G. (Ed.) 1975. Proceedings of seminar on mastitis control 1975. p. 155-164.

PolitieK, R. D. 1968. Selection on ease of milking worth while? World Rev. Anim. Prod. 4: $94-98$.

Pounden, W. D., Pratt, A. D., Frank, N. A. \& Smith, H. R. 1958. The incidence of mastitis in cows fed legume-grass mixtures as fresh cut crop and as silage. J. Amer. Vet. Med. Ass. 132: $337-339$.

Rabold, K., Lanser, E., Mayntz, M. \& Paizs, L. 1974. Biotechnik der Milchgewinnung. 138 p. Stuttgart.

Rasbech, O. \& Jochumsen, P. 1963. (Ref. Pedersen, P. S. 1975).

- , Jochumusen, P. \& Christiansen, I. J. 1967. Undesøgelser over sygdomsforekomst og bedriftsforhold. Kgl. Vet. Landbohøjsk. Inst. Sterilitetsforskn. Aarsber. p. 265308. København.

- 1970. Danske stalltype till køer og svin i relation til dyrehelse og dyreværn. XI Nord. Vet. Kongr. Bergen, p. 212-215.

RAthore, A. K. 1976. Relationships between teat shape, production and mastitis in Friesian cows. Br. Vet. J. $132 \cdot 389-392$.

- 1977. Teat shape, cup crawl and milk production in Guernsey and Australian Illawarra shorthorn cows. Br. Vet. J. 133: 454-457.

Rendel, J. \& Sundberg, T. 1962. Factors influencing the type and incidence of mastitis in Swedish dairy cattle. Acta Vet. Scand. 3: 13-32.

RoINE, K. 1969. Potilaskortti praktiikkakäyttöön. (Patient register in ambulatory practice). Suom. Eläinlääk. Lehti 75: 299-302.

- \& Munsterhjelm, H. 1974. Kliinisiä ja bakteriologisia havaintoja akuuteista mastiiteista. (Clinical and bacteriological observations on acute mastitis.) Suom. Eläinlääk. Lehti 80: 194-204.

- 1975. Observations on teat stenosis. Nord. Vet. Med. 27: 107-111. 
Rutzmoser, K. 1975. Krankheitshäufigkeiten und Kosten der tierärztlichen Betreuung der Milchviehherde des Lehr- und Verscuchsgutes Wildschwaige. Berl. Münch. Tierärzt. Wschr. 88: 62-65.

Ryniewicz, Z. \& Bassaljk-Chabielska, L. 1978. The influence of the build of the udder and of milkability on the incidence of mastitis. 29th Ann. Meet. Eur. Ass. Anim. Prod. Stcckholm. M-C/3.05: 1-5.

SAARI, S. 1978. Joka neljäs testattu lypsykone vajaatehoinen. Karjatalous 54, 5: $32-33$.

SAlONIEMI, H. 1973. Rakenteiden ja navetan laitteiden merkitys utaretulehduksen syntymisessä. (Role of cowshed structures and appliances in udder inflammations.) Teho 1973. 5: $163-164$.

- \& RoINE, K. 1976. Nautakarjan sairastavuudesta ja karjakoon vaikutuksesta sairastavuuteen. (Incidence of illness in dairy cattle with special reierence to heid size.) Suom. Eläinläăk. Lehti 82: 231-243.

- 1977 a. Karjan koon ja muiden tuotantoympäristötekijöiden vaikutus lypsykarjan sairastavuuteen. Eläinlääket. Korkeakoulu. Julk. 1. 147 p. Helsinki.

- 1977 b. Havaintoja pehmeän parsimaton käytöstä. Suom. Eläinlääk. Lehti 83: 223 - 227.

- 1977 c. Havaintoja lehmien terveydentilasta peruskorjatuissa navetoissa. Maatal. Teknol. Lait. Tutk.tied. 21: 1-40, Helsinki.

- 1978 a. Utaretulehduksen, asetonitaudin ja poikimahalvauksen taloudellinen merkitys. Karjatalous 54, 2: $31-33$.

- 1978 b. Spenarnas avstånd till båspallen och dess samband med juverhälsan. 13. Nord. Vet. Kongr. Turku, Föredr. Rapp. p. 315.

- 1978 c. Eläinten terveydentilan muuttuminen peruskorjatuissa navetoissa. Maatal. Teknol. Lait. Tutk.tied. 27: 1-36. Helsinki.

- 1979. Sorkkahoidon tarve ja ammattimainen sorkkahoito Suomessa. (Professional cattle hoof trimmers and the need of the trimming in Finland.) Suom. Eläinlääk. Lehti 85: $181-190$.

- \& Auvinen, M. 1979. Neuvontatyön vaikutus tuottajamaidon laatuun. (The effect of a dairy farm advicer consultation on the quality of farm milk.) Suom. Eläinlääk. Lehti 85: 277-285.

Schalm, O. W., Carroll, E. J. \& Jain, N. C. 1971. Bovine mastitis. 360 p. Philadelphia.

SCHLUEP, J. 1966. Weitere Untersuchungen über die Frage der Zusammenhänge zwischen Melkbarkeit und Eutergesundheit. Z. Tierzücht. Züchtungsbiol. 83: 193-218.

Schneider, H. 1971. Der Einfluss der Melkmaschine auf die Eutergesundheit - Eine Literaturübersicht. Diss. 114 p. Hannover.

Seflemann, M. \& Obiger, G. 1959. Beziehungen zwischen Maschinenmelken und Eutergesundheit. Kieler Milchw. Forschungsber. 11: 381-395.

Simensen, E. 1976 a. Trekk som årsak till mastitt? Norsk Vet. Tidsskr. 88: 617-620.

- 1976 b. Mjolkeproduksjon og sjukdom hos storfe i Hedmark fylke. Norsk Vet. Tidsskr. $88: 640-647$.

- 1979. Oppdtallingsforhold og traumatiske skader hos storfe. Norsk. Vet. Tidsskr. 91: $237-240$.

Smith, J. W., Pearson, R. E. \& Thompson, P. D. 1978. Eliminating stripping in machine milking. J. Dairy Sci. 1: 781-787.

SolbU, H. 1977. Helsekortordningen 1976. Buskap Avdrått 29:97-101.

- 1978. Forhold som virker inn på forskjellige sykdommer hos kviger. Buskap Avdrått 30: $176-178$.

- 1979. Helsekortordningen 1978. Buskap Avdrått 31: 78-81.

Stanley, D. E., Kesler, E. M. \& Bortree, A. L. 1962. Effect of a fluctuating milking vacuum on certain measures of udder health. J. Dairy Sci. 45: 1343-1347.

Strandberg, P. \& Funke, H. 1978. Spendoppning - effect av olika preparat, jodkontamination av mjölk och dess risker - en litteraturstudie. Medd. Svensk Husdjurskötsel 90: 46-67. Eskilstuna.

Sundahl, A.-M. 1977. Belysning i lantbruksbyggnader. Akt. Lantbr. Högsk. 243. 45 p. Uppsala. Syrstad, O. \& Ron, I. 1978. Dagligvariasjon i celletall i mjölk. (Day-to-day variation in cell counts in milk). Nord. Vet. Med. 30: 192-198. 
SYVÄJÄRVI, J. \& LiNDSTRöM, U. 1978. Terveystarkkailun kehittäminen on välttämätöntä. Nautakarja 8, 5:9-11.

- 1979. Personal communication.

SÄLlviK, K. 1973. Ventilation och värme i djurstallar. Akt. Lantbr. Högsk. 193. 32 p. Uppsala.

SørENSEN, B. 1963. Sammanhæng mellen malkemaskinens vacuum og ventiltype og mastitis, bedømt ved vævs - og sekretforandringer. (Relation between the incidence of mastitis, as judged by tissue reaction and changes in secretion, and the milking machine vacuum and type of regulator.) 9. Nord. Vet. Møde. København 1962. Beretn. 2:670-676.

TAYLOR, J. I. 1949. Some aspects of the epidemiology of bovine mastitis. Vet. Rec. 61: 455-456.

Terplan, G. \& Hounens, H. 1967. Beziehungen zwischen Melkbarkeit, Keimgehalt und Zellgehalt des klinisch gesunden Kueuters. Tierärztl. Umschau 22: 138-145.

Thiel, C. C., Thomas, C. L., Westgarth, D. R. \& Reiter, B. 1969. Impact force as a possible cause of mechanical transfer of bacteria to the interior of the cow's teat. J. Dairy Res. 36: $279-297$.

- , Cousins, C. L., Westgarth, D. R. \& Neave, F. K. 1973. The influence of some physical characteristics of the milking machine on the rate of new mastitis infections. J. Dairy Res. 40: 117-129.

- 1975. Prevention of infection - milking machine factors. In: DodD, F. H., GRIFFIN. T. K. \& Kingwill, R. G. (ed.) 1975. Proceedings of seminar on mastitis control 1975. p. $165-178$.

— \& Dodd, F. H. (Ed.) 1977. Machine milking. 391 p. Reading.

- \& Mern, G. A. 1977. Action of the cluster during milking. In: Thiel, C. C. \& DodD, F. H. (Ed.) 1977. Machine milking. p. 116-155.

Thomas, C. L., Neave, F. K., Dodd, F. H. \& Higgs, T. M. 1972. The susceptibility of milked and unmilked udder quarters to intra-mammary infection. J. Dairy Res. 39: 113-131.

Thompson, P. D. \& Mrller, R. H. 1974. Retrograde flow of milk within machine-milked teats. J. Dairy Sci. 57: 1489-1496.

- 1977. Effects of physical characteristics of milking machines on teats and udders. J. Amer. Vet. Med. Ass. 170: 1150-1154.

- , Schultze, W. D., Sauls, J. N. \& Arapis, S. C. 1978. Mastitis infection from abrupt loss of milking vacuum. J. Dairy Sci. 1: $344-351$.

Tolle, A. 1975. Mastitis - the disease in relation to control methods. In: Dodd, F. H., Griffin, T. K. \& Kingwill, R. G. 1975. Proceedings of seminar on mastitis control 1975. p. $3-15$.

- \& Whittlestone, W. G. 1976. Grundlagen der Hygiene der Milchgewinnung. Kieler. Milchw. Forschungsber. 28: 81-224.

- , Heeschen, W. \& Hamann, J. 1977. Grundlagen einer systematischen Bekämpfung der subklinischen Mastitis des Rindes. Kieler Milchw. Forschungsber. 29: 3-103.

WALSER, K. 1966. Melkmaschine und Mastitis. 110 p. Berlin und Hamburg.

- , Bieber, E., Dannerbeck, G., Gropper, M., Hropot, M., Lankenfeldt, H., Mayer, J., Vergho, H. \& ViктоR, M. 1972. Klinische Beiträge zur Kenntnis der akuten Mastitis (Mastitis acuta gravis) des Rindes. Berl. Münch. Tierärztl. Wschr. 55: 266269, 305-309, 330-333, 364-367.

VASEnIUS, L. 1965. Transferrin polymorphism in Finnish ayrshire cattle. Ann. Acad. Sci. Fenn. A IV 98. Thesis. 58 p. Helsinki.

Whittlestone, W. G. \& Fell, L. R. 1969. Machine milking and mastitis. Proc. N. Z. Soc. Anim. Prod. 29: 22-25.

- 1972. The milking machine as a vector for mastitis infections. III. Inter unit liquid flow. Milchwissenschaft 27: 626-629.

Willburg, A. C. von. 1775. Anleitung für das Landvolk in Absicht auf die Erkenntnis und Heilungsart der Krankheiten des Rindviehes, sammt den Hülfsmitteln und einem Anhang über die Materie der Medicin, und Erläuterung der einfachen Heilungsmittel durch beygefügte lateinische Benennungen. Nürnberg. (Ref. Tolle et al. 1977).

Wilson, C. D. 1968. Mastitis control. Vet. Ann. 9:61-68.

Witt, M., Lauprecht, E., Andreae, U. \& Flock, D. 1967. Biometrische Untersuchungen an morphologischen Eutermerkmalen von frischmelkenden und altmelkenden Kühen in der ersten und dritten Laktation. Z. Tierzücht. Züchtungsbiol. 83: 111-143. 
WorstorfF, H. 1970. Zum Einfluss strömungstechnischer Bedingungen in Melkanlagen auf die Anzahl somatischer Zellen in der Milch. Diss. Kiel.

- , Baer, H. von, Reichmuth, J., Zeidler, H. \& Tolle, A. 1972. Die Melkanlage als Vektor der Mastitis-Infektion. II. Zur übertragung pathogener Mikroorganismen innerhalb Tier. Milchwissenschaft 27:620-626.

Zeidler, H., Tolle, A., Reichmuth, J. \& Heeschen, W. 1969. Úber die Beziehungen des Zellhaltes der Sammelmilch zur Mastitissituation im Herkunftsbestand. Arch. Lebensmittelhyg. 20: 193-199.

Young, C. W., Legates, J. E. \& Lecce, J. G. 1960. Genetic and phenotypic relationships between clinical mastitis, laboratory criteria, and udder height. J. Dairy Sci. 43: 54-62.

Áström, G. 1972. On the influence of ovariectomy, diethylstilboestrol and progesterone on healthy and chronically infected bovine udders. Acta Vet. Scand. Suppl. 39: 1-105.

\title{
SELOSTUS
}

\section{Lehmän utaresairaudet - kenttähavaintoja esiintymisestä, lehmästä ja ympäristöstä johtuvista tekijöistä sekä torjunnasta}

\author{
Hannu SaLONIEMI \\ Eläinlääketieteellinen korkeakoulu, kotieläinhygienian laitos
}

Tutkimuksessa tarkastellaan utaresairauksien esiintymistä ja lehmästä johtuvien tekijöiden sekä tuotantoympäristötekijöiden vaikutusta mainittujen sairauksien esiintymiseen. Tulosten ja käytettyjen tutkimusmenetelmien soveltuvuutta utaretulehduksen järjestelmällisessä torjuntatyössä tiloilla pohditaan.

Tutkimusaineisto käsittää 500 lypsylehmää 32 karjasta koillis-Uudeltamaalta. Kliinistä utaretulehdusta esiintyi vuosina 1975 - 77 keskimäärin 0.32 tapausta lehmää kohti vuodessa. Piileväå utaretulehdusta sairasti maitonäytetutkimusten perusteella näytteenottohetkellä keskimäärin $36.5 \%$ lehmistä. Vuoden 1977 kuluessa sairasti $61.2 \%$ lehmistä vähintään yhdellä tutkimuskerralla piilevää utaretulehdusta.

Karjan utareiden terveydentilasta saadaan luotettava kuva vain, jos sekä kliinisten että piilevien utaretulehdusten esiintymistä seurataan, sillä näiden utaretulehdusmuotojen karjakohtaisten esiintymisien välinen korrelaatiokerroin oli vain $0.56^{* * *}$. Sekä eläinlääkärin tilakäynneillä hoitamat että karjanomistajan puhelinmääräysten avulla hoitamat utaretulehdukset on rekisteröitävä, sillä näiden hoitomuotojen suhde vaihteli karjojen välillä suuresti $\left(\mathrm{r}=0.61^{* * *}\right)$. Piilevän utaretulehduksen esiintymistä lehmässä tai karjassa ei voida luotettavasti kuvata yhden maitonäytteen tuloksilla.

Yhteispohjoismaisen maitonäytetutkimusmenetelmän mukaan tutkimustulos sbakteeriesiintymä» ei osoita utareen sairastavan utaretulehdusta. Tämän tutkimuksen mukaan sbakteeriesiintymä merkitsee usein tartunnan olemassaoloa ja utaretulehduksen todennäköistä esiintymistä.

Omistajan ilmoitusten mukaan $33.6 \%$ lehmistä oli sairastanut utaretulehdusta ja ilmoituksista laskettu sairastavuus oli keskimäärin 0.18 tapausta lehmää kohti vuodessa. Haastatteluun perustuva sairastavuus oli yhteydessä kliinisen utaretulehduksen esiintymiseen karjoissa $\left(\mathrm{r}=0.58^{* * *}\right)$. Karjoissa, joissa utaretulehdusta esiintyi runsaasti, saatiin haastattelemalla selville suhteellisesti suurempi osa tapauksista.

Eläinlääkärin hoitoa vaativia vedinvaurioita esiintyi 0.03 tapausta lehmää kohti vuodessa. Yksittäisessä tarkastuksessa todettiin utareen ja vetimien iholla vaurioita $4 \%$ :lla lehmistä ja vetimen pään vaurioita $44 \%$ :lla lehmistä. Vauriot olivat lieviä.

Utareiden terveydentilasta tehtyjen havaintojen pisteyttäminen ja niistä muodostetut indeksit osoittautuivat käyttökelpoisiksi apuvälineiksi utaresairauksien ja niihin altistavien tekijöiden välisten vuorovaikutusten tutkimisessa. 
Lehmän ikä ei lisää terveen lehmän sairastumisvaaraa. Vanhoista lehmistä sairastaa suurempi osa piilevää utaretulehdusta kuin nuorista, sillä tartunnan saamisen mahdollisuus lisääntyy ajan kuluessa ja kerran sairastunut lehmä sairastuu uudelleen helpommin kuin terve.

Kliinisistä utaretulehduksista esiintyy lähes puolet poikimisen jälkeisenä kuukautena. Piilevän utaretulehduksen esiintymiseen lypsykauden vaihe ei tässä tutkimuksessa vaikuta.

Takavetimien kärkien etäisyys parresta oli keskimäärin $43.9 \mathrm{~cm}$ (keskipoikkeama $6.8 \mathrm{~cm}$ ). Parsietäisyyden laskiessa alle $40 \mathrm{~cm}: n$ lisääntyy piilevien utaretulehdusten esiintyminen selvästi. Lehmien vedinmuodolla ei ollut yhteyttä utareen terveyteen, mutta hajavetimisyys lisäsi utaresairauksien esiintymistä. Lehmien lypsettävyys, maitomäärällä korjattua keskimääräistä minuuttimaitomäärä mittana käytettäessä, ei vaikuttanut utareen terveyteen.

Utaretulehduksen torjunnassa lehmästä johtuvien altistavien tekijöiden osoittaminen antaa perusteita lehmien karsintaan, sillä mainittuja tekijöitä ei lehmäyksilön kohdalla yleensä voida muuttaa.

Tuotantoympäristötekijöistä vaikutti lypsykoneiden toiminta voimakkaimmin utaretulehduksen, erityisesti kliinisen utaretulehduksen esiintymiseen. Virheellisten yksityiskohtien lukumäärä oli merkityksellisempi kuin havaittujen virheiden paikka. Lypsykoneiden kunto tutkimustiloilla oli huono, vain yksi kone täytti kaikkien yhdeksän testauskohteen osalta vaatimukset.

Yli viiden ${ }^{\circ} \mathrm{C}: \mathrm{n}$ vuorokautiset lämpötilavaihtelut navetassa lisäsivät sekä kliinisten että piilevien utaretulehdusten esiintymistä merkitsevästi. Lämpötilan tai suhteellisen kosteuden yksittäiset mittaukset ovat utaretulehduksen torjuntaan tähtäävän tilakäynnin yhteydessä hyödyttömiä. Ilmastoinnin puutteiden osoittamiseen tulee käyttää termohygrografia.

Navetan ja parren rakenteellisten yksityiskohtien tai lypsyhygienian vaikutus utareiden terveyteen voitiin tässä tutkimuksessa luotettavasti osoittaa vain muutaman yksityiskohdan osalta navetoiden vähäisestä lukumäärästä johtuen. Tehdyt havainnot eivät olleet ristiriidassa muissa Pohjoismaissa julkaistujen tulosten kanssa.

Karjantarkkailuun kuuluvilla tiloilla utaretulehduksen esiintyminen oli hiukan vähäisempää kuin muilla tiloilla. Karjantarkkailutiloilla hoidettiin puhelinmääräyksen perusteella 1.5 kliinistä utaretulehdusta ja muilla tiloilla 2.0 kliinistä utaretulehdusta yhtä tilakäynnillä hoidettua tapausta kohti.

Karjanhoitajan merkitys »ympäristötekijänä» on suuri, vaikka sen mittaaminen on vaikeaa. Utaretulehduksen torjuntatyössä on pyrittävä hoitajan asenteiden ohjaamiseen osoittamalla karjan utaretulehdustilanne luotettavasti, esittämällä tilalla todetut, utaretulehdusta aiheuttavat tekijät havainnollisesti, antamalla selväpiirteiset korjausehdotukset ja korostamalla toiminnan taloudellista vaikutusta. 